Universidade de São Paulo

Instituto de Física de São Carlos

\title{
ESTUDO DE PROCESSOS DE TRANSPORTE \\ ELETRÔNICO EM DISPOSITIVOS A BASE DE \\ SEMICONDUTORES ORGÂNICOS
}

FERNANDO ARAÚJO DE CASTRO

Dissertação apresentada ao Instituto de Física de São Carlos, da Universidade de São Paulo, para obtenção do título de Mestre em Física Aplicada

Orientador: Prof. Dr. Carlos Frederico de Oliveira Graeff

São Carlos

2004 
Dedico este trabalho à minha família, em especial à minha querida esposa, Mabel, a meu irmão, Gustavo, e aos meus pais, Sérgio e Inês, que, com carinho, sempre me apoiaram e me incentivaram. 
Ao Prof. Carlos F. O. Graeff, meu orientador, pela inestimável orientação, pelas oportunidades apresentadas e, principalmente, pela amizade e confiança em mim depositadas.

Ao Prof. Roberto Mendonça Faria, pelo apoio irrestrito a este trabalho.

Ao amigo Dr. Lucas Fugikawa, pelas inestimáveis contribuições a este trabalho, pelo auxílio na preparação dos diodos de MEH-PPV e nas medidas de impedância e por ter cedido a figura 7.6, assim como pelas inúmeras discussões.

Ao amigo George Silva, pelas inúmeras discussões e pelo inestimável auxílio no aprendizado da técnica de RMDE.

Ao amigo Dr. Paulo Bueno, pela recente amizade, pelas ótimas discussões e pelo inestimável auxílio sobre os resultados de impedância.

Ao Dr. Frank Nüesch pela preparação dos OLEDs de $\mathrm{Alq}_{3}$ e pelas ótimas discussões.

Ao amigo Carlão e à Dr. Débora Balogh, pelas dicas e pela ajuda em todas as horas.

Aos Professores e amigos Dr. Francisco E. G. Guimarães e Dr. Alexandre Marletta, por terem me introduzido à pesquisa científica, assim como pela sua amizade $\mathrm{e}$ confiança.

Aos colegas e professores do grupo de polímeros e do grupo ressomat, pelo bom ambiente de trabalho e pelas discussões oportunas. Em especial, ao Jair Junior, ao Célio Borges, ao Edivaldo Queiroz e ao Dr. Rodrigo Bianchi, pela amizade, pelas discussões e pela ajuda em todas as horas.

Ao CNPQ pela bolsa de mestrado e ao IMMP/MCT pelo auxílio financeiro. 


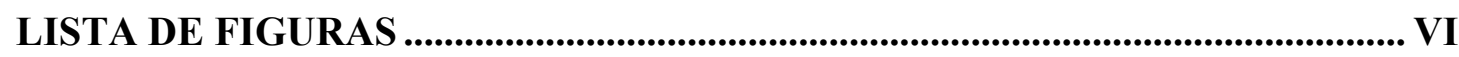

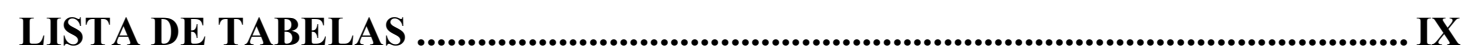

LISTA DE ABREVIATURAS E SIGLAS ..............................................................

LISTA DE SÍMBOLOS..............................................................................................

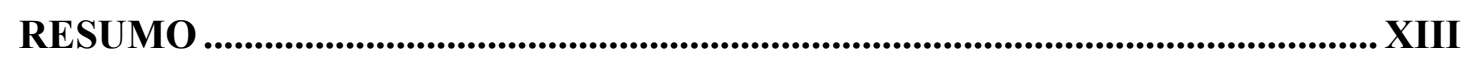

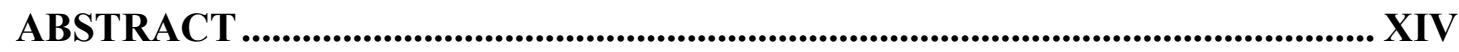

CAPÍTULO 1: INTRODUÇÃO ............................................................................1

CAPÍTULO 2: POLÍMEROS CONDUTORES.................................................................5

2.1 Portadores de carga em sistemas conjugados...................................................

2.2 Defeitos estruturais: sólitons, pólarons e bipólarons. .............................................

2.3 Diodos emissores de luz poliméricos (PLEDs) ................................................... 10

CAPÍTULO 3: RESSONÂNCIA PARAMAGNÉTICA ELETRÔNICA E RESSONÂNCIA MAGNÉTICA DETECTADA ELETRICAMENTE.....................13

3.1 Ressonância Paramagnética Eletrônica...................................................................13

3.1.1 Fenômenos de alargamento ou estreitamento do espectro de ressonância ......15

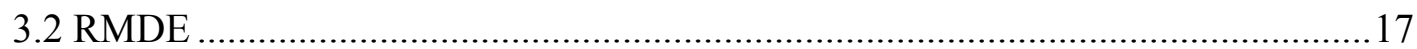

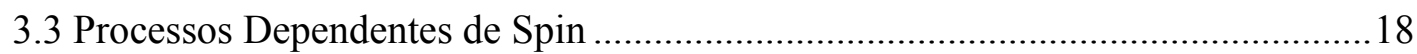

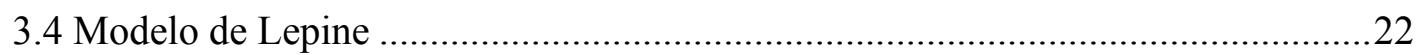

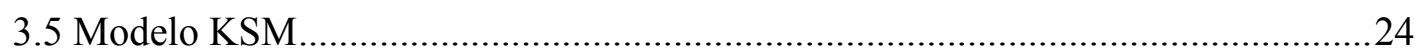

CAPÍTULO 4: MATERIAIS E MÉTODOS ......................................................25

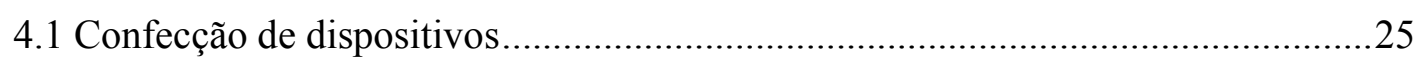

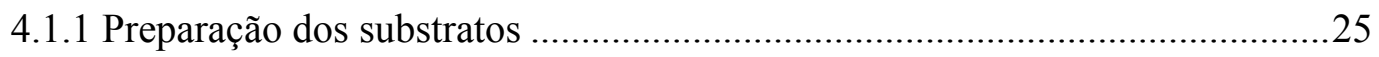

4.1.2 Deposição dos filmes orgânicos .....................................................................26

4.1.3 Evaporação dos contatos metálicos..............................................................29

4.1.4 Resumo dos tipos de dispositivos estudados..................................................30

4.2 Medidas de Ressonância Paramagnética Eletrônica e Ressonância Magnética

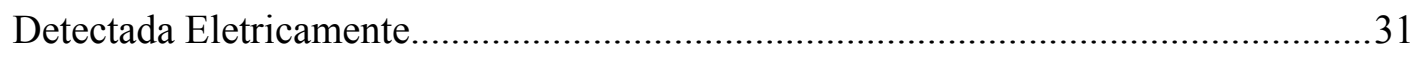

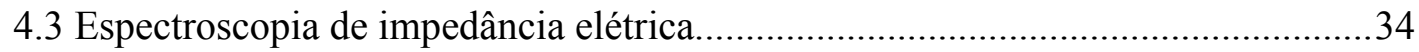

CAPÍTULO 5: POLIANILINA ................................................................................35

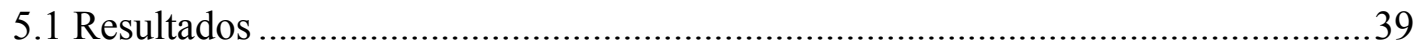


5.1.1 Ressonância Paramagnética Eletrônica........................................................39

5.1.2 Ressonância Magnética Detectada Eletricamente..........................................4

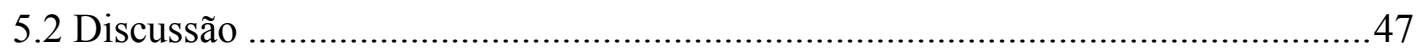

CAPÍTULO 6: RMDE DE DIODOS DE MEH-PPV ..............................................52

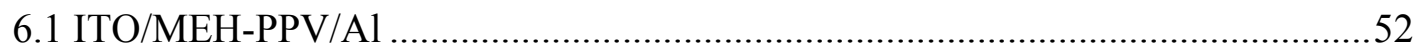

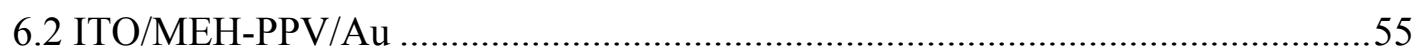

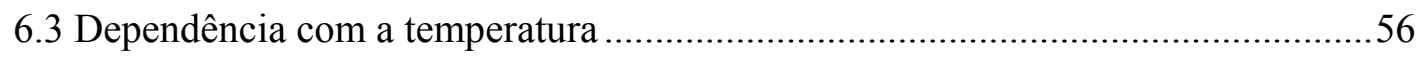

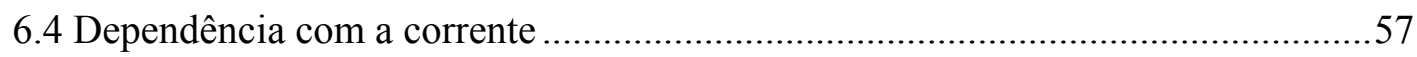

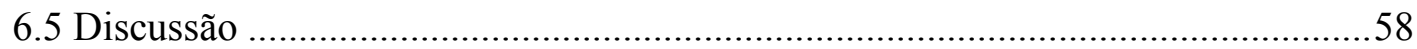

CAPÍTULO 7: ESPECTROSCOPIA DE IMPEDÂNCIA ELÉTRICA EM OLEDS

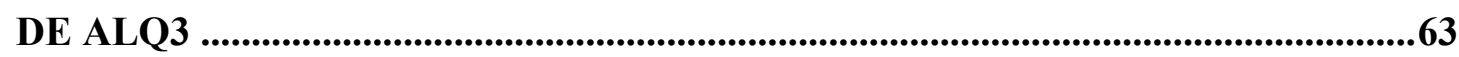

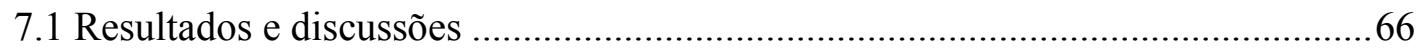

CAPÍTULO 8: CONCLUSÕES............................................................................77

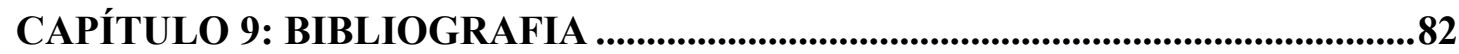


Figura 2.1: Distribuição de probabilidade eletrônica do butadieno. (a) Orbitais $\sigma$

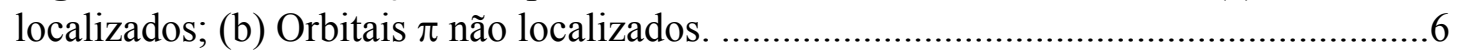

Figura 2.2: Estrutura de alguns tipos de polímeros conjugados mais comuns...................7

Figura 2.3: Ilustração de um sóliton dividindo uma cadeia de trans-poliacetileno em duas regiões A e B degeneradas.

Figura 2.4: Diagramas de bandas e respectivas representações de um sóliton dentro da estrutura do trans-poliacetileno. Defeito a) carregado positivamente $(S=0)$, b)

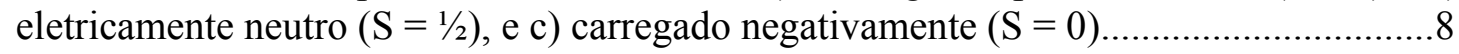

Figura 2.5: Níveis de energia de pólarons, bipólarons e éxciton singleto em um polímero com estado fundamental não-degenerado.........................................................

Figura 2.6: Exemplo de curva típica de diodo............................................................

Figura 2.7: Diagrama de energias do ITO, MEH-PPV e diferentes cátodos metálicos..11

Figura 4.1: Esquema de remoção do ITO. .26

Figura 4.2 Esquema do aparato experimental para formação de filmes de MEH-PPV pelo método "spin casting".

Figura 4.3: Esquema do aparato experimental para formação de filmes de Pani pelo método casting...

Figura 4.4: Estrutura das moléculas que compõem o OLED a base de $\mathrm{Alq}_{3}$

Figura 4.5: (a) Estrutura de dispositivo tipo "sanduíche", (b) dispositivo com contatos paralelos (visão da superfície superior).

Figura 4.6: (a) Absorção das microondas em um espectro de EPR com uma amplitude de modulação $\mathrm{H}_{\bmod }$ e (b) espectro de EPR: primeira derivada do espectro de absorção da microonda.

Figura 4.7: Foto do aparato experimental usado nas medidas de RPE e RMDE............32

Figura 4.8: Foto de um dispositivo de $\mathrm{Alq}_{3}$ encapsulado para medidas de RMDE.........33

Figura 4.9: Ilustração de uma medida de impedância em uma amostra de um material de

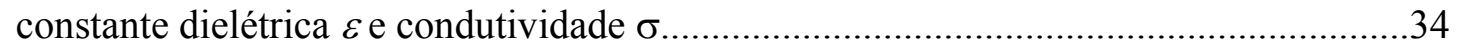

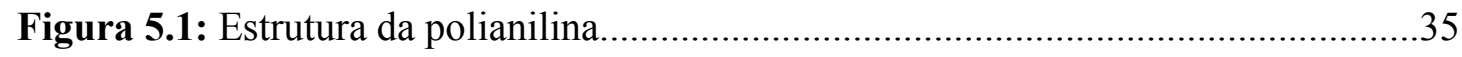

Figura 5.2: Esquema genérico de dopagem da polianilina em solução de $\mathrm{HCl}$...............36

Figura 5.3: Sinal de RPE em temperatura ambiente de um filme de polianilina.............39

Figura 5.4: (a) Sinal de RPE integrado (círculos abertos) de um filme de polianilina, decomposto em duas lorentzianas, uma larga (tracejada) e uma fina (pontilhada), cuja soma mostrada pela linha sólida. (b) Zoom do pico de absorção para melhor visualização das componentes.

Figura 5.5: Dependência da amplitude do sinal das componentes fina e larga com a temperatura...... 
Figura 5.6: Dependência da susceptibilidade magnética de um filme de pani com a

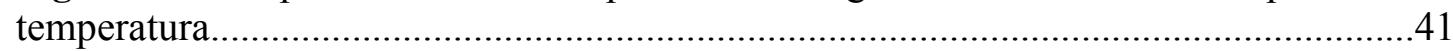

Figura 5.7: Dependência do fator $g$ da componente fina do espectro de RPE

Figura 5.8: Dependência da largura de linha da componente dominante do sinal de RPE em função da temperatura.

Figura 5.9: Sinal integrado de RMDE de um dispositivo com contatos coplanares (círculos abertos), decomposto em duas componentes, uma gaussiana larga (linha pontilhada) e uma lorentziana fina (linha tracejada). A linha sólida representa a soma das componentes.

Figura 5.10: Sinal integrado de RMDE (círculos abertos) de um dispositivo de polianilina com contatos tipo sanduíche, ajustado por uma gaussiana larga (linha sólida).

Figura 5.11: Intensidade do sinal de RMDE em função da temperatura. Figura cedida por Graeff et al.[32].

Figura 6.1: Sinal de RMDE típico de um PLED de MEH-PPV (círculos abertos) decomposto em duas componentes (pontilhada e tracejada). A linha sólida é a soma das duas componentes.

Figura 6.2: (a) sinal de RMDE integrado de um PLED péssimo emissor de luz simulado por uma lorentziana, (b) sinal de RMDE integrado de um PLED bom emissor de luz composto por duas componentes, uma gaussiana e uma lorentziana.

Figura 6.3: Sinal de RMDE de um diodo de ITO/MEH-PPV/Au (círculos abertos) ajustado pela derivada de uma curva tipo gaussiana (linha sólida).

Figura 6.4: Sinal de RMDE de um diodo de ITO/MEH-PPV/Au (círculos abertos) decomposto em duas componentes (pontilhada e tracejada). A linha sólida é a soma das duas componentes.

Figura 6.5: Dependência da amplitude do sinal de RMDE com a temperatura para a) LEDs com diferentes eficiências de emissão de luz; b) diodo em que a injeção de elétrons é bastante minimizada (não emite luz).A linha em preto representa a máxima amplitude esperada utilizando o modelo de Lepine.

Figura 6.6: Dependência do sinal de RMDE com a corrente para um diodo bipolar (quadrados cheios) e um diodo hole-only (círculos abertos).

Figura 7.2: Componentes real (a) e imaginária (b) da resposta de impedância de um OLED operando em modo direto em diferentes voltagens dc. No detalhe em (a) é mostrada a dependência de $Z^{\prime}$ com $V_{\mathrm{dc}}$ em $\mathrm{f} \rightarrow 0$.

Figura 7.2: Componentes real (a) e imaginária (b) da resposta de impedância de um OLED operando em modo reverso em diferentes voltagens dc. 
Figura 7.3: Diagrama de energias do HOMO (inferior), LUMO (superior) e nível de Fermi (dos eletrodos) em relação ao nível de vácuo para as camadas que compõem o OLED. .69

Figura 7.4: Componentes real (a) e imaginária (b) da capacitância complexa para um OLED operando em modo reverso.

Figura 7.5: Componentes real (a) e imaginária (b) da capacitância complexa do OLED operando em modo direto

Figura 7.6: Componente real da capacitância complexa para diferentes valores de voltagem dc: (a) de $0 \mathrm{~V}$ a $2,5 \mathrm{~V}$; e (b) de $3 \mathrm{~V}$ a $6 \mathrm{~V}$. Em (b) $\mathrm{V}_{\mathrm{dc}}=0 \mathrm{~V}$ também é mostrado para comparação. 72

Figura 7.7: Componente real da capacitância complexa para um PLED (a) e um dispositivo hole-only (b), ambos de MEH-PPV e operando em modo direto e em modo reverso. Figura cedida por L.F. Santos. .73

Figura 7.8: Diagrama de energias do HOMO e do LUMO do MEH-PPV e do nível de Fermi dos eletrodos usados no PLED e no hole-only. 
Tabela 4.1: Resumo dos dispositivos analisados com a configuração de cada tipo.........30

Tabela 7.1: Relações entre as quatro funções de representação de medidas de impedância mais usuais. 
Al - alumínio

$\alpha$-NPD -N,N'-difenil-N,N'-bis(1-naftil)-1,1'-bifenil-4,4'-diamina

Alq3 - tris(8-hidroxiquinolato) de alumínio (III)

Au $\quad-$ ouro

bulk - volume do material a que se refere

CuPc - ftalocianina de cobre

FFCLRP - Faculdade de Filosofia Ciências e Letras de Ribeirão Preto

gap - diferença de energia entre o HOMO e o LUMO.

GPBG - Grupo de Polímeros Bernhard Gross

HOMO - orbital molecular mais alto ocupado

IFSC - Instituto de Física de São Carlos

LiF - fluoreto de lítio

LUMO - orbital molecular mais baixo desocupado

MEH-PPV - poli(2-metóxi, 5-(2'-etil-hexilóxi)-1,4-fenileno vinileno)

Pani $\quad-$ polianilina

PPV $\quad-$ poli(p-fenileno vinileno)

RESSOMAT - Grupo de Ressonância Magnética e Materiais

RMDE - ressonância magnética detectada eletricamente 


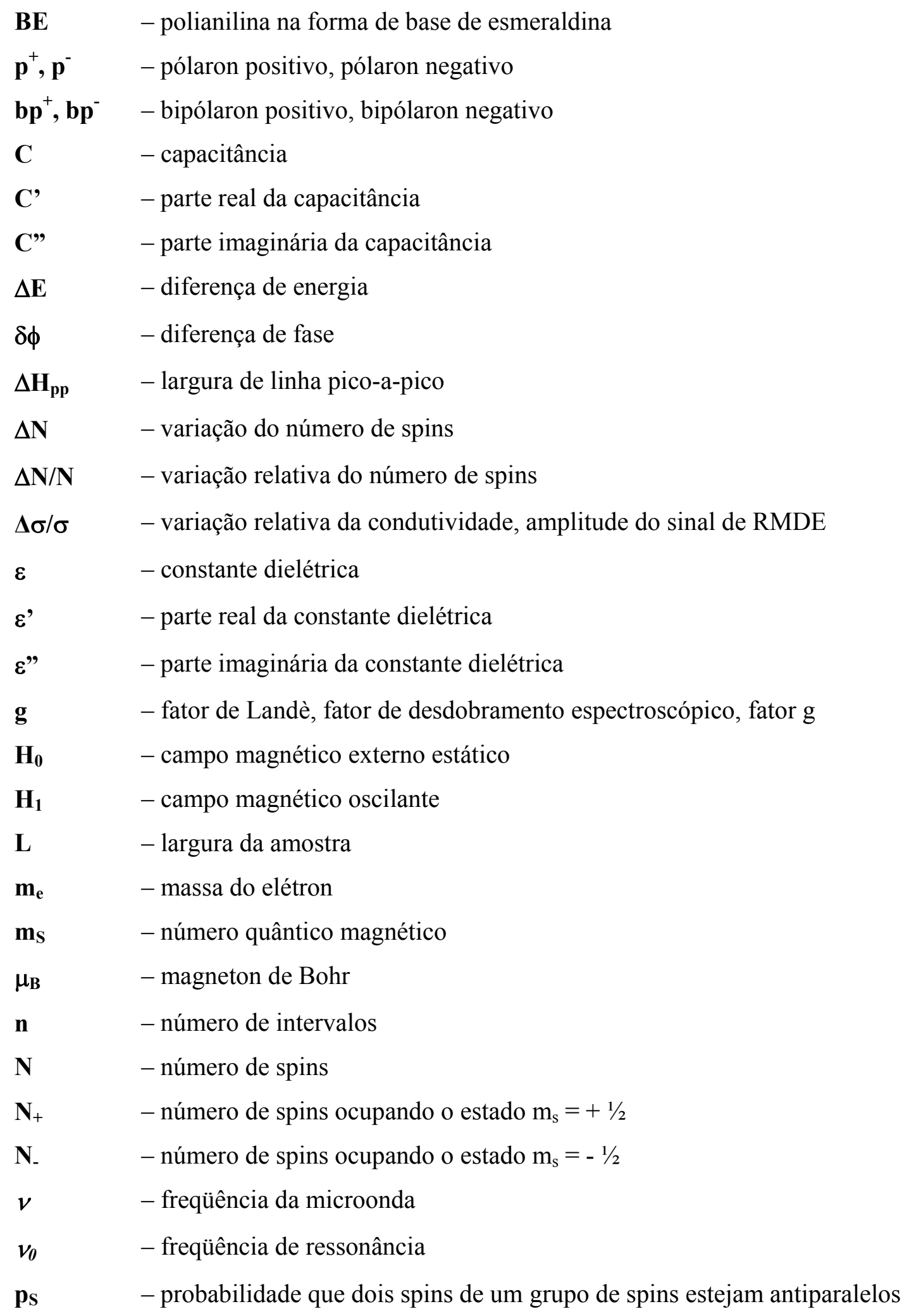




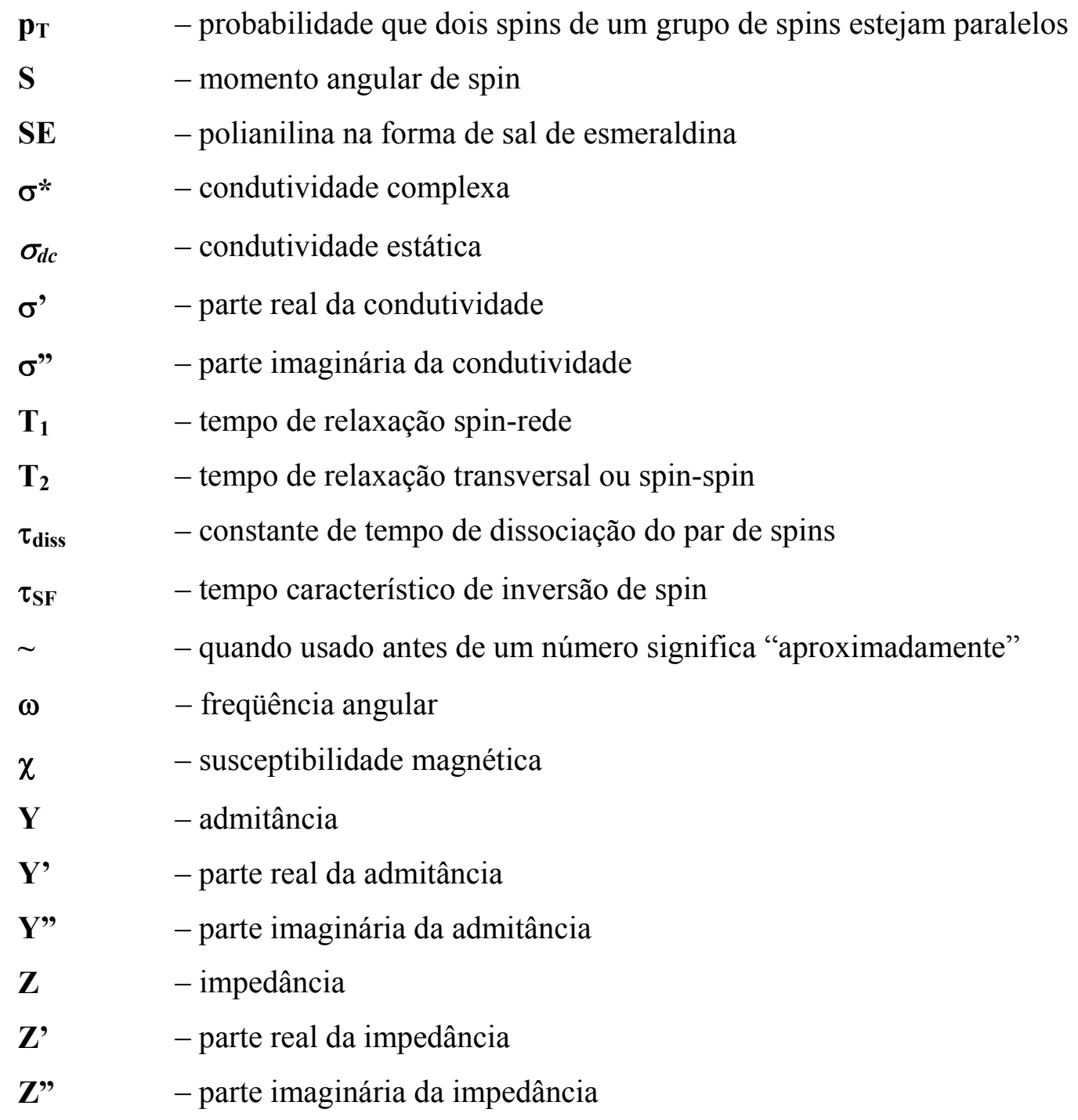




\section{RESUMO}

O objetivo deste trabalho foi de estudar processos de transporte eletrônico em dispositivos a base de semicondutores orgânicos através de técnicas avançadas, como ressonância magnética detectada eletricamente (RMDE) e espectroscopia de impedância elétrica em corrente alternada. Além destas, medidas de ressonância paramagnética eletrônica (RPE) convencional também foram realizadas de forma a complementar as medidas de RMDE. Os dispositivos e materiais estudados foram: (hole-only e PLED) de MEH-PPV, polianilina e OLED multicamadas de $\mathrm{Alq}_{3}$ e $\alpha$-NPD. A técnica de RMDE mede a variação de condutividade da amostra na condição de ressonância magnética, permitindo relacionar processos microscópicos com os seus efeitos nos processos de transporte eletrônico. Os estudos de RPE e RMDE em polianilina mostraram uma transição entre os tipos de spin observados em função da temperatura. Os resultados obtidos indicam que o sinal de RPE se deve principalmente a estados de superfície, enquanto a técnica de RMDE permite observarmos também estados do volume, dependendo da forma de preparação dos dispositivos e dos parâmetros utilizados nas medidas. O sinal de RMDE foi atribuído ao hopping de pólarons intercadeias poliméricas. Nos dispositivos de MEH-PPV, o sinal de RMDE apresenta duas componentes, uma foi atribuída à fusão de pólarons negativos para formar bipólarons negativos e a outra foi atribuída à fusão de pólarons positivos. A deficiência na emissão de luz de alguns dos PLEDs estudados foi atribuída ao desbalanceamento de injeção de cargas, que pode ser observado pela diferença de intensidade entre as componentes do sinal. Nos OLEDs a base de $\mathrm{Alq}_{3}$, medidas de espectroscopia de impedância elétrica em função da voltagem dc $\left(\mathrm{V}_{\mathrm{dc}}\right)$ mostraram um acúmulo de cargas nas interfaces internas do dispositivo, em baixas tensões. Entretanto, para valores mais altos de $\mathrm{V}_{\mathrm{dc}}$, quando começa o processo de recombinação, foi observado um fenômeno pouco estudado na literatura, conhecido como "capacitância negativa". Possíveis abordagens a este problema foram propostas. 


\begin{abstract}
The subject of this work is the investigation of electronic transport processes in organic semiconductors based devices using advanced techniques, such as electrically detected magnetic resonance (EDMR) and ac electrical impedance spectroscopy. Electron Paramagnetic Resonance (EPR) measurements were also carried out to complement the EDMR results. The studied devices and materials were: MEH-PPV hole-only devices and PLEDs, polyaniline and multilayer $\mathrm{Alq}_{3}$ and $\alpha$-NPD based OLEDs. EDMR measures the sample conductivity variation during magnetic resonance condition, which allows relating microscopic processes to its effects on electronic transport processes. EPR and EDMR investigations on polyaniline showed a transition between two kinds of observed spins as a function of temperature. The results indicate that EPR probes especially surface paramagnetic states, while EDMR allows observing both surface and bulk paramagnetic states, depending on how devices are prepared and on some measurement parameters. The EDMR signal was assigned to interchain hopping of pólarons. On MEH-PPV devices, the EDMR signal was composed of two lines, one was attributed to negative pólarons fusion to form negative bipólarons and the other was assigned to positive pólarons fusion. The light emitting deficiency presented by some of the PLEDs investigated was assigned to a misbalanced charge injection, what could be observed by the difference between the intensity of the two components. Impedance spectroscopy measurements on $\mathrm{Alq}_{3}$ based OLEDs as a function of the $\mathrm{dc}$ voltage $\left(\mathrm{V}_{\mathrm{dc}}\right)$ showed charge accumulation at the inner interfaces of the device at low $\mathrm{V}_{\mathrm{dc}}$ values. However, at higher $\mathrm{V}_{\mathrm{dc}}$ values, when recombination starts to take place, a strange phenomenon, usually called "negative capacitance", was observed. Possible approaches were proposed.
\end{abstract}




\section{Capítulo 1}

\section{INTRODUÇÃO}

No início dos anos 60, houve um grande interesse no estudo de cristais moleculares que apresentavam atividades eletrônicas e optoeletrônicas devido às suas propriedades de transporte e de recombinação eletrônicas [1,2]. Essas propriedades, tais como retificação de corrente e emissão de luz devido a fenômenos foto e eletroluminescentes, eram até então somente estudadas em semicondutores inorgânicos. Entretanto, a baixa mobilidade eletrônica dos cristais orgânicos associado às suas frágeis propriedades mecânicas não permitiram o seu sucesso em aplicações na área de dispositivos. Por esse motivo, esses estudos foram pouco a pouco sendo abandonados. A descoberta dos polímeros de condução eletrônica no final dos anos 70 [3] fez renascer o interesse das pesquisas relacionadas a processos de condução eletrônica em sistemas orgânicos. Os polímeros conjugados, que mostraram uma grande variação em sua condutividade elétrica sob dopagem química são os grandes responsáveis por essa nova adequação, elevando os materiais poliméricos à categoria de materiais de grau eletrônico. Os semicondutores orgânicos exibem propriedades de retificação quando interfaciados a metais e, sob determinadas condições, apresentam propriedades luminescentes. É cada vez mais relevante, portanto, compreendermos os mecanismos de injeção, transporte e recombinação de portadores de carga nesses semicondutores 
orgânicos à medida que estes materiais se firmam como elementos ativos de dispositivos eletrônicos e opto-eletrônicos $[4,5,6,7,8]$. O sucesso dessas aplicações pode ser medido pelos grandes investimentos realizados por empresas do setor $[9,10,11]$. Dentre as características mais atraentes do ponto de vista tecnológico está o baixo custo aliado à possibilidade da produção de dispositivos com áreas grandes, como displays [12].

Apesar do atual estágio de desenvolvimento tecnológico de dispositivos a base destes materiais orgânicos, os mecanismos de injeção, transporte e recombinação, responsáveis pela eficiência desses sistemas, ainda são pouco compreendidos e há muita controvérsia sobre o tema na literatura $[4,13,14]$. Parte desta pouca compreensão advém da dificuldade de se relacionar medidas de grandezas macroscópicas com sua origem microscópica ou mesmo de se compreender em que região do dispositivo ${ }^{1}$ está ocorrendo o processo que estamos interessados em estudar.

A possibilidade de se separar os diferentes fenômenos e estudar a dinâmica dos portadores de cargas nas diferentes regiões do material é particularmente importante em dispositivos compostos por mais de uma camada orgânica. Experimentalmente, isto pode ser obtido por medidas de resposta em freqüencia, como a espectroscopia de impedância elétrica em corrente contínua (ac). Basicamente, uma voltagem oscilante no tempo $\left[\mathrm{V}(\mathrm{t})=\mathrm{V}_{\mathrm{ac}} \cos (\omega \mathrm{t})\right]$ é aplicada ao dispositivo a ser estudado e a resposta em corrente é obtida na mesma freqüência mas com um certa defasagem em relação a $V(t)$. Em baixas freqüências, somente os portadores (ou processos) mais lentos irão responder à perturbação em freqüência. Em freqüências intermediárias, alguns portadores mais lentos vão deixando de responder até que, em altas freqüências, apenas os portadores com maior mobilidade, aqueles presentes nos eletrodos, irão contribuir para a resposta do sistema. Assim, é possível selecionar os processos a serem estudados, permitindo uma correlação da resposta em freqüência com a estrutura do dispositivo, por exemplo, através da mobilidade dos portadores em cada camada.

Por outro lado, a possibilidade de se investigar o ambiente microscópico destes materiais é dada por métodos de ressonância magnética, como ressonância paramagnética eletrônica (RPE) ou ressonância magnética nuclear (RMN). Entretanto,

\footnotetext{
${ }^{1}$ Por exemplo, no volume do material orgânico ou próximo à interface com o eletrodo metálico.
} 
enquanto os métodos de ressonância magnética permitem acesso a informações microscópicas sobre centros paramagnéticos, eles não são capazes de revelar muita informação sobre atividades de transporte e recombinação. Devido a esta limitação, métodos experimentais foram desenvolvidos para combinar a sensibilidade microscópica e seletividade da RPE com outros métodos como condutividade ou fotoluminescência. A descoberta de processos de recombinação que dependem do spin eletrônico remonta às primeiras medidas de ressonância magnética detectada opticamente (RMDO ou, da sigla em inglês, ODMR) realizadas por Geschwind et al. [15,16] em 1959. Nestes experimentos, configurações de spin em estados eletrônicos excitados são manipulados por RPE, levando a uma mudança relativa entre os processos de recombinação, que podem ser observadas por medidas de luminescência. Alternativamente à detecção de RPE por medidas de luminescência, processos de transporte dependentes de spin podem ser detectados por mudanças na condutividade, ou fotocondutividade do material. Este método é chamado de ressonância magnética detectada eletricamente (RMDE, ou do inglês, EDMR), e também é conhecido pelos nomes: condutividade dependente de spin (CDS), ressonância paramagnética eletrônica detectada eletricamente (EDEPR), entre outras. As primeiras medidas de RMDE foram realizadas por Maxwell e Honig [17,18] que investigaram o impacto da RPE no espalhamento de portadores de carga em impurezas em 1966.

Os métodos que combinam RPE com detecção de variáveis macroscópicas são muito mais sensíveis do que as medidas de RPE convencional e, portanto, podem ser aplicados a materiais e dispositivos onde o número de defeitos paramagnéticos é muito pequeno para possibilitar uma investigação por medidas de ressonância convencional. Essas técnicas são adequadas ao estudo do processo de transporte e recombinação em filmes finos semicondutores, orgânicos e inorgânicos, e seus dispositivos. Em particular, a técnica de Ressonância Magnética Detectada Eletricamente (RMDE) tem sido empregada com sucesso no estudo dos processos de transporte e recombinação em semicondutores cristalinos [18,19,20,21], em semicondutores amorfos, micro ou policristalinos $[22,23,24,25,26,27,28,29,30]$ e em semicondutores orgânicos $[31,32,33,34,35,36,37]$. 


\section{Descrição do trabalho}

Este trabalho tem por objetivo estudar processos de transporte em dispositivos eletrônicos à base de três diferentes semicondutores orgânicos: polianilina (Pani); poli(2metóxi, 5-(2'-etil-hexilóxi)-1,4-fenileno vinileno) (MEH-PPV); e tris(8hidroxiquinolato) de alumínio (III) $\left(\mathrm{Alq}_{3}\right)$; através de técnicas avançadas, como ressonância magnética detectada eletricamente e espectroscopia de impedância elétrica. No CAPÍTULO 2, serão introduzidos conceitos básicos sobre os semicondutores orgânicos, em especial sobre polímeros condutores. No CAPÍTULO 3, serão introduzidos conceitos fundamentais sobre as técnicas de ressonância paramagnética eletrônica e ressonância magnética detectada eletricamente, e sobre como processos eletrônicos podem depender da orientação dos spins envolvidos. No CAPÍTULO 4, serão descritos os métodos de preparação dos dispositivos utilizados, assim como as técnicas de medidas de RMDE e impedância. No CAPÍTULO 5, serão apresentados e discutidos os resultados de medidas de RPE e RMDE em dispositivos de polianilina. O CAPÍTULO 6 apresenta e discute os resultados de medidas de RMDE em diodos de MEH-PPV. No CAPÍTULO 7, serão apresentados e discutidos os resultados de medidas de impedância elétrica em dispositivos de Alq3. No CAPÍTULO 8, serão apresentadas as principais conclusões e as perspectivas futuras.

O Grupo de Ressonância Magnética e Materiais (RESSOMAT - FFCLRP USP) é o primeiro grupo de pesquisa brasileiro a introduzir a técnica de RMDE no país e, em colaboração com o Grupo de Polímeros Bernhard Gross (GPBG - IFSC - USP), aplicá-la a dispositivos poliméricos [36,37]. Este trabalho mostrará que a técnica de ressonância magnética detectada eletricamente pode trazer informações importantes para uma melhor compreensão dos mecanismos de transporte em semicondutores orgânicos, tendo a vantagem de permitir o estudo destes materiais na forma de dispositivos eletrônicos reais e não apenas na forma de filmes finos ou em solução. 


\section{CAPÍTULO 2}

\section{POLÍMEROS CONDUTORES}

Um polímero é uma molécula de cadeia longa formada por muitas ("poli”) unidades ("meros") idênticas repetidas. Em geral, são compostos de carbono e hidrogênio ${ }^{2}$, porém, eventualmente podem aparecer outros átomos, como, por exemplo, oxigênio ou nitrogênio, ligados à cadeia principal. Muita pesquisa científica é destinada às propriedades e aplicações de materiais poliméricos, devido a grande quantidade de diferentes moléculas, com diferentes características, que podem ser sintetizadas. Como exemplo, diferentes polímeros podem ser utilizados tanto como isolantes em revestimento de fios de alta tensão [38,39], quanto como camada ativa (eletroluminescente) em displays [9,10,11].

Neste trabalho, o interesse é voltado aos polímeros com propriedades eletrônicas, que, em geral, são polímeros conjugados. Um polímero é dito conjugado quando há uma alternância de ligações simples e duplas entre os carbonos da sua cadeia principal. A estrutura eletrônica destes materiais pode ser descrita em termos da sobreposição entre orbitais $\mathrm{p}_{z}$ adjacentes provenientes da hibridização $\mathrm{sp}^{2}$ dos átomos de carbono [40]. Os carbonos da cadeia polimérica principal são unidos pelas fortes ligações $\sigma$ (ligações

\footnotetext{
${ }^{2}$ Daí a denominação de materiais orgânicos.
} 
simples formadas pelos orbitais $\mathrm{sp}^{2}$ ), enquanto que os orbitais $\mathrm{p}_{z}$ se superpõem em um plano perpendicular ao da cadeia, formando orbitais preenchidos $\pi$ e vazios $\pi^{*}$.

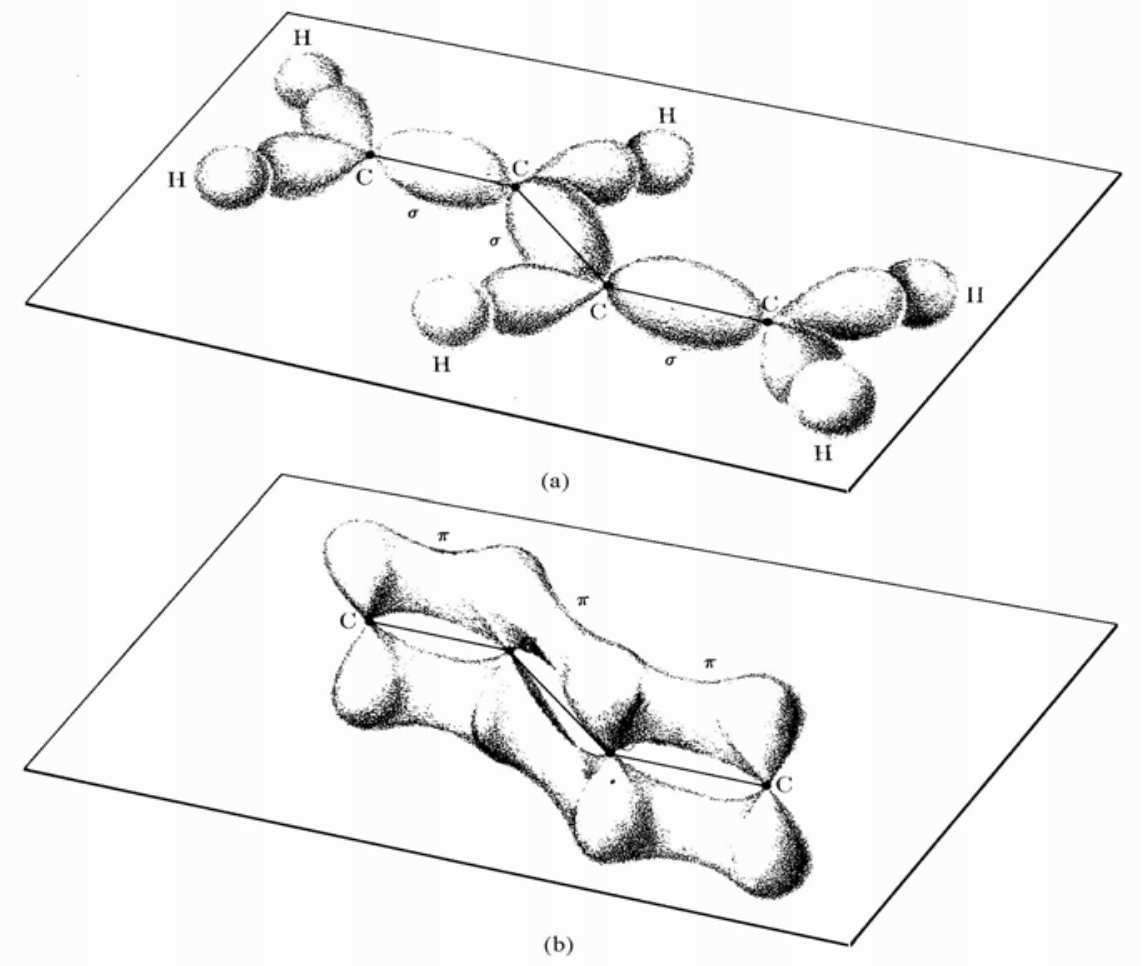

Figura 2.1: Distribuição de probabilidade eletrônica do butadieno. (a) Orbitais $\sigma$ localizados; (b) Orbitais $\pi$ não localizados [41].

Como estes materiais podem ser tratados aproximadamente como condutores unidimensionais, existe uma separação ("gap") energética entre o orbital molecular mais alto ocupado (HOMO, highest occupied molecular orbital) e o orbital molecular mais baixo desocupado (LUMO, lowest unoccupied molecular orbital), devido à instabilidade de Periels [42]. Em geral, nestes polímeros condutores, o "gap" de energia é da ordem de 1,5 a 4,0 eV, semelhante ao de semicondutores inorgânicos. 


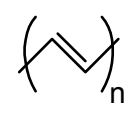

Poliacetileno

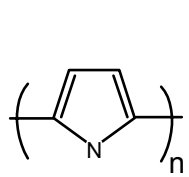

Polipirrol - PPy

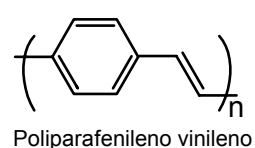

PPV

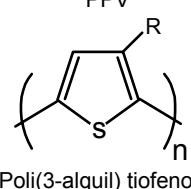

P3AT (R = metil,

butil, etc.)

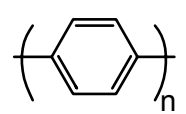

Poliparafenileno - PPP

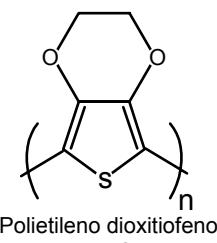
PEDOT
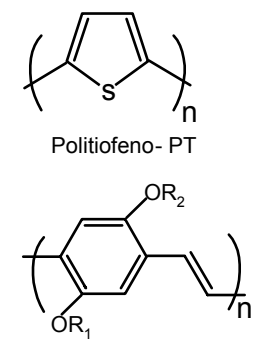

Poli(2,5 dialcoxi) parafenileno vinileno (e.g.: MEH-PPV)

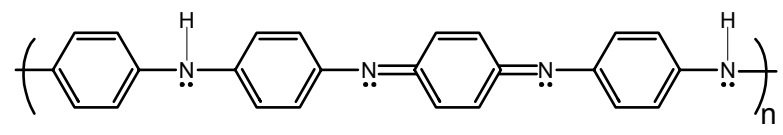

Polianilina - PANI

Figura 2.2: Estrutura de alguns tipos de polímeros conjugados mais comuns.

A figura 2.2 apresenta os nomes e fórmulas estruturais de alguns polímeros condutores. Apesar de ter sua conjugação interrompida pela presença de nitrogênios amina, a polianilina, cuja estrutura simplificada é mostrada nesta figura, também se comporta como um sistema conjugado.

\subsection{Portadores de carga em sistemas conjugados}

Como já foi mencionado na introdução deste trabalho, o interesse em processos de condução em sistemas orgânicos renasceu no final da década de 1970 [3] devido à descoberta de que polímeros conjugados poderiam ter sua condutividade elétrica aumentada através de dopagem química, sob ação de agentes oxidantes ou redutores. $\mathrm{O}$ papel destes agentes é o de retirar (ou introduzir) um elétron na banda $\pi\left(\pi^{*}\right)$. A carga líquida introduzida no sistema leva a uma relaxação estrutural da cadeia polimérica, ocasionando uma certa localização da densidade de carga eletrônica. Vamos ver o que significa esta relaxação estrutural. 


\subsection{Defeitos estruturais: sólitons, pólarons e bipólarons.}

No trans-poliacetileno, no estado fundamental, defeitos estruturais, chamados sólitons, podem inverter a seqüência entre as ligações (simples/dupla ou dupla/simples). Neste sistema, estas duas regiões são degeneradas, ou seja, apresentam a mesma energia. O nome sóliton se deve à sua localização e translação sem perda de energia. O resultado da formação de tal defeito pode ser representado pelo esquema da figura 2.3, onde, embora a cadeia permaneça eletricamente neutra, um elétron $\pi$ do carbono assinalado $(\bullet)$ se encontra desemparelhado.

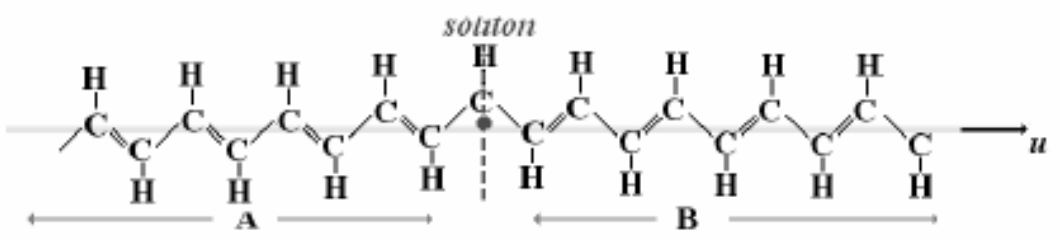

Figura 2.3: Ilustração de um sóliton dividindo uma cadeia de trans-poliacetileno em duas regiões A e B degeneradas [61].

Esse sóliton, portanto, possui carga nula, spin $1 / 2$ e leva à formação de um estado não-ligante, degenerado e localizado, no meio do gap entre $\pi$ e $\pi^{*}$ [43]. Quando uma carga líquida é introduzida na cadeia polimérica são nestes defeitos estruturais que ela irá se localizar, dando origem a um sóliton eletricamente carregado e com spin total nulo (figura 2.4).

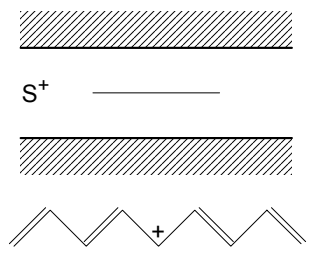

a)

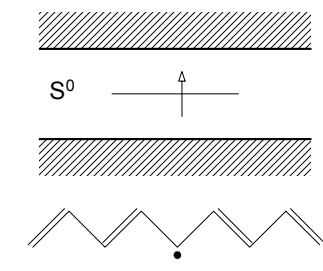

b)

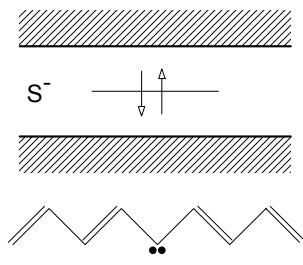

c)

Figura 2.4: Diagramas de bandas e respectivas representações de um sóliton dentro da estrutura do trans-poliacetileno [61]. Defeito a) carregado positivamente $(\mathrm{S}=0), \mathrm{b})$ eletricamente neutro $(\mathrm{S}=1 / 2)$ e c) carregado negativamente $(\mathrm{S}=0)$. 
Todos os demais polímeros conjugados, porém, apresentam estas duas regiões, onde a seqüência de ligações é invertida, com energias diferentes, ou seja, um estado fundamental não-degenerado [40,44]. Para que a relaxação estrutural seja estável, os defeitos nesses materiais sempre ocorrem juntamente com a presença de um anti-defeito (ou anti-sóliton), de modo que a seqüência de energia mais alta fique entre eles [43]. Estes defeitos são chamados pólarons (p). Um pólaron é um estado formado por um sóliton carregado e um sóliton neutro, levando à formação de dois níveis no meio do gap, um ligante e outro antiligante. O resultado disso é uma quase-partícula, dotada de carga eletrônica $\left(q=+e\right.$, pólaron positivo, $\mathrm{p}^{+} ;$ou $\mathrm{q}=-\mathrm{e}$, pólaron negativo, $\left.\mathrm{p}^{-}\right)$e momento de $\operatorname{spin}(s=1 / 2)$. Esse defeito, portanto, atua como um portador de carga e de spin eletrônicos, mas que é acompanhado de uma distorção estrutural da cadeia polimérica. Atualmente, acredita-se que esta distorção da cadeia, no caso do PPV, se estenda por entre 4 a 5 unidades monoméricas [45]. Quando dois pólarons de mesma carga se encontram eles podem formar um outro tipo de defeito, chamado bipólaron (bp), que pode ser positivo $\left(\mathrm{bp}^{++}\right.$) ou negativo $\left(\mathrm{bp}^{--}\right)$dependendo do sinal da carga dos pólarons que o formaram. Este novo defeito possui spin nulo e carga +2 ou -2 .

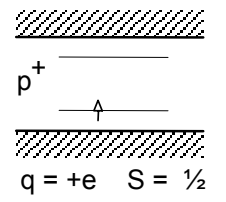

a)

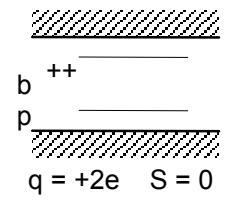

b)

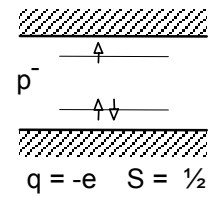

c)

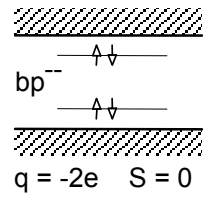

d)

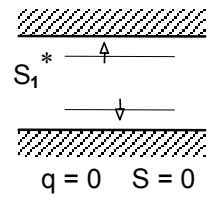

e)

Figura 2.5: Níveis de energia de pólarons, bipólarons e éxciton singleto em um polímero com estado fundamental não-degenerado.

Além disso, quando dois pólarons de cargas opostas se encontram eles podem formar um estado excitado chamado éxciton, que pode ser singleto $(\mathrm{S}=0)$ (figura 2.5e) ou tripleto $(S=1)$, dependendo da orientação relativa entre os spins que o formaram (antiparalelos ou paralelos, respectivamente). Os éxcitons singletos podem relaxar radiativamente (emitindo luz) para o estado fundamental. Acredita-se que seja este o mecanismo responsável pela luminescência nestes materiais [46,47] após a injeção de 
cargas (formação de pólarons) através de contatos metálicos (eletroluminescência) ou por foto-geração (fotoluminescência).

\subsection{Diodos emissores de luz poliméricos (PLEDs)}

Na década de 1980, verificou-se que uma fina camada de polímero condutor entre dois eletrodos metálicos poderia retificar correntes elétricas, dependendo da escolha dos metais e das propriedades semicondutoras do polímero $(40,44,48)$. A curva de corrente por tensão (I vs. V) característica de diodo é mostrada na figura 2.6. A corrente no modo direto $(\mathrm{V}>0)$, é várias ordens de grandeza maior (em alguns casos, $10^{6}$ ) do que no modo reverso.

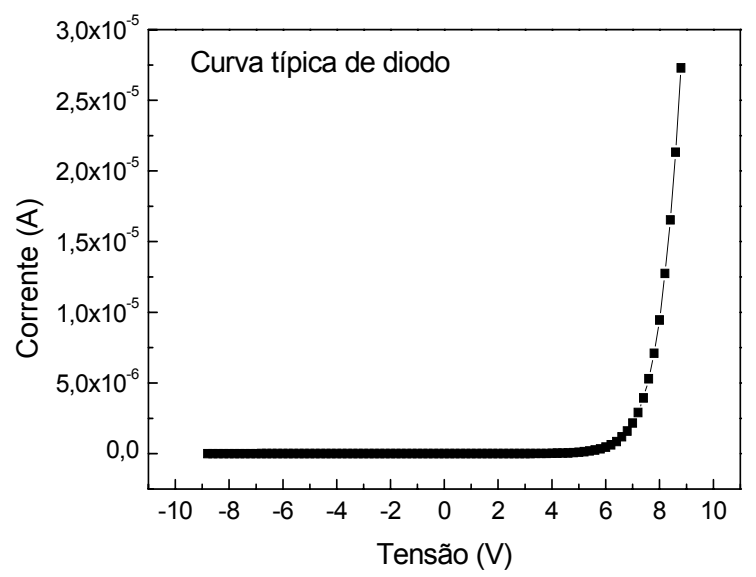

Figura 2.6: Exemplo de curva típica de diodo.

Em 1990, foi reportado o primeiro PLED, diodo emissor de luz usando um polímero conjugado como camada ativa [46]. A confirmação da potencialidade de aplicação destes materiais em dispositivos opto-eletrônicos despertou o interesse de várias empresas, como Philips, Uniax, Kodak, entre outras. O grande investimento em pesquisa e desenvolvimento de produtos baseados em eletrônica orgânica permitiu o aparecimento de diversos protótipos e produtos que já começaram a ser comercializados $[9,10,11]$. Entretanto, apesar do rápido desenvolvimento tecnológico, muitos fenômenos 
responsáveis pelo funcionamento destes dispositivos ainda permanecem mal compreendidos.

Um fator importante no desempenho dos PLEDs é a escolha dos metais usados como eletrodos. A função destes materiais é de controlar a injeção de cargas (elétrons e buracos) no polímero condutor [40,4,49].

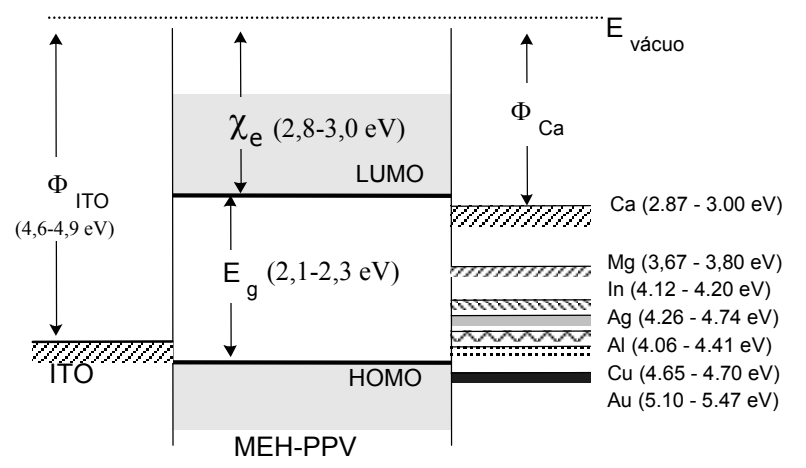

Figura 2.7: Diagrama de energias do ITO, MEH-PPV e diferentes cátodos metálicos.

A figura 2.7 ilustra o diagrama de energia para um PLED de MEH-PPV com ânodo de óxido de estanho e índio (ITO) e diferentes cátodos metálicos [50,51]. Os valores das funções trabalho apresentados podem variar de acordo com a pureza do metal utilizado e/ou da interação entre o metal e o polímero [51]. Podemos ver pela figura 2.7 que, para facilitar a injeção de elétrons e buracos, o catodo deve possuir uma função trabalho baixa, próxima à energia do LUMO do polímero, e o anodo deve possuir um alto valor de função trabalho, próximo à energia do HOMO. Em geral, utiliza-se o ITO como anodo em PLEDs devido a sua transparência à luz visível e alta função trabalho. Apesar de o cálcio ser o cátodo mais adequado para a injeção de elétrons, sua alta reatividade na presença de água e oxigênio limita a sua utilização.

Acredita-se que a eletroluminescência nestes materiais ocorra da seguinte forma [46,47]. Portadores positivos e negativos são injetados pelo ânodo e pelo cátodo, respectivamente. A eficiência desta injeção depende da barreira energética entre a função trabalho do metal e a energia do HOMO ou do LUMO do polímero (injeção de buracos e elétrons, respectivamente). Uma vez injetadas, estas cargas dão origem a 
pólarons positivos e negativos que podem se mover pela influência do campo elétrico aplicado. Estes portadores de carga podem (a) ser aprisionados por armadilhas no polímero, (b) formar um éxciton, que pode ou não decair emitindo luz, ou (c) atravessar a camada polimérica e atingir o seu contra-eletrodo. 


\section{CAPÍTULO 3}

\section{RESSONÂNCIA PARAMAGNÉTICA ELETRÔNICA E RESSONÂNCIA MAGNÉTICA DETECTADA ELETRICAMENTE}

Neste capítulo, vamos ver como os processos eletrônicos geralmente dependem do spin dos estados envolvidos. Antes, porém, vamos considerar o caso simples de um spin $S=1 / 2$ (ex. um elétron) a fim de entender como funcionam as medida de RPE convencional e de RMDE.

\subsection{Ressonância Paramagnética Eletrônica}

O spin de um elétron isolado sujeito a um campo magnético externo $\mathbf{H}_{0}$ poderá se orientar paralelo ou antiparalelo à direção do campo, tendo, portanto, dois possíveis níveis de energia para ocupar, correspondendo a $m_{S}=+1 / 2$ e $m_{S}=-1 / 2$, respectivamente, onde $\mathrm{m}_{\mathrm{S}}$ é o número quântico magnético que caracteriza os níveis de energia $\left(\mathrm{m}_{\mathrm{S}}=-\mathrm{S}\right.$, $\mathrm{S}+1, \ldots, \mathrm{S})$. Estas duas orientações diferem em energia (desdobramento Zeeman), sendo 
esta diferença dada por $\Delta \mathrm{E}=g \mu_{B} H_{0}$, onde $\mu_{\mathrm{B}}$ é o magneton de Bohr ${ }^{3}$ e $g$ é o fator de Landé ou fator de desdobramento espectroscópico, conhecido como "fator g", e vale 2,002319 para o elétron livre. Nas medidas de RPE, o valor do fator g difere do valor escalar encontrado para o elétron livre como um meio de aproximar as interações com o momento angular orbital e de incorporar os efeitos das interações com a rede no movimento dos elétrons. Como, em equilíbrio térmico, o estado de menor energia $\left(\mathrm{m}_{\mathrm{S}}=\right.$ - $1 / 2$ ) estará mais povoado do que o de maior energia $\left(m_{\mathrm{S}}=+1 / 2\right)$, o campo $\mathbf{H}_{0}$ levará a uma polarização de um sistema de $\mathrm{N}$ spins.

Transições entre estes níveis podem ser induzidas aplicando-se um campo magnético oscilante $\mathbf{H}_{1}$, perpendicular a $\mathbf{H}_{0}$, quando a freqüência de oscilação de $\mathbf{H}_{1}$ é igual à freqüência de ressonância $v_{0}=\Delta \mathrm{E} / h=g \mu_{B} H_{0} / h$. Em RPE, geralmente, esta freqüência está na faixa de microondas $(\mathrm{GHz})$. As transições induzidas por $\mathbf{H}_{1}$ vão mudar a situação de equilíbrio tendendo a igualar o número de spins nos dois níveis (condição de saturação). Elas podem ser de dois tipos: absorção estimulada ou emissão estimulada. A primeira ocorre quando um spin é invertido de $m_{S}=-1 / 2$ para $m_{S}=+1 / 2$, absorvendo um fóton da radiação eletromagnética ressonante. O processo inverso, transição do estado $m_{S}=+1 / 2$ para $m_{S}=-1 / 2$ leva à emissão de um fóton ressonante. $A$ inversão de spin ocorre em um tempo característico $\tau_{\mathrm{SF}}$. Como existem mais elétrons no estado $m_{S}=-1 / 2$, o efeito observado é o de absorção das microondas.

Transições espontâneas de inversão de spin também podem ocorrer devido à movimentação térmica de átomos ou portadores de carga. Estas transições são bastante complicadas microscopicamente, mas podem ser descritas macroscopicamente por uma constante de tempo $\mathrm{T}_{1}$, conhecida como tempo de relaxação spin-rede. $\mathrm{T}_{1}$ é o tempo característico com o qual a polarização de spins em equilíbrio térmico é restabelecida, após ter sido perturbada por um campo alternado $\mathbf{H}_{1}$. O seu efeito é o de contrabalançar a influência do campo $\mathbf{H}_{1}$ no grau de polarização de spins $\Delta N / N$. Para $T_{1}<<\tau_{\mathrm{SF}}$, o sistema de spin vai permanecer próximo ao equilíbrio térmico, enquanto para $T_{1} \gg \tau_{\mathrm{SF}}$ o sistema ficará praticamente saturado $(\Delta \mathrm{N}=0)$.

\footnotetext{
${ }^{3} \mu_{\mathrm{B}}=\mathrm{e \hbar} / 2 \mathrm{~m}$, onde "e" e "m" são, respectivamente, a carga e a massa do elétron e h é a constante de Plank dividida por $2 \pi$.
} 
Portanto, o que se observa em RPE são mudanças na magnetização da amostra induzidas por transições de spin a partir do monitoramento da absorção de microondas pela amostra.

\subsubsection{Fenômenos de alargamento ou estreitamento do espectro de ressonância}

Classicamente a interação de um campo magnético (H) com o vetor magnetização (M) vai provocar um torque no momento de spin resultante que o fará precessionar em torno da direção de $\mathbf{H}_{0}$, que vamos chamar de direção z. Postulando mecanismos de decaimento e tempos de relaxação $\left(T_{1}\right.$ e $\left.T_{2}\right)$ diferentes para as componentes horizontal e vertical da magnetização, Bloch [52] criou uma teoria clássica modificada capaz de descrever satisfatoriamente os fenômenos associados à ressonância, como absorção de microondas, formas de linha e efeitos de relaxação. $\mathrm{O}$ tempo $\mathrm{T}_{1}$, também conhecido como tempo de relaxação spin-rede está relacionado à relaxação da componente $\mathrm{M}_{\mathrm{z}}$, paralela ao campo $\mathbf{H}_{\mathrm{o}}$, enquanto $\mathrm{T}_{2}$, também conhecido como tempo de relaxação transverso, está relacionado ao tempo de decaimento de qualquer componente da magnetização transversa ao campo $\mathbf{H}_{\mathrm{o}}\left(\mathrm{M}_{\mathrm{x}}\right.$ ou $\left.\mathrm{M}_{\mathrm{y}}\right)$.

Os spins do sistema precessionam independentemente, com diferentes fases entre as suas componentes, em torno do campo magnético. As componentes transversas de dois spins precessionando no mesmo sentido, com uma diferença de fase de $180^{\circ}$, se cancelam, mas as suas componentes longitudinais se somam. As diferenças de fase entre os spins do sistema podem apresentar uma distribuição tal que a resultante da magnetização transversa seja muito baixa, ou zero, mesmo quando a componente $\mathrm{M}_{\mathrm{z}}$ é grande. Além disso, a relação entre as fases destes spins, tendo freqüências de precessão ligeiramente diferentes, vai estar em constante mudança. Processos que destruam a coerência de fase contribuem para o decaimento da magnetização transversa, alterando o valor de $\mathrm{T}_{2}$.

Se todos os spins alinhados pelo campo $\mathbf{H}_{0}$ permanecessem em fase, a largura da curva de ressonância tenderia a zero, exceto pelo alargamento devido ao princípio de incerteza. Entretanto, vários tipos de interações podem levar a uma defasagem de alguns 
spins em relação ao grupo. Esta defasagem significa uma distribuição de freqüências de precessão dos spins em relação à direção do campo $\mathbf{H}_{0}$. Dessa forma, haverá uma distribuição de estados com diferentes energias e, portanto, um alargamento da linha de ressonância. Quanto maior a defasagem, maior o alargamento. A seguir, vamos ver como o movimento de spins e a colisão com centros paramagnéticos podem alterar a largura de linha do espectro de RPE.

\section{Efeito de "Motional Narrowing" (estreitamento por movimento)}

Vamos assumir que um campo local permanece com valor $|\mathrm{H}|$ por um tempo $\tau$. A seguir, ele salta, randomicamente para $\pm\left|H_{z}\right|$. Uma mudança de campo como esta, na prática, ocorre porque o spin se move relativamente a seus vizinhos, por exemplo, por difusão. Em um tempo $\tau$, um spin vai precessionar uma fase angular $\delta \phi$ extra além de sua precessão normal [52], dada por:

$$
\delta \phi= \pm \gamma_{\mathrm{n}}\left|\mathrm{H}_{\mathrm{z}}\right| \tau \text {, onde } \gamma \text { é o fator giromagnético. }
$$

Após $\mathrm{n}$ intervalos como este, a defasagem quadrática média $\Delta \phi^{2}$ será dada por:

$$
\overline{\Delta \phi^{2}}=\mathrm{n} \delta \phi^{2}=\mathrm{n} \gamma_{\mathrm{n}}^{2} \mathrm{~Hz}^{2} \tau^{2}
$$

$\mathrm{O}$ número de intervalos $\mathrm{n}$ em um tempo t é simplesmente $\mathrm{n}=\mathrm{t} / \tau$.

Se tomarmos $\mathrm{T}_{2}$ como o tempo médio ${ }^{4}$ para que um grupo de spins em fase em $\mathrm{t}$ $=0$ se defasem de 1 radiano, nós temos:

$$
\begin{gathered}
1=\left(\frac{T_{2}}{\tau}\right) \gamma_{n}^{2} H_{z}^{2} \tau^{2} \text { ou } \\
\frac{1}{T_{2}}=\gamma_{n}^{2} H_{z}^{2} \tau
\end{gathered}
$$

Podemos notar, portanto, que um $\tau$ mais curto, ou seja, um movimento mais rápido, leva a uma linha de ressonância mais estreita, uma vez que a largura de linha é proporcional ao inverso do tempo de relaxação $1 / \mathrm{T}_{2}$. O movimento estreita a linha de

\footnotetext{
${ }^{4} \mathrm{O}$ tempo de memória de fase não é necessariamente o mesmo da relaxação spin-spin, mas é estritamente equivalente ao tempo de relaxação $\mathrm{T}_{2}$ obtido pelas equações de Bloch. Normalmente, porém, estas três constantes temporais são usadas como numericamente equivalentes e são designadas por $\mathrm{T}_{2}$.
} 
ressonância porque ele permite que um dado spin experimente vários campos $\mathrm{H}_{\mathrm{z}}$, alguns dos quais fazem com que ele aumente a fase, e outros com que ele diminua a fase. A defasagem, portanto é pequena, ocorrendo por um movimento randômico de pequenos passos, cada um muito menor que um radiano.

Por outro lado, quando não há nenhum movimento, um dado spin experiência um campo local constante. Ele precessiona mais rápido ou mais lento do que a média, e a defasagem de um grupo de spins vem da acumulação de fase positiva ou negativa.

\section{Alargamento da linha por colisão}

A diferença do fenômeno descrito anteriormente em relação ao alargamento de linha por colisão é grande. Com o "motional narrowing", não há mudança de fase quando $\mathrm{H}_{\mathrm{z}}$ está mudando de um valor para outro porque a variação é muito rápida, mas existe uma mudança de fase durante o tempo em que $\mathrm{H}_{\mathrm{z}}$ persiste. Assim, um movimento mais rápido diminui o tempo que $\mathrm{H}_{\mathrm{z}}$ persiste, diminuindo a perda na memória da fase em cada intervalo. No caso da colisão, a fase da oscilação é alterada a cada evento. Como a freqüência não é perturbada entre as colisões, não há perda de memória de fase exceto durante a colisão. Como cada colisão leva a uma perda de memória de fase, uma maior taxa de colisão produz uma memória de fase mais curta e, portanto, maior largura de linha.

\section{$3.2 R M D E$}

Na Ressonância Magnética Detectada Eletricamente, assim como nas demais técnicas que aliam RPE a medidas de grandezas macroscópicas, as mudanças na magnetização da amostra são monitoradas por variações das taxas de transição de processos dependentes de spin. Em RMDE medimos a variação relativa $(\Delta \sigma / \sigma)$ da condutividade da amostra durante a condição de ressonância. Como veremos adiante, processos eletrônicos podem depender do spin das entidades envolvidas. 
Um experimento de RMDE sempre envolve uma transição de spin relacionado a transporte ou recombinação de cargas, sendo, portanto, adequado ao estudo de processos de condução. A primeira conseqüência disto é uma maior sensibilidade em relação a RPE convencional, característica relevante para tecnologias de baixa dimensionalidade onde o número de spin participando dos processos é muito reduzido. As razões disto ficarão claras mais adiante.

Além disso, nas medidas de RPE, o substrato, ou qualquer material que entre junto com a amostra na cavidade ressonante do espectrômetro não deve ser ativo a RPE, restringindo os materiais que podem ser utilizados. Isto não ocorre nas medidas de RMDE, o que torna esta técnica interessante para o estudo de dispositivos que normalmente estão embutidos em uma matrix que nem sempre é inativa a RPE (por exemplo, transistores de filme fino, TFTs).

\subsection{Processos Dependentes de Spin}

Agora que vimos rapidamente o princípio da RPE convencional e algumas diferenças entre esta e a técnica de RMDE, vamos ver como se dá, pelo menos qualitativamente, a origem da dependência com o spin nas transições eletrônicas em semicondutores. Para isto vamos ver como o spin pode afetar o destino de um elétron ou buraco durante sua passagem por uma amostra semicondutora em três casos: no espalhamento, no tunelamento e na recombinação. Pelo menos dois spins diferentes estão envolvidos em cada um destes casos: o elétron considerado, mais um segundo elétron, um buraco ou um centro paramagnético (ex. defeito). Ao se aproximarem espacialmente, estes dois spins vão interagir e os processos subseqüentes dependerão da orientação relativa entre eles. Como descrito acima, cada um dos spins é orientado ou paralelo ou antiparalelo ao campo magnético $\mathbf{H}_{0}$, tal que o par de spin formado pode estar tanto em uma configuração $\uparrow \uparrow$ ou em uma configuração $\downarrow \uparrow$. Estas duas possíveis configurações trazem diferentes conseqüências para o par de spins, como será discutido a seguir. 
i) Espalhamento dependente de spin:

Se ambos o elétron e o spin doador localizado estão paralelos, o princípio de exclusão de Pauli requer que a componente espacial da função de onda seja anti-simétrica, (ex. antiligante), por outro lado, se os spins estão no estado singleto, anti-simétrico, a componente espacial da função de onda tem que ser simétrica, causando uma ligação do tipo covalente entre o elétron doador e o elétron livre. Isto leva a uma pequena, mas perceptível diferença entre as seções de choque de espalhamento (maior no caso paralelo), que foi descrita por Honig [18] e foi confirmada experimentalmente por vários grupos $[17,53]$.

ii) Tunelamento dependente de spin:

Após o tunelamento o estado será ocupado por dois elétrons, que, de acordo com o princípio de Pauli, precisam ter uma função de onda assimétrica (spins antiparalelos). Portanto, apenas pares antiparalelos podem contribuir para o processo de tunelamento, enquanto que os pares paralelos não poderão contribuir. Existe, assim, uma severa regra de seleção dependente de spin para o processo de tunelamento.

iii) Recombinação ou amardilhamento dependente de spin:

O mesmo argumento usado para o caso do tunelamento pode ser aplicado. Após o evento de amardilhamento ou de recombinação, ambos os spins ocuparão o mesmo orbital eletrônico e, portanto, de acordo com o princípio de exclusão de Pauli, devem estar antiparalelos. Assim, apenas pares nesta configuração podem realizar esta transição enquanto pares de spins paralelos não podem.

A partir do que foi discutido acima, podemos resumir algumas características comuns às transições dependentes de spin. $\mathrm{Na}$ presença de um campo magnético 
externo, $\mathbf{H}_{0}$, ambos a polarização de spins e o longo tempo de vida de recombinação de pares tripletos, produzem um excesso de pares paralelos em comparação a pares antiparalelos. A ressonância de spin causa uma conversão deste excesso de tripletos em singletos, aumentando, portanto, a taxa de transição dos processos dependentes de spin. Note que um aumento da taxa de transição não implica em um aumento do sinal de RMDE, por exemplo. O efeito do aumento da taxa de transição na condutividade, por exemplo, pode ser de aumentá-la ou diminuí-la, dependendo do processo que estamos observando.

Outra característica a se notar é que os espectros de transições dependentes de spin nos trazem informações sobre ambos os estados paramagnéticos envolvidos na transição: para transformar um estado tripleto em um singleto (e vice-versa), é possível inverter tanto um quanto o outro spin do par, de modo que ambas as transições ressonantes de spin irão contribuir para a composição do espectro de ressonância. Em princípio, este processo permite a identificação de ambos os estados paramagnéticos envolvidos na transição, o que faz estas técnicas experimentais particularmente úteis para a investigação de complexos mecanismos de transporte e recombinação. Note, entretanto, que existem situações em que apenas um sinal de ressonância de spin é observado. Um exemplo é o transporte de portadores por hopping em uma banda de defeitos, como, por exemplo, dangling bons em Si cristalino ou amorfo [22]. Neste caso, as assinaturas de ambos os estados iniciais de tunelamento são idênticas. Um segundo exemplo ocorre quando um dos dois níveis paramagnéticos envolvidos tem tempo de vida de spin $\left(\mathrm{T}_{1}\right)$ ou propriedades estruturais muito diferentes do outro. Neste caso, uma das duas linhas de ressonância pode ser muito mais larga do que a outra, de modo que para uma dada relação sinal-ruído apenas a componente mais estreita pode ser detectada ${ }^{5}$. Esta situação é tipicamente o caso de amardilhamento de elétrons da banda de condução por doadores em semicondutores cristalinos, onde a ressonância devido aos elétrons de condução não é observada [22].

Outra característica importante é que processos dependentes de spin são várias ordens de grandeza mais sensíveis à detecção de defeitos paramagnéticos do que

\footnotetext{
${ }^{5}$ A largura de linha do espectro depende do inverso do tempo de relaxação $T_{2}$.
} 
medidas de RPE convencional. A razão para esta maior sensibilidade é uma transformação da deteç̧ão da inversão de spin por absorção diretamente, devido a transições entre os níveis Zeeman (energia de algumas dezenas de $\mu \mathrm{eV}$ ), para transições entre diferentes níveis eletrônicos governados por regras de seleção de spins (energias de até $\approx 1 \mathrm{eV}$ ). Este aumento de sensibilidade se torna cada vez mais importante na medida em que a dimensão dos dispositivos eletrônicos vai sendo reduzida. Por exemplo, em um processador Pentium 4, a dimensão do canal ativo de um transistor típico é da ordem de $10^{-9} \mathrm{~cm}^{2}$. Por outro lado, a densidade de estados paramagnéticos na interface $\mathrm{SiO}_{2} / \mathrm{Si}$, usado em tecnologia CMOS, é de aproximadamente $10^{10}$ a $10^{12} \mathrm{~cm}^{-2}$. Portanto, neste transistor há em torno de 10 a 1000 estados paramagnéticos. O limite de detecção dos espectrômetros de RPE modernos é de aproximadamente $10^{9}$ spins por Gauss de largura de linha. No caso do Si e do $\mathrm{SiO}_{2}$, as larguras de linha de RPE são da ordem de $10 \mathrm{G}$, o que significa que, na melhor situação, $10^{10}$ spins podem ser medidos usando RPE convencional. Comparado com o número esperado de spins ativos no transistor, de $10 \mathrm{a}$ 1000, a falta de sensibilidade é clara [22,54]. O aumento de sensibilidade no caso de fotocondutividade dependente de spin em a-Si:H foi demonstrado por Kawachi et al. [28] usando estruturas de transistores de filme fino (TFT) com diferentes dimensões. É razoável esperar que para estruturas de dispositivos menores a sensibilidade das transições dependentes de spin possa ser ainda melhorada, até a capacidade de se detectar um único spin [55].

Um ponto que preocupa um pouco aqueles que não estão familiarizados com os processos dependentes de spin é o relativo pequeno efeito da ressonância de spin em uma observável macroscópica dependente de spin, tal como a fotoluminescência, fotocondutividade ou condutividade por hopping. Normalmente, as mudanças relativaș $\triangle A / A$ de uma amplitude de sinal $A$ são da ordem de $10^{-8}, \ldots, 10^{-2}$, dependendo da potência de microondas, temperatura e detalhes do processo observado. Nos materiais orgânicos estudados neste trabalho a amplitude dos sinais foi da ordem de $10^{-4}$ a $10^{-6}$. Este pequeno efeito dependente de spin, no entanto, não implica que apenas uma pequena fração dos estados paramagnéticos está diretamente envolvida no processo 
dependente de spin. Ao contrário, teorias quantitativas de transições dependentes de spin prevêem tais pequenos efeitos, e bastante progresso tem sido obtido no entendimento de quais parâmetros afetam a relativa mudança do sinal, $\Delta A / A$, em situações específicas. $\mathrm{O}$ primeiro modelo quantitativo descrevendo variações ressonantes na fotocondutividade, $\Delta \sigma / \sigma$, é o modelo de polarização de spins considerado por Lepine [56] para o caso de recombinação de foto-portadores com estados de superfície em Si cristalino. A seguir, vamos usá-lo como exemplo ilustrativo, apesar de hoje já sabermos que a realidade é bem mais complicada.

\subsection{Modelo de Lepine}

Como já foi dito anteriormente, em equilíbrio térmico, sem a presença do campo de microondas $\mathbf{H}_{1}$, os dois níveis Zeeman, separados energeticamente devido ao campo magnético $\mathbf{H}_{0}$, terão diferentes números de ocupação, $\mathrm{N}_{+}<\mathrm{N}_{-}$(onde $\mathrm{N}_{+}$e $\mathrm{N}_{-}$ representam, respectivamente, o número de ocupação dos estados $m_{S}=+1 / 2$ e $m_{S}=-1 / 2$ ). Para h $v_{0}<<\mathrm{kT}$, usando estatística convencional temos:

$$
\frac{N_{+}}{N_{-}}=e^{-\left[\frac{\left(E_{+}-E_{-}\right)}{k T}\right]}=e^{-\left[\frac{h v_{0}}{k T}\right]} \approx 1-\frac{h v_{0}}{k T}=1-k T
$$

onde $\mathrm{N}_{+}=(1-\mathrm{P}) \mathrm{N}_{\text {- e }} \mathrm{P}=\mathrm{h} v_{0} / \mathrm{kT}$. Usando a mesma aproximação nós encontramos, para a polarização macroscópica de spin:

$$
\Delta \mathrm{N} / \mathrm{N}=\left(\mathrm{N}_{-}-\mathrm{N}_{+}\right) /\left(\mathrm{N}_{-}+\mathrm{N}_{+}\right) \approx \mathrm{h} v_{0} / 2 \mathrm{kT}=\mathrm{P} / 2
$$

Pares distantes podem ser formados, com dois subestados com spins antiparalelos $(\mathrm{S}=0)$ ou dois subestados com spin paralelos $(\mathrm{S}=1)$. Daqui a diante usaremos os termos singleto e tripleto, respectivamente, para estes pares apesar de não ser, em princípio, correto. A probabilidade de que dois spins deste grupo polarizado estejam antiparalelos é dado por:

$$
p_{S}=\left(\frac{N_{+} N_{-}}{N^{2}}\right)+\left(\frac{N_{-} N_{+}}{N^{2}}\right)=2 \cdot(1-P) \cdot\left(\frac{N_{-}^{2}}{N^{2}}\right)
$$


Enquanto a probabilidade de se formar pares paralelos é dada por:

$$
p_{T}=\left(\frac{N_{+} N_{+}}{N^{2}}\right)+\left(\frac{N_{-} N_{-}}{N^{2}}\right)=\left(\left(1-P^{2}\right)+1\right) \cdot\left(\frac{N_{-}^{2}}{N^{2}}\right)
$$

Portanto, devido à polarização de spins existem mais tripletos do que singletos, e a diferença é dada por:

$$
p_{T}-p_{S}=\frac{P^{2} N_{-}^{2}}{N^{2}} \approx\left(\frac{P}{2}\right)^{2}=\left(\frac{\Delta N}{N}\right)^{2}
$$

aqui foi usada a aproximação $\mathrm{N}_{-} \approx \mathrm{N} / 2$.

Como foi discutido anteriormente, o campo $\mathbf{H}_{1}$ atua no sentido de destruir a polarização de spin e assim reduzir o excesso de população de tripletos a zero. Os pares tripletos, porém, não podem se recombinar enquanto os singletos podem, de modo que a variação relativa da fotocondutividade controlada por recombinação $\Delta \sigma / \sigma$ será dada por:

$$
-\frac{\Delta \sigma}{\sigma} \leq\left(\frac{\Delta N}{N}\right)^{2}=\left(\frac{h v_{0}}{2 k T}\right)^{2}
$$

Isto significa que, segundo o modelo de Lepine, o máximo valor da variação relativa da condutividade devido a RPE é dada pela diferença relativa de população entre os níveis Zeeman. Uma vez que, se temos inicialmente um excesso de tripletos e estes não podem se recombinar, a fotocondutividade só irá variar quando ocorrer inversão de um dos spins do par para a formação de um par singleto.

Note que a ressonância de spin diminui a fotocondutividade devido ao aumento da taxa de recombinação. Para ressonância de spin em banda $X$, o valor máximo esperado é de $6 \times 10^{-7}$ em $\mathrm{T}=300 \mathrm{~K}$, que deveria aumentar com a diminuição da temperatura e com o aumento da freqüência de microondas.

Os sinais observados experimentalmente, entretanto, especialmente em semicondutores inorgânicos desordenados, em geral, são muito mais intensos [30] e apresentam dependências com a temperatura e com a freqüência muito menores do que as previstas. De fato, a dependência segundo a equação acima só é observada em alguns poucos casos, apesar de que a dependência fundamental do spin com a polarização deve sempre estar presente. 


\subsection{Modelo KSM}

As discrepâncias entre o modelo de Lepine e os resultados experimentais podem ser explicadas em parte por um modelo teórico alternativo (conhecido como modelo KSM) proposto por Kaplan, Solomon e Mott [57], que assume que antes da transição dependente de spin, ambos os spins estão envolvidos em um par ligado. Se os dois spins estão em uma configuração singleto eles podem fazer a transição, com uma constante de

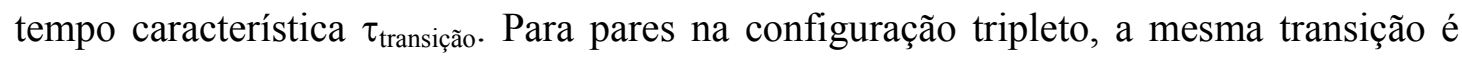
proibida por regra de seleção de spin. Portanto pares tripletos vão permanecer ligados neste estado pré-transição até que uma das três possibilidades ocorra:

- Um dos dois spins espontaneamente é invertido, o que, na média, ocorre em um tempo característico $\mathrm{T}_{1}$ (tempo de relaxação spin-rede);

- Um dos dois spins é invertido devido ao campo da microondas em ressonância, o que ocorre com uma constante de tempo $\tau_{\mathrm{SF}}=1 / \gamma \mathrm{H}_{1}$;

- O par ligado se dissocia com uma constante de tempo $\tau_{\text {diss, }}$ por exemplo por excitação térmica, antes que uma inversão, espontânea ou induzida, ocorra.

Nos dois primeiros casos, o tripleto é transformado em um singleto e, portanto, pode fazer a transição. No terceiro caso, o par é quebrado antes que ocorra a transição e todo o processo começa novamente, ou seja, os spins podem formar novos pares pré-transição.

Neste modelo, a variação máxima devido à ressonância ocorrerá para a condição $\tau_{\text {transição }}<<\tau_{\mathrm{SF}}<<\mathrm{T}_{1}, \tau_{\text {diss, }}$ em que $\Delta \sigma / \sigma$ pode atingir valores de até $50 \%$. Por outro lado, $\Delta \sigma / \sigma$ será muito pequeno para $T_{1}, \tau_{\text {diss }}<<\tau_{\text {SFF }}$.

O modelo KSM tem sido refinado por vários autores [24,25,58,59] e vem sendo empregado com sucesso em vários materiais e dispositivos baseados em semicondutores inorgânicos. Entretanto, ele não consegue explicar completamente os resultados experimentais de medidas dependentes de spin em dispositivos a base de semicondutores orgânicos. Este ponto ficará claro no decorrer deste trabalho. 


\section{CAPÍTULO 4}

\section{MATERIAIS E MÉTODOS}

\subsection{Confecção de dispositivos}

A confecção de diodos orgânicos segue basicamente as seguintes etapas: preparação dos substratos; deposição do(s) filme(s) orgânico(s); evaporação dos eletrodos metálicos; conexões dos eletrodos com o circuito externo; e encapsulamento. Em geral, utiliza-se como substrato uma placa de vidro coberta com óxido de estanho e índio (ITO), que pode ser obtido comercialmente. O ITO é muito utilizado como eletrodo (anodo) por ser um condutor transparente a luz visível e ser um bom injetor de buracos na maior parte dos semicondutores orgânicos.

\subsubsection{Preparação dos substratos}

A limpeza e o tratamento da superfície do substrato sobre o qual o filme orgânico é depositado é de fundamental importância para a obtenção de uma amostra de boa qualidade. Primeiramente, é preparada a geometria do ânodo. Como o substrato já é comprado com o ITO depositado, é necessário proteger a área a ser utilizada como 
eletrodo e remover o restante do ITO. A área a ser protegida é coberta com uma fita adesiva e uma solução de pó de zinco diluído em água é aplicada sobre o ITO descoberto. Em seguida, mergulhamos o substrato em ácido clorídrico $(\mathrm{HCl}) 1 M$. Após alguns minutos, a reação do ácido com o pó de zinco deixa a região prateada. Com um cotonete raspamos suavemente está região até a completa remoção do ITO. Após esta etapa, lavamos os substratos com água milli-Q em abundância para eliminar qualquer

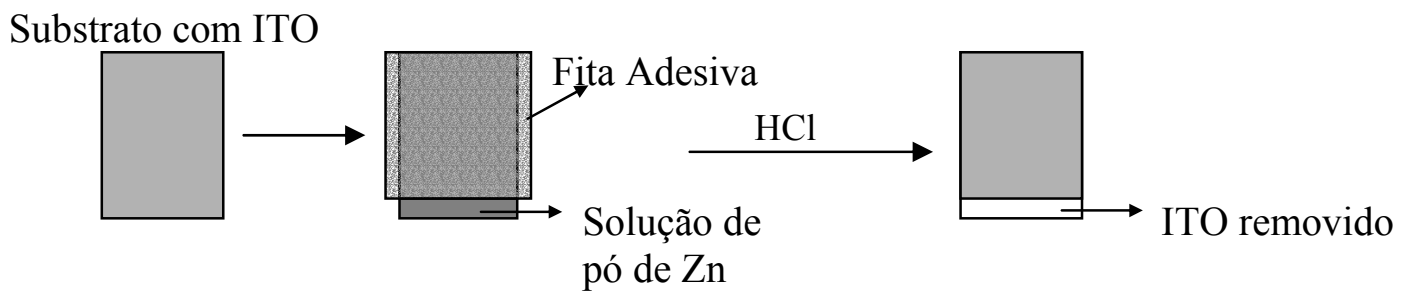

Figura 4.1: Esquema de remoção do ITO.

vestígio de $\mathrm{HCl}$. Retiramos, então a fita adesiva e mergulhamos os substratos em acetona. A acetona é aquecida até começar a ferver e então deixamos resfriar. Em seguida, repetimos este procedimento trocando a acetona por álcool isopropílico. Posteriormente, todos os substratos são lavados cuidadosamente com água milli-Q em abundância. Antes da deposição do polímero, os substratos são tratados com plasma de oxigênio.

\subsubsection{Deposição dos filmes orgânicos}

\section{i) $M E H-P P V$}

A etapa seguinte consiste da deposição do polímero MEH-PPV diluído em clorofórmio pela técnica spin-coating. Basicamente, uma solução do polímero é despejada sobre toda a área do substrato e este é posto para girar, de modo a espalhar homogeneamente a solução sobre ele e evaporar o solvente. A espessura dos filmes obtidos pode variar desde, aproximadamente, 50 a $2000 \mathrm{~nm}$, dependendo, basicamente, da concentração, da viscosidade da solução e da velocidade de rotação dos substratos. 
a)

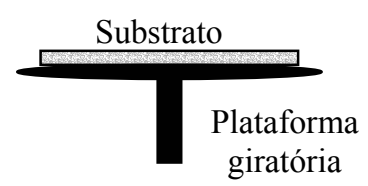

c)

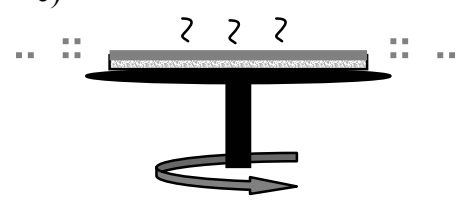

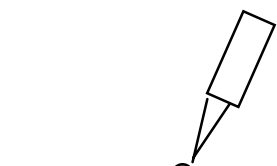

b)

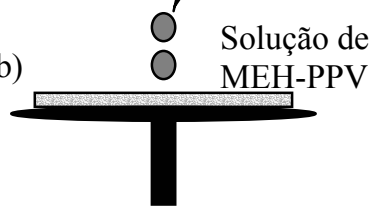

d)

Figura 4.2: Esquema do aparato experimental para formação de filmes de MEH-PPV pelo método "spin casting".

Após a obtenção dos filmes, eles são secados em vácuo ( 1 mbar), a temperaturas entre 60 e $100{ }^{\circ} \mathrm{C}$, por no mínimo 2 horas, para liberação de quaisquer resquícios de solventes. Os filmes utilizados nos dispositivos tinham entre 300 e $400 \mathrm{~nm}$ de espessura.

\section{ii) Polianilina (Pani)}

Os filmes de Pani foram obtidos pelo método casting. A Pani, obtida comercialmente e dissolvida em n-metil-pirrolidona (NMP), em concentração de $0,1 \mathrm{M}$, é despejada cuidadosamente sobre uma placa de vidro previamente tratada, como

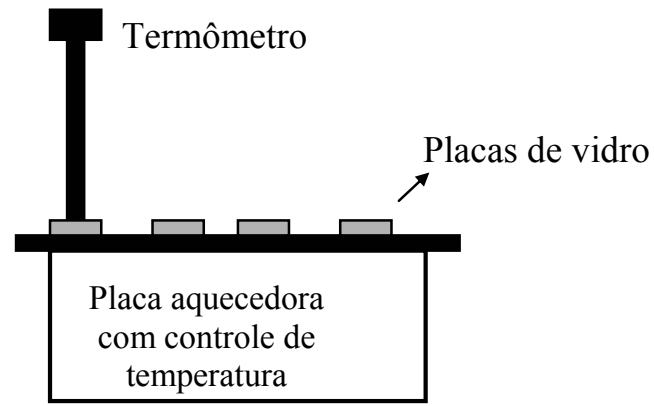

Figura 4.3: Esquema do aparato experimental para formação de filmes de pani pelo método casting. 
descrito anteriormente. $\mathrm{O}$ substrato é aquecido a aproximadamente $60^{\circ} \mathrm{C}$ até que o solvente evapore. Temos assim um filme formado sobre o vidro. Após o resfriamento à temperatura ambiente, o substrato com o filme de Pani é submerso em água milli-Q. Após algumas horas, o filme polimérico se desprende do substrato. Com a ajuda de uma folha de papel retiramos o filme de Pani da água e o prensamos entre duas folhas de papel liso para secarmos o polímero, com a ajuda de placas planas de vidro. Esta última etapa pode levar dias. Finalmente, temos um filme de Pani auto-sustentado que pode ser cortado na dimensão desejada.

iii) Alq3

A confecção dos diodos de Alq3 foi realizada em Lausanne, Suíça, pelo Dr. Frank Nuesch no Laboratoire d'Optoélectronique des Matériaux Moléculaire (LOMM), na École Polytechnique Fédérale de Lausanne (EPFL), em colaboração com o professor Dr. Libero Zuppiroli. A deposição das moléculas orgânicas para a confecção dos dispositivos multicamadas de Alq3 foram feitas por evaporação a vácuo.
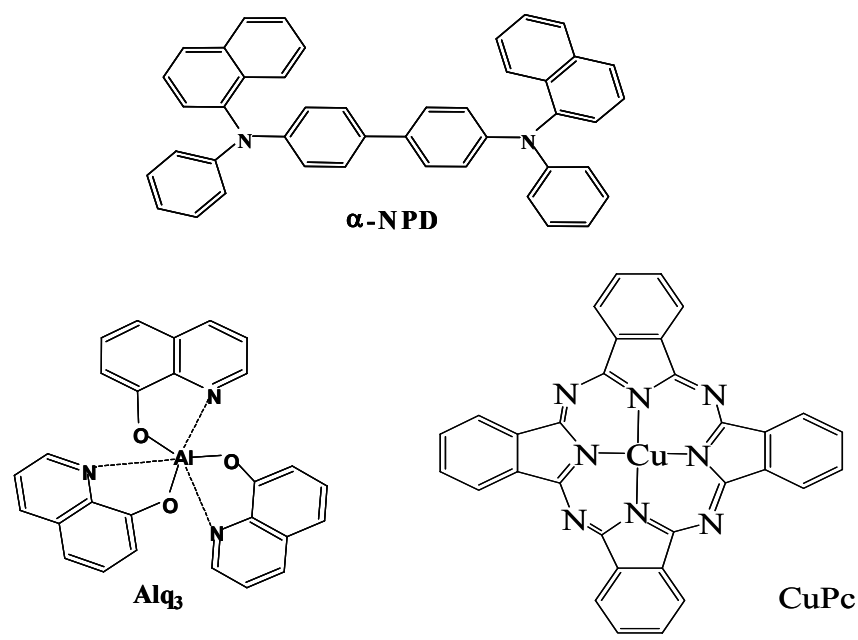

Figura 4.4: Estrutura das moléculas que compõem o OLED a base de $\mathrm{Alq}_{3}$.

Todos os materiais foram obtidos comercialmente e purificados por sublimação gradiente antes de serem utilizados. As moléculas orgânicas são evaporadas 
termicamente dentro de uma câmara em ultra alto vácuo $\left(<5 \times 10^{-7} \mathrm{mbar}\right)$ a uma taxa de $0,1 \mathrm{~nm} / \mathrm{s}$. Sobre o ITO, uma camada de $10 \mathrm{~nm}$ de ftalocianina de cobre $(\mathrm{CuPc})$ é evaporada para melhorar a injeção de buracos. Em seguida é evaporada uma camada de 40nm de N,N'- difenil - N,N'-bis(1-naftil)-1,1'bifenil - 4,4''diamina ( $\alpha-N P D)$, usada como camada transportadora de buracos e bloqueadora de elétrons. Sobre o NPD é evaporado $60 \mathrm{~nm}$ de Alq3, usado como camada transportadora de elétrons e emissoras de luz. Sobre esta camada foi evaporada uma fina camada $(0,8 \mathrm{~nm})$ de fluoreto de lítio (LiF) para melhorar o contato com o eletrodo metálico.

\subsubsection{Evaporação dos contatos metálicos}

Para definir a geometria dos catodos usamos máscaras previamente confeccionadas no formato desejado. Os metais utilizados foram alumínio (Al) e ouro $(\mathrm{Au})$. Ambos são evaporados termicamente em alto vácuo. Após a metalização, os contatos são testados para verificar a existência de curto-circuito. Em seguida são feitas as conexões externas. Para isso usamos fios de cobre conectados aos eletrodos por tinta prata. Para a conexão com o ITO, raspamos cuidadosamente um pedaço do filme orgânico, deixando o eletrodo descoberto. Como estes materiais orgânicos se degradam facilmente por foto-oxidação, os dispositivos foram encapsulados em tubos de quartzo. Todos os dispositivos foram confeccionados em estrutura tipo "sanduíche", exceto parte dos dispositivos de Pani, cujos contatos foram colocados paralelos em uma mesma superfície do filme auto-sustentado. 


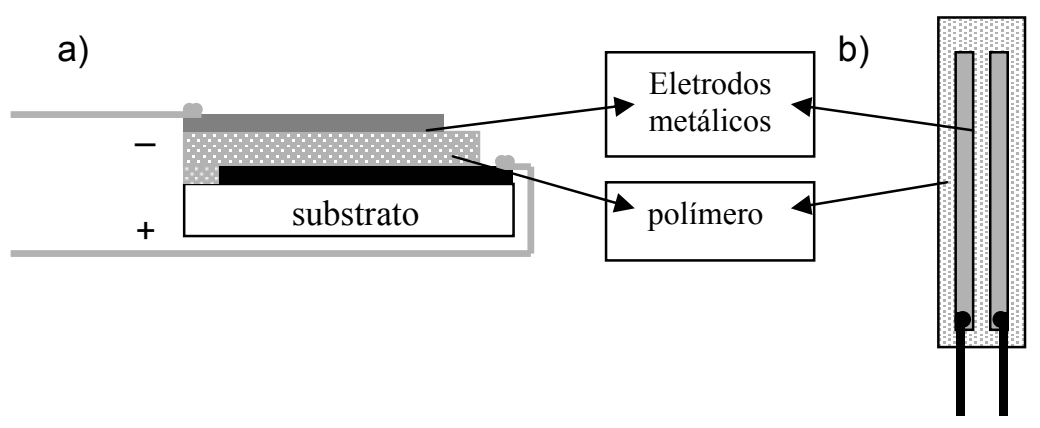

Figura 4.6: (a) Estrutura de dispositivo tipo "sanduíche", (b) dispositivo com contatos paralelos (visão da superfície superior).

Nos dispositivos de MEH-PPV, quando usamos Au como catodo, a injeção de elétrons é praticamente nula devido à alta barreira energética entre o nível de Fermi do metal e o LUMO do polímero. Por isso, vamos chamá-los, daqui a diante, de diodos hole-only ${ }^{6}$. Entretanto, em altos campos elétricos uma pequena injeção de carga negativa pode ocorrer, devido, em especial, ao grande número de defeitos na interface metalpolímero. Nos diodos de MEH-PPV, com Al como catodo, ocorre a injeção tanto de portadores de carga positiva quanto negativa. A partir daqui vamos nos referir a eles como diodos bipolares ou PLEDs, devido ao fato de apresentarem eletroluminescência.

\subsubsection{Resumo dos tipos de dispositivos estudados}

\begin{tabular}{|c|c|c|}
\hline Material ativo & Configuração & Eletroluminescente? \\
\hline \multirow{2}{*}{ MEH-PPV } & ITO/MEH-PPV $(360 \mathrm{~nm}) / \mathrm{Al}$ & Sim \\
\cline { 2 - 3 } & ITO/MEH-PPV $(360 \mathrm{~nm}) / \mathrm{Au}$ & Não \\
\hline Alq3 & $\mathrm{ITO} / \mathrm{CuPc}(12 \mathrm{~nm}) / \alpha-$ & Sim \\
& $\mathrm{NPD}(40 \mathrm{~nm}) / \mathrm{Alq}(60 \mathrm{~nm}) / \mathrm{LiF}(0.8 \mathrm{~nm}) / \mathrm{Al}$ & \\
\hline Polianilina & Contatos com tinta prata em paralelo ou & Não \\
& contatos tipo sanduíche & \\
\hline
\end{tabular}

Tabela 4.1: Resumo dos dispositivos analisados com a configuração de cada tipo.

\footnotetext{
${ }^{6}$ Hole-only é um termo em inglês usado para designar diodos cuja corrente é composto por portadores de carga positiva (hole $=$ buraco, only $=$ só, somente).
} 


\subsection{Medidas de Ressonância Paramagnética Eletrônica e Ressonância Magnética Detectada Eletricamente}

Durante as medidas de ressonância, um gerador de microondas $^{7}$ produz a radiação continuamente em intensidade e freqüência constantes, enquanto varremos o campo magnético externo $\left(\mathbf{H}_{\mathbf{0}}\right)$. Quando este atinge um valor tal que a distância energética entre os níveis de spin é equivalente à freqüência $(v)$ da microonda $(h v=$ $\mathrm{g} \mu_{\mathrm{B}} \mathbf{H}_{\mathbf{0}}$ ), a radiação é absorvida e a intensidade de microondas na cavidade diminui (vide figura 4.6). Entretanto, em geral não obtemos uma curva de absorção como na figura 4.6a, mas sim a primeira derivada desta curva (figura 4.6b). Isto ocorre, pois uma modulação é superposta à varredura linear do campo magnético para permitir a detecção do sinal por um amplificador lock-in.

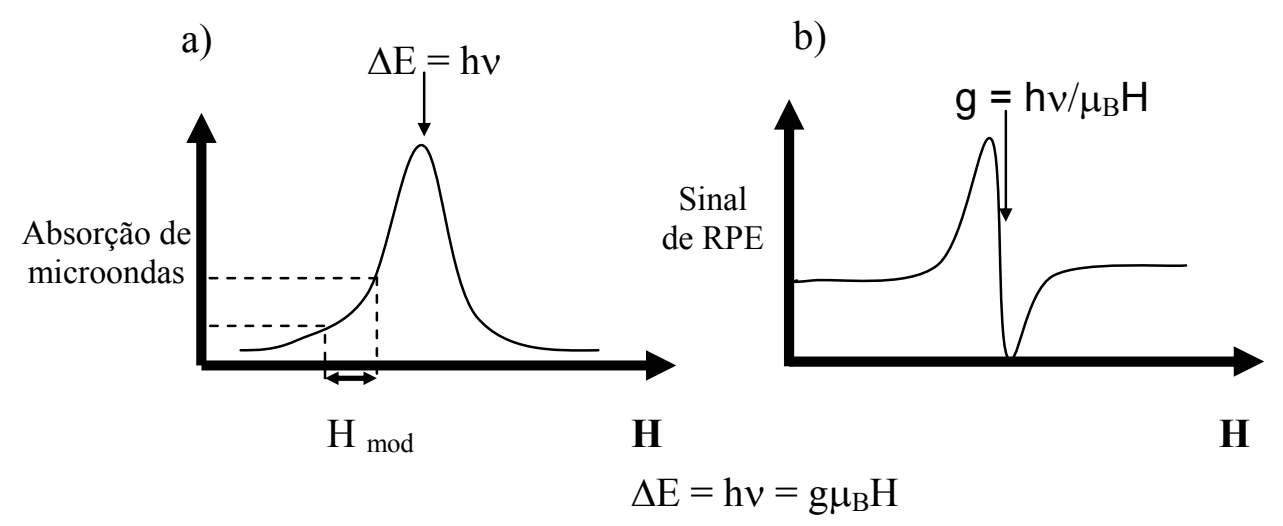

Figura 4.6: (a) Absorção das microondas em um espectro de EPR com uma amplitude de modulação $\mathrm{H}_{\bmod }$ e (b) espectro de EPR: primeira derivada do espectro de absorção da microonda

Nas medidas de RMDE, ao invés de medirmos a absorção de microondas pela amostra, um potencial elétrico é aplicado ao dispositivo ligado em série com uma resistência de referência. Durante a condição de ressonância a condutividade da amostra pode aumentar ou diminuir, causando uma variação na queda de potencial sobre o resistor. Esta variação é detectada por um amplificador Lock-in sincronizado na freqüência de modulação do campo magnético.

\footnotetext{
${ }^{7}$ No nosso caso o gerador de microondas é um Klystron.
} 
Para a realização de estudos da forma de linha das curvas de RPE e de RMDE foi utilizado o software ORIGIN. Verificou-se, após algumas tentativas de ajuste dos espectros, que a convergência das curvas aos dados experimentais acontece muito mais rapidamente quando o espectro está na forma integral. Por isso, a maior parte dos espectros será representada desta forma, com exceção daqueles em que a visualização é mais clara na forma de derivada. O modelo de ajuste utiliza curvas gaussianas e lorentzianas, que são descritas, respectivamente, por:

$$
\begin{aligned}
& \mathrm{Y}(\mathrm{X})=\frac{\mathrm{A}}{\mathrm{W} \sqrt{\pi / 2}} \exp \left[-2 \frac{\left(\mathrm{X}-\mathrm{X}_{\mathrm{C}}\right)^{2}}{\mathrm{~W}^{2}}\right]+\mathrm{Y}_{0} \\
& \mathrm{Y}(\mathrm{X})=\frac{2 \mathrm{~A}}{\pi} \frac{\mathrm{W}}{4\left(\mathrm{X}-\mathrm{X}_{\mathrm{C}}\right)^{2}+\mathrm{W}^{2}}+\mathrm{Y}_{0}
\end{aligned}
$$

onde os parâmetros a serem ajustados são: o campo central ${ }^{8}$ ou centro do pico de ressonância $\left(\mathrm{X}_{\mathrm{C}}\right)$; a largura do pico à meia altura $(\mathrm{W})$; a linha de base $\left(\mathrm{Y}_{0}\right)$; e a área sob a curva a partir da linha de base (A).

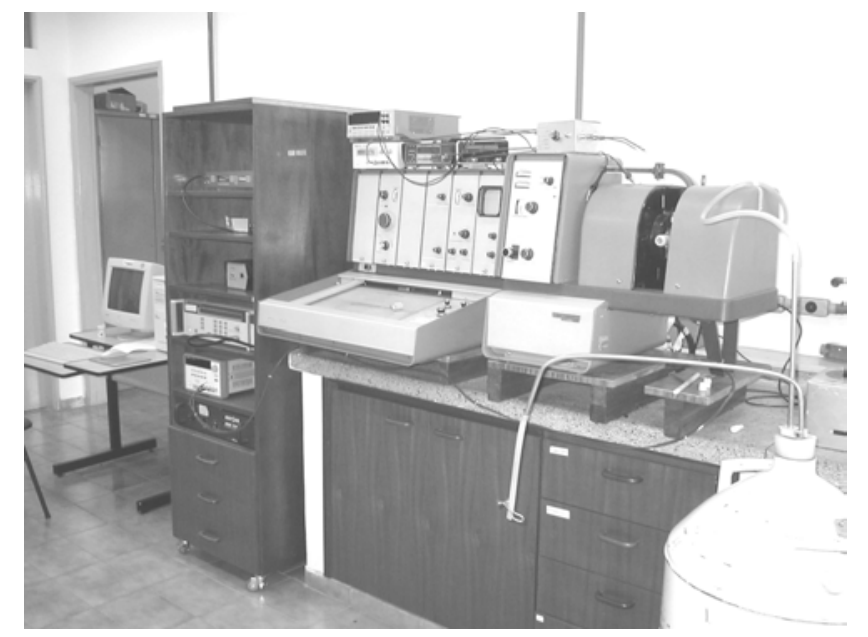

Figura 4.7: Foto do aparato experimental para medidas de RPE e RMDE.

\footnotetext{
${ }^{8}$ Valor do campo magnético em que a absorção de microondas é máxima.
} 
O espectrômetro utilizado foi um Varian E-4 que opera em banda $X$, aproximadamente $9 \mathrm{GHz}$, acoplado a um freqüencímetro e a um amplificador lock-in adaptados para serem controlados remotamente por computador através de conexões GPIB. Para as medidas de RMDE, uma fonte de tensão, um pré-amplificador, um picoamperímetro e uma caixa de resistores foram acoplados aos sistemas descritos anteriormente.

A intensidade do sinal de $\operatorname{RMDE}(\Delta \sigma / \sigma)$ pode ser calculada da seguinte forma:

$$
\Delta \sigma / \sigma=\frac{\text { Amplitude }(V)}{I(A) \cdot R(\Omega) \cdot \text { ganho }}
$$

onde I(A) é o valor da corrente fora do estado de ressonância, $\mathrm{R}(\Omega)$ é o valor da resistência ligada em série com a amostra, a "Amplitude" é a intensidade do sinal em volts e "ganho" é o ganho fornecido pelo pré-amplificador, que, nas medidas apresentadas nesta dissertação, foi de 50 vezes.

A temperatura da amostra pôde ser variada usando um criostato de fluxo de nitrogênio. Para caber dentro da cavidade do espectrômetro, o tamanho dos dispositivos, incluindo o encapsulamento, não pôde exceder $12 \times 4 \mathrm{~mm}$.

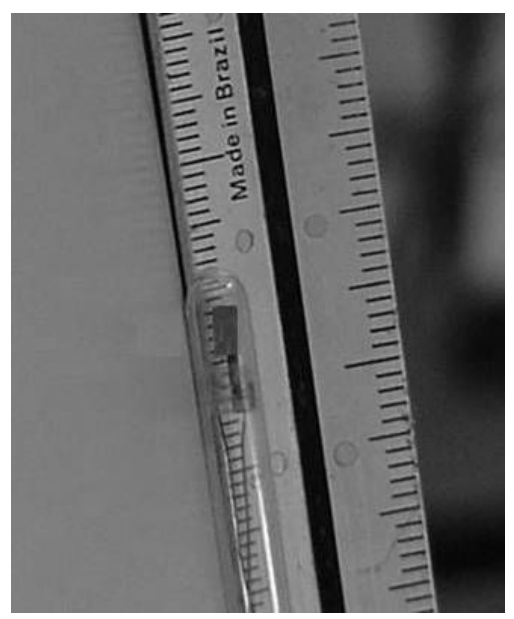

Figura 4.8: Foto de um dispositivo encapsulado para medida de RMDE. 


\subsection{Espectroscopia de impedância elétrica}

A técnica de espectroscopia de impedância consiste na detecção das componentes da corrente em uma amostra que estão em fase e em quadratura com uma dada tensão alternada, ao mesmo tempo em que é feita uma varredura na freqüência de oscilação. A partir da amplitude da corrente e de sua defasagem com a tensão aplicada, pode-se calcular a impedância complexa da amostra, que pode ser expressa da seguinte forma:

$$
Z^{*}(\omega)=Z^{\prime}(\omega)+i Z^{\prime \prime}(\omega)
$$

onde $Z^{\prime}(\omega)$ e $Z$ ”' $(\omega)$ são, respectivamente, a componente real e imaginária da impedância complexa $Z^{*}(\omega)$

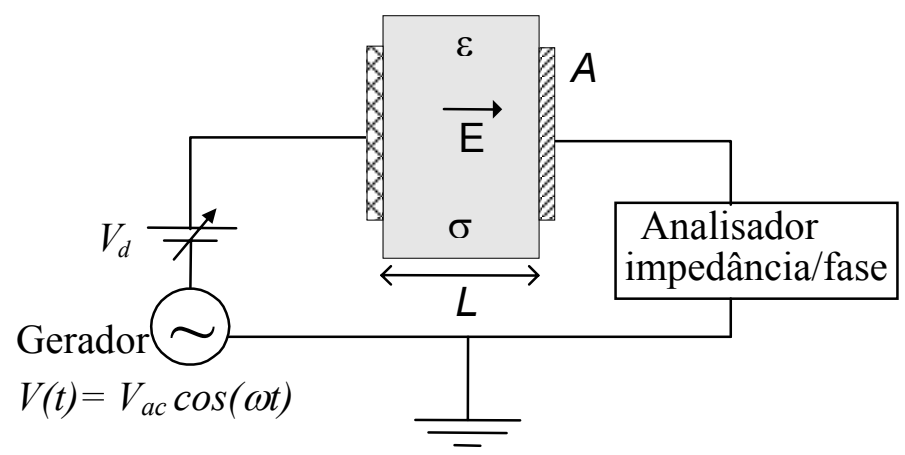

Figura 4.9: Ilustração de uma medida de impedância em uma amostra de um material de constante dielétrica $\varepsilon$ e condutividade $\sigma$.

O sistema experimental utilizado é composto, basicamente, por um analisador de impedância/fase Solartron (modelo SI1260), operando em freqüências desde $10^{-1}$ (quase estático) até $10^{7} \mathrm{~Hz}$. Tensões alternadas $\left(V_{a c}\right)$, de 0 a $3 \mathrm{~V}$ de amplitude, podem ser aplicadas sobre níveis dc $\left(V_{d c}\right)$ entre -41 e $41 \mathrm{~V}$, fornecidas pelo próprio equipamento, para a análise da impedância da amostra. 


\section{CAPÍTULO 5}

\section{POLIANILINA}

Neste capítulo, é feita uma análise de possíveis processos de transporte em filmes e dispositivos de polianilina através de medidas de RPE e RMDE, em função da temperatura. A polianilina é um forte candidato para aplicações em dispositivos eletrônicos [60] devido, principalmente, à sua fácil obtenção e ao controle da sua condutividade através de dopagem química. Sua fórmula estrutural consiste de uma fração de unidades reduzidas (contendo grupos amina: y) e uma fração de unidades oxidadas (contendo grupos imina: 1-y), como mostra a figura 5.1. Desse modo, seu estado pode variar de completamente oxidado (quando $\mathrm{y}=0$ ) a completamente reduzido $(y=1)$.

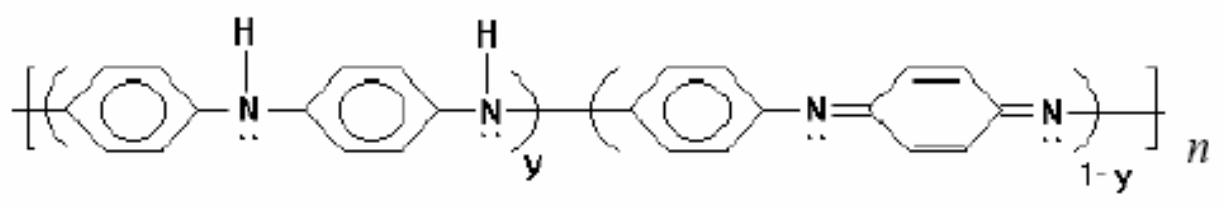

Figura 5.1: Estrutura da polianilina [61]. 


\section{Processo de Dopagem}

Em solução aquosa de ácido clorídrico, a PANI pode ter sua condutividade aumentada em mais de 10 ordens de grandeza. Essa variação ocorre através da protonação do nitrogênio do grupo imina e, conseqüentemente, pela formação de um pólaron positivo. No seu estado não dopado, os pares de elétrons anti-ligantes, associados à hibridação $\mathrm{sp}^{3}$ dos seus nitrogênios amina e imina, classificam-na como base de Brönsted (espécie aceitadora de prótons), sendo denominada de base esmeraldina $(\mathrm{BE})$ quando $\mathrm{y}=0,5$. Quando a Pani $\mathrm{BE}$ está na presença de um ácido de Brönsted (espécie doadora de prótons), ela passa a ser encontrada na forma de um sal denominado de sal de esmeraldina (SE) possuindo condutividade várias ordens de grandeza maior do que a encontrada na forma de BE. O ácido comumente utilizado é o ácido clorídrico $(\mathrm{HCl})$, por ser um ácido forte, com alto grau de dissociação em meio aquoso, porém vários outros ácidos também podem ser utilizados [61,62]. Este processo de dopagem é reversível e o retorno ao polímero original, processo de desdopagem ou desprotonação, por exemplo, em solução aquosa de hidróxido de amônio $\left(\mathrm{NH}_{4} \mathrm{OH}\right)$, acarreta pouca ou nenhuma degradação da sua cadeia polimérica principal.

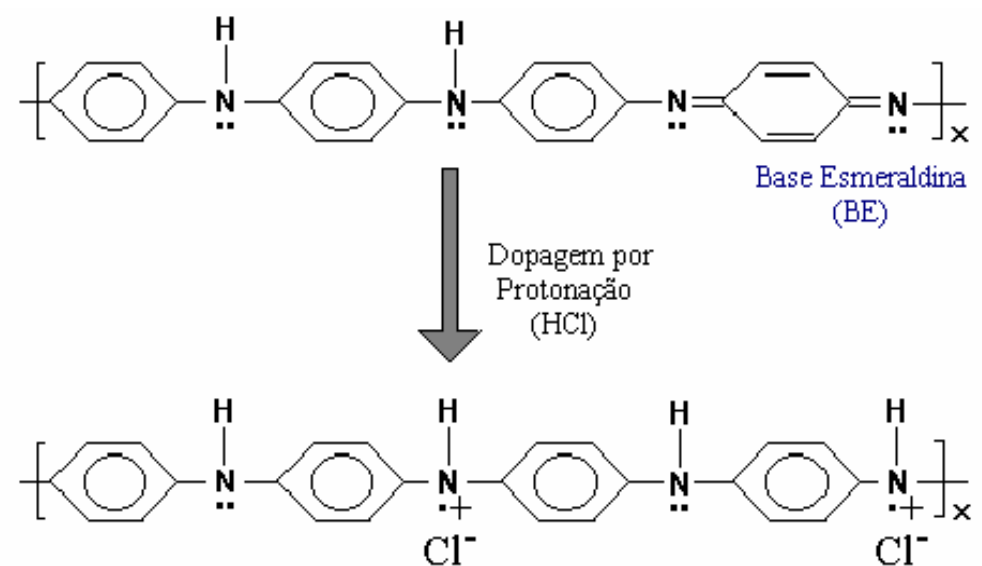

Sal de Esmeraldina

(SE)

Figura 5.2: Esquema genérico de dopagem da polianilina em solução de $\mathrm{HCl}$ [61]. 
Nos filmes de polianilina, durante o processo de dopagem, algumas regiões são mais protonadas do que outras e, conseqüentemente, mais condutoras. Isto torna a análise dos processos de transporte ainda mais complexa uma vez que temos regiões mais ou menos condutoras distribuídas aleatoriamente pelo filme polimérico, e cujos tamanhos variam de acordo com o nível de dopagem da amostra.

\section{Modelos de condução}

Medidas de RPE in-situ, em função da dopagem, mostraram que a quantidade de spins cresce com o aumento da dopagem atingindo um valor máximo e, então, diminuindo. Por outro lado, um aumento da condutividade da polianilina com o aumento do nível de protonação é observado mesmo depois que o número de spins começa a diminuir. Devido a esta discrepância entre o número de pólarons criados pela dopagem e o aumento da condutividade, diferentes modelos para os mecanismos de condução na polianilina foram propostos. Os mais aceitos atualmente são os modelos de rede polarônica e de bipólarons $[63,64]$. Segundo o modelo de bipólarons, com o aumento da dopagem, pólarons são mais oxidados em bipólarons, que, apesar de serem desprovidos de spin, atuam como portadores de carga. Ou seja, contribuem para a condutividade, porém não para o sinal de RPE. Por outro lado, o modelo de rede polarônica, sugere que, com o aumento da concentração de pólarons (aumento da dopagem), pólarons vizinhos se agrupam para formar uma "rede de pólarons", que corresponde a uma banda semipreenchida no gap original da Pani (não dopada) e, portanto, pode conduzir elétrons como no caso de metais. Em baixos níveis de dopagem, a concentração de pólarons é baixa e todos contribuem para o sinal de RPE individualmente. Quando a concentração de pólarons aumenta, para formar a rede polarônica, os spins se rearranjam, semipreenchendo os níveis da nova banda de energia. Somente os spins ocupando níveis de energia próximos ao nível de Fermi contribuem para o sinal de RPE, explicando, assim, a diminuição deste sinal. Alguns autores observaram a formação de bipólarons com o aumento do nível de dopagem [65], ao passo que outros autores mostraram que o modelo de bipólarons não é apropriado para Pani em sua forma condutora (dopada) [66]. 
Apesar dos resultados aparentemente contraditórios, talvez a composição entre a formação de bipólarons em baixos níveis de dopagem e a formação de uma rede polarônica em mais altas dopagens seja o modelo mais correto para descrever o processo de condução na polianilina. Jozefowics et al. [67] mostraram que a forma como a Pani é preparada leva a diferenças significativas no seu comportamento em relação à dopagem. Eles estudaram dois métodos de preparação. Primeiro método $\left(\mathrm{BE}_{1}\right)$ : pode ser preparado por síntese química de pó de SE ou deposição eletroquímica de filmes de SE com subseqüente conversão para $\mathrm{BE}_{1}$ com $\mathrm{NH}_{4} \mathrm{OH}$. Segundo método $\left(\mathrm{BE}_{2}\right)$ : pó de $\mathrm{BE}$ é dissolvido em NMP e depois filmes de $\mathrm{BE}_{2}$ são formados diretamente com esta solução. As amostras estudadas nesta dissertação são do tipo $\mathrm{BE}_{2}$. Por medidas de difração de raios- $\mathrm{X}$ os autores mostraram que a polianilina não-dopada $\mathrm{BE}_{1}$ é um material praticamente amorfo e a medida em que a dopamos com $\mathrm{HCl}$, uma nova estrutura cristalina vai aparecendo. Medidas de susceptibilidade magnética $(\chi)$ mostraram um aumento quase linear de $\chi$ com a dopagem. Entretanto, nos filmes de Pani $\mathrm{BE}_{2}$, até uma dopagem de, aproximadamente, $25 \%$, nenhuma mudança é observada no espectro de raios-X. Acima deste nível, um novo padrão de difração é observado e vai aumentando a medida em que o padrão da Pani não-dopada diminui. Nas medidas de susceptibilidade, $\chi$ é praticamente independente do nível de dopagem até $\sim 25 \%$. A partir daí, $\chi$ aumenta rapidamente. Portanto, enquanto $\chi$ esperado para uma rede polarônica é observado tanto em $\mathrm{BE}_{1}$ quanto em $\mathrm{BE}_{2}$, protonação nas regiões amorfas de $\mathrm{BE}_{2}$ levam a formação de defeitos desprovidos de spin (bipólarons). O estado introduzido pela protonação na parte amorfa de $\mathrm{BE}_{2}$ vai permanecer desprovida de spin até que máxima protonação da região amorfa seja atingida, depois a protonação passa para a parte cristalina causando o aumento de $\chi$. A formação de bipólarons em baixos níveis de dopagem, seguida do aparecimento de condução metálica, em altas dopagens, foi também observada por Harima et al. [68] em filmes de poli(3-metil tiofeno). 


\subsection{Resultados}

\subsubsection{Ressonância Paramagnética Eletrônica}

Todas as medidas de RPE em filmes de polianilina foram realizados com potência de microondas de $50 \mathrm{~mW}$ para evitar a saturação do sinal. A figura 5.3 mostra o sinal de RPE de um filme de polianilina não-dopada medido em temperatura ambiente. A largura de linha pico-a-pico é de 2,6 G e o fator g é igual a 2,0031. Estes valores estão de acordo com os encontrados na literatura, apesar de que os valores reportados de largura de linha de espectros de EPR em polianilina variam bastante, desde 0,29 G [66] a

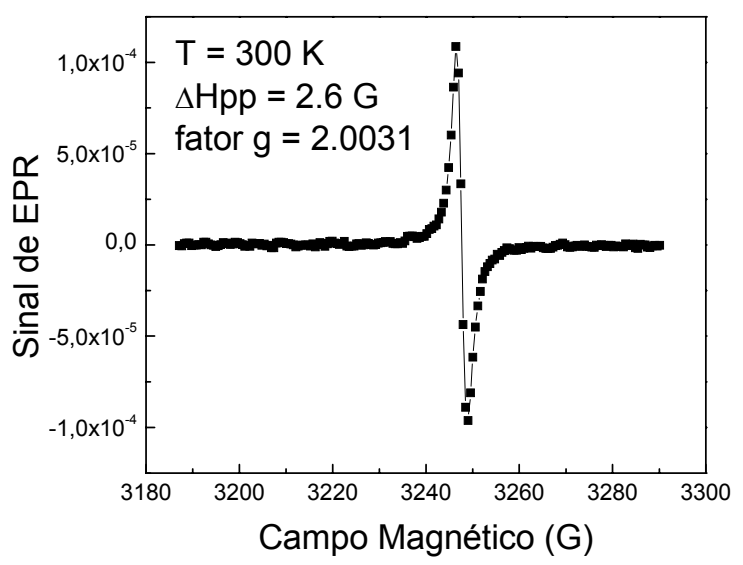

Figura 5.3: Sinal de RPE em temperatura ambiente de um filme de polianilina.

23 G [69]. Essas diferenças se devem ao efeito de oxigênio e/ou umidade sobre as medidas. Sabe-se que a presença de oxigênio alarga a linha de ressonância devido a interações magnéticas dos pólarons com o estado tripleto da molécula de oxigênio [70]. Além disso, como este alargamento estaria baseado na colisão de pólarons e oxigênio, o que seria proporcional à freqüência de hopping destes portadores de carga, a largura de linha induzida por oxigênio aumenta com o aumento da mobilidade dos pólarons. 
a)

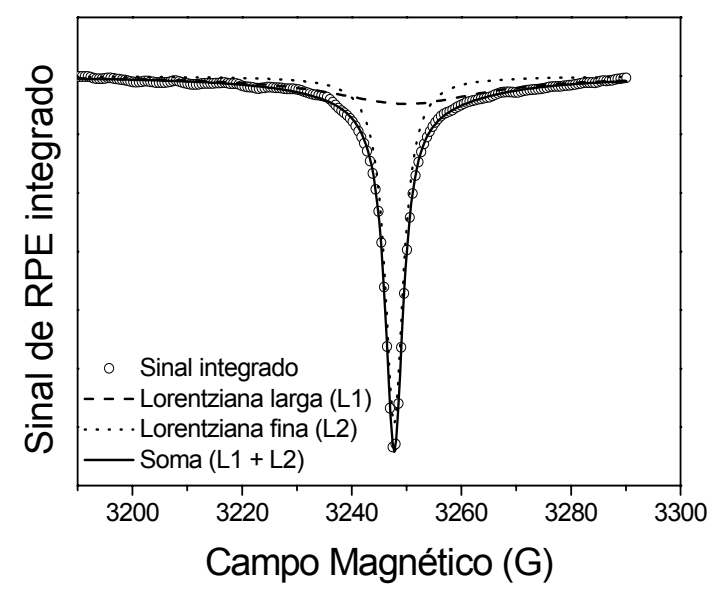

b)

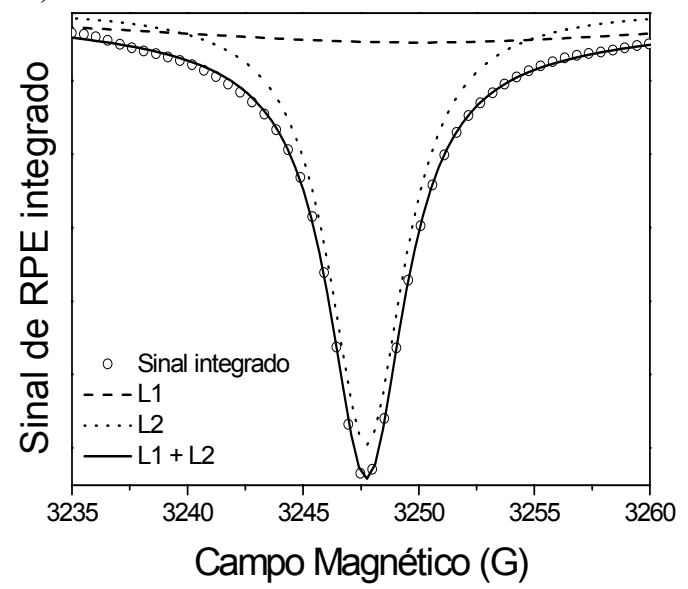

Figura 5.4: (a) Sinal de RPE integrado (círculos abertos) de um filme de polianilina, decomposto em duas lorentzianas, uma larga (tracejada) e uma fina (pontilhada), cuja soma mostrada pela linha sólida. (b) Zoom do pico de absorção para melhor visualização das componentes.

Analisando a forma de linha dos espectros de EPR foi observado que o sinal não pode ser ajustado por apenas uma curva (figura 5.4). O sinal, na realidade é composto por duas curvas lorentzianas, uma fina (pontilhada), com largura de linha a meia altura de $\sim 4 \mathrm{G}$, e uma larga (tracejada), com largura de linha que varia entre 30 e $40 \mathrm{G}$. Na figura 5.4b, é mostrado com maior detalhe o pico de absorção e as componentes do sinal.

Em toda a faixa de temperatura estudada, de $168 \mathrm{~K}$ e $300 \mathrm{~K}$, os espectros de RPE apresentaram duas componentes, sendo que a mais fina era sempre dominante. Espectros de RPE em polianilina compostos por duas curvas lorentzianas com diferentes larguras de linha já foram reportados por Mizoguchi et al. [71]. Eles observaram que em amostras pouco dopadas o sinal era formado por apenas uma lorentziana fina, ao passo que, aumentando a dopagem, uma segunda lorentziana larga começava a aparecer e, sob determinadas condições, em níveis altos de dopagem, esta segunda componente passava a ser dominante. O aparecimento de uma segunda componente no espectro de RPE devido ao aumento da dopagem também foi observado por C.E. Lee et al. [72] em um polímero derivado do PPV, dopado com iodo. A dependência da susceptibilidade 
magnética destes filmes com a temperatura é muito similar à que foi observada nos filmes de Pani, como será discutido mais adiante.

A dependência do sinal de RPE com a temperatura é dominado praticamente pela dependência da componente fina com a temperatura. Por isso, a análise da forma de

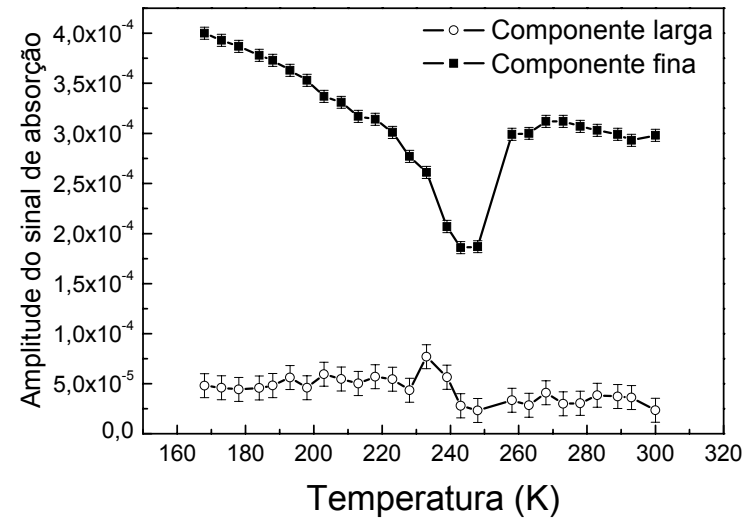

Figura 5.5: Dependência da amplitude do sinal das componentes fina e larga com a temperatura. linha será realizada apenas para esta componente. Pelo comportamento da amplitude do sinal de absorção com a temperatura fica claro que algum fenômeno importante ocorre por volta de $240 \mathrm{~K}$. Isto fica claro também quando vemos a dependência da susceptibilidade magnética da linha dominante com a temperatura.

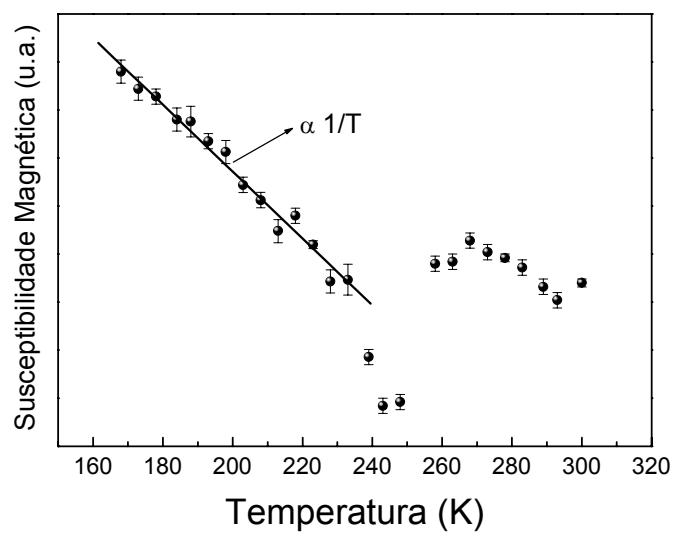

Figura 5.6: Dependência da susceptibilidade magnética de um filme de Pani com a temperatura. 
$\mathrm{Na}$ figura 5.6, é mostrada a dependência da susceptibilidade magnética $(\chi)$ da componente dominante do espectro de RPE de um filme de polianilina em função da temperatura (esferas cheias). A linha sólida, usada como um guia para os olhos, mostra que $\chi$ depende do inverso da temperatura (1/T) entre $168 \mathrm{~K}$ e $233 \mathrm{~K}$, seguindo a lei de Curie. Ocorre, então, um aumento abrupto, e o valor de $\chi$ passa a ser independente da temperatura entre 258 e $300 \mathrm{~K}$, apresentando uma contribuição tipo Pauli. Note que, entre 233 e $248 \mathrm{~K}$, a dependência da susceptibilidade com a temperatura desvia de 1/T. As razões para este desvio serão discutidas mais adiante. Esta transição Curie-Pauli já foi observada por diferentes grupos de pesquisa tanto em polianilina [66] como em outros polímeros condutores [72,73], como polipirrol e politiofeno. Porém a temperatura $\left(\mathrm{T}_{\mathrm{c}}\right)$ em que ocorre esta transição varia em função da dopagem e da cristalinidade da amostra [74,75]. Quanto mais desordenada ou menos dopada a amostra, maior o valor de $\mathrm{T}_{\mathrm{c}}$. Esta dependência com a dopagem foi observada experimentalmente em POMA, polímero derivado da polianilina, por Magon et al. [76].

Outro indicativo de que uma mudança importante ocorre nesta temperatura crítica é o comportamento peculiar do fator $g$ da linha dominante em função da temperatura.

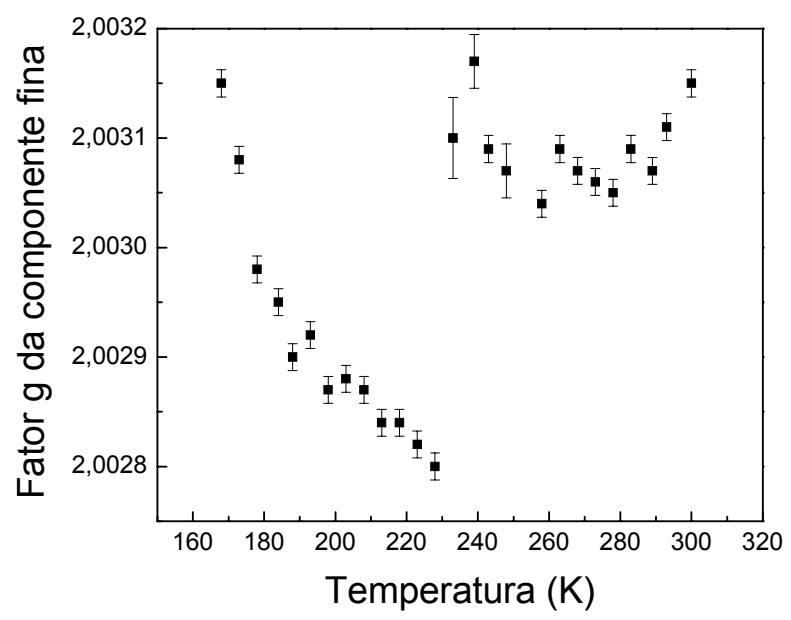

Figura 5.7: Dependência do fator g da componente fina do espectro de RPE. 
O seu valor diminui de $\sim 2,0031$ para $\sim 2,0028$ com o aumento da temperatura entre $168 \mathrm{~K}$ e $228 \mathrm{~K}$. Depois ocorre um aumento abrupto para 2,0031 e o valor de $\mathrm{g}$ fica aproximadamente independente de $\mathrm{T}$ entre $233 \mathrm{~K}$ e $300 \mathrm{~K}$. A razão para este comportamento do fator $g$ em função da temperatura não é compreendido no momento. Nenhum dos trabalhos usados como referência para esta dissertação, que relatam medidas de RPE em polianilina, comentam ou mostram como é a dependência do fator $g$ com a temperatura.

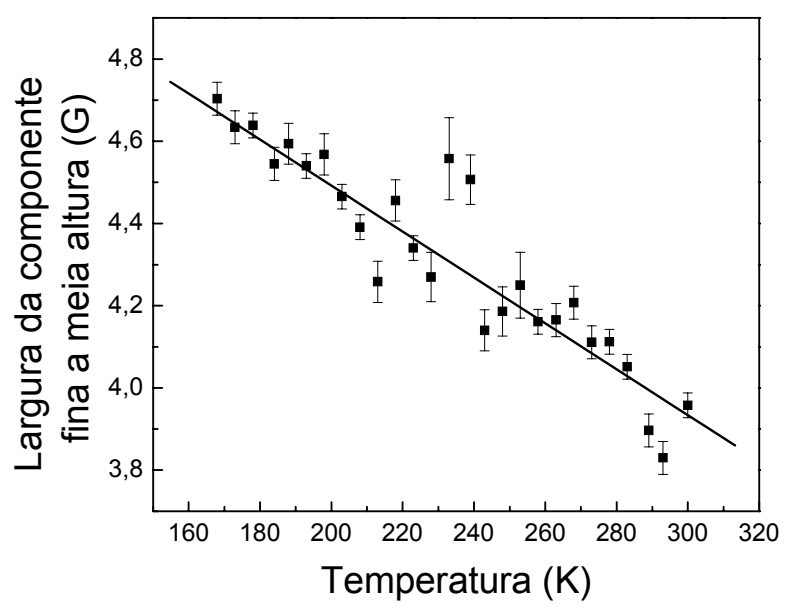

Figura 5. 8: Dependência da largura de linha da componente dominante do sinal de RPE em função da temperatura.

A largura de linha (figura 5.8), por outro lado, não apresenta mudança de comportamento em função da temperatura. A linha sólida na figura 5.8 é apresentada apenas como um guia para os olhos. O que se observa é uma diminuição da largura com o aumento da $\mathrm{T}$ em toda a faixa de temperatura estudada. Provavelmente, isto se deve ao efeito de "motional narrowing" devido ao aumento do movimento térmico dos elétrons desemparelhados em estados localizados próximos ao nível de Fermi [77]. Resultado semelhante já foi reportado por Saricifcti et al. [66] em polianilina dopada com ácido sulfônico canforoso (CSA). 


\subsubsection{Ressonância Magnética Detectada Eletricamente}

Diferente dos resultados das medidas de RPE, o sinal de RMDE de dispositivos de polianilina é dominado por uma linha lorentziana larga. O sinal é "enhancing”, ou seja, a condutividade aumenta na condição de ressonância, como é esperado para condução por hopping. Dois possíveis processos que poderiam resultar em um sinal de RMDE são: o hopping de pólarons intercadeias ou o hopping de pólarons para outro pólaron na mesma cadeia. Note que, como foi discutido no capítulo 3, para se obter um sinal de RMDE é preciso que haja dois spins participando do processo observado, portanto, um pólaron só irá contribuir para o sinal se ele saltar para um sítio já ocupado por um outro pólaron. O fato de a ressonância aumentar a condutividade do dispositivo se deve ao aumento da taxa de transição (hopping) dependente de spin.

A figura 5.9 mostra o sinal integrado de RMDE (círculos abertos) de um dispositivo com contatos coplanares, em $\mathrm{T}=294 \mathrm{~K}$, sob uma tensão de $50 \mathrm{~V}$ (campo elétrico da ordem de $10^{3} \mathrm{~V} / \mathrm{cm}$ ). O sinal é formado por duas componentes, uma gaussiana larga (linha pontilhada) e uma lorentziana fina (linha tracejada). A linha sólida representa a soma das duas componentes.

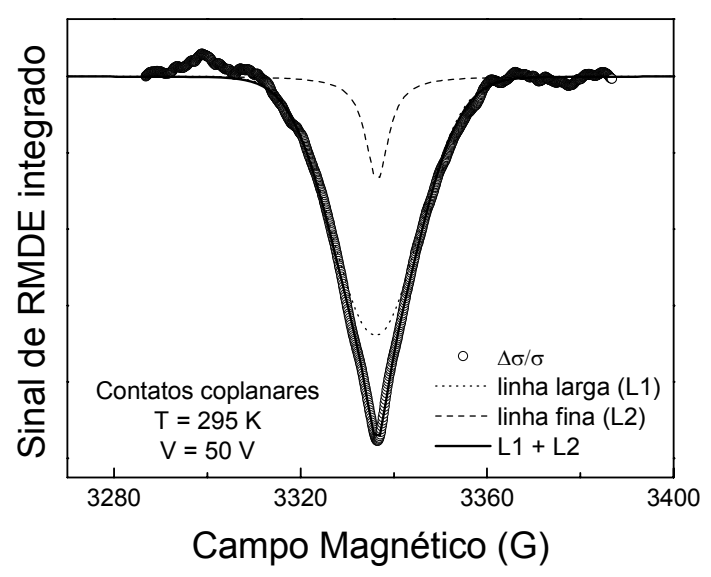

Figura 5.9: Sinal integrado de RMDE de um dispositivo com contatos coplanares (círculos abertos), decomposto em duas componentes, uma gaussiana larga (linha pontilhada) e uma lorentziana fina (linha tracejada). A linha sólida representa a soma das componentes. 
A componente fina apresenta fator $g$ igual a 2,0033 e largura de linha pico-a-pico igual a 3,2 G. Este valor é bem próximo da componente fina do sinal de RPE. A componente larga, por sua vez, apresenta fator g ligeiramente deslocado, igual a 2,0035, e largura de linha pico-a-pico igual a 14,5 G. Graeff et al. [31] reportaram o aparecimento de duas componentes em espectros de RMDE de dispositivos de Pani com contatos coplanares, e observaram uma forte dependência da intensidade da linha fina com a tensão. Segundo os autores, a componente fina é dominante em baixos campos elétricos $\left(<10^{3} \mathrm{~V} / \mathrm{cm}\right)$ e diminui drasticamente com o aumento do campo. $\mathrm{O}$ aparecimento de uma componente larga só foi observada para campos acima de $10^{3}$ $\mathrm{V} / \mathrm{cm}$.

As medidas de RMDE em dispositivos de polianilina com contatos tipo sanduíche apresentaram um sinal formado por apenas uma componente larga. Na figura 5.10, o sinal integrado é mostrado pelos círculos abertos e a linha sólida representa o ajuste com uma gaussiana larga com fator $\mathrm{g}=2,0035$ e largura de linha pico-a-pico igual a $22 \mathrm{G}$.

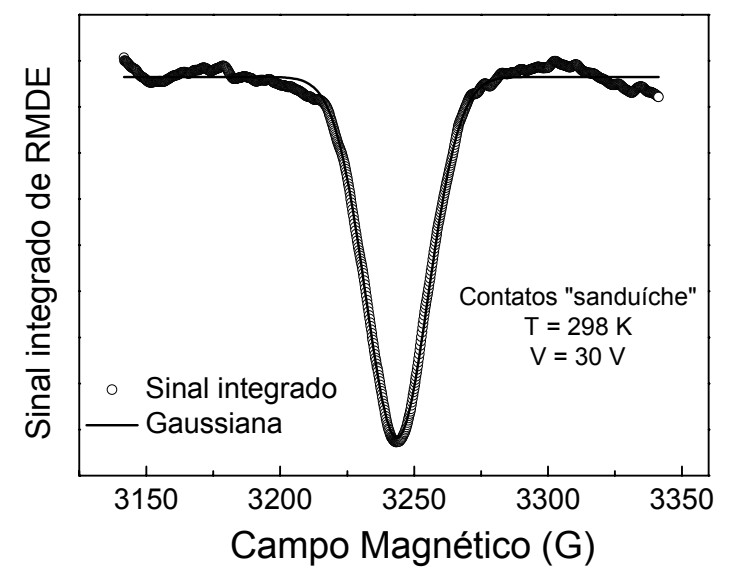

Figura 5.10: Sinal integrado de RMDE (círculos abertos) de um dispositivo de polianilina com contatos tipo sanduíche, ajustado por uma gaussiana larga (linha sólida).

Possíveis razões para as diferenças observadas entre dispositivos com contatos coplanares e dispositivos com contatos tipo "sanduíche" serão discutidos mais adiante. 
A figura 7.11 mostra a dependência da intensidade do sinal de RMDE em função da temperatura obtida por Graeff et al. [32], para dois dispositivos de Pani, um levemente dopado (círculos abertos) e outro não dopado (quadrados sólidos). O sinal de RMDE não pôde ser observado em baixas temperaturas. A temperatura a partir da qual o sinal é observado e a dependência com a temperatura são diferentes para cada tipo de amostra. No caso da amostra não-dopada, na medida em que aumentamos a temperatura, a intensidade do sinal de RMDE diminui, apresentando um início de saturação a partir de $335 \mathrm{~K}$. A intensidade do sinal de RMDE da amostra dopada é praticamente independente da temperatura até $300 \mathrm{~K}$. Aumentando a temperatura, acima de $300 \mathrm{~K}$, o sinal aumenta rapidamente.

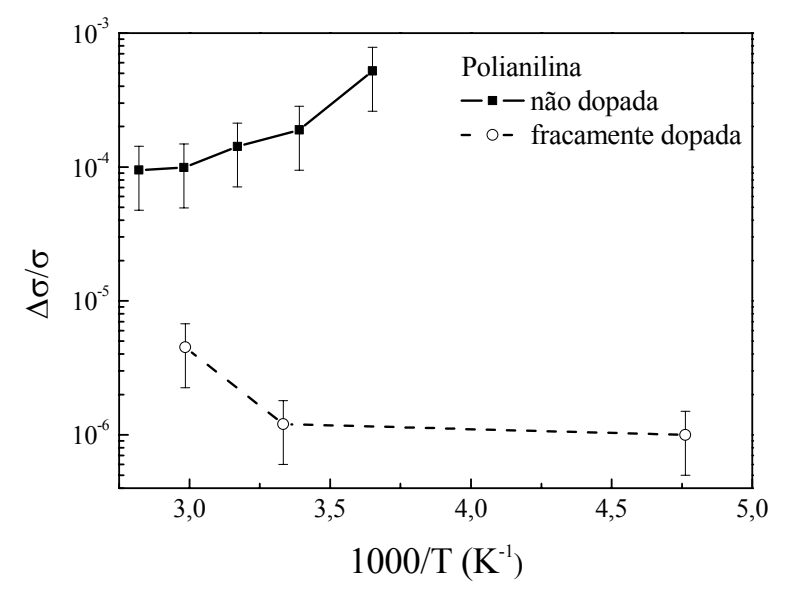

Figura 5.11: Intensidade do sinal de RMDE em função da temperatura. Figura cedida por Graeff et al.[32].

As possíveis razões para o comportamento da intensidade do sinal de RMDE com a temperatura e para as diferenças entre a amostra dopada e a não-dopada serão discutidas mais adiante. 


\subsection{Discussão}

Medidas de RPE em filmes de Pani mostraram uma transição entre os tipos de spin observados, tipo Curie para tipo Pauli, com o aumento da temperatura. Abaixo de $220 \mathrm{~K}$ a susceptibilidade magnética depende de $1 / \mathrm{T}$ e acima desta temperatura é independente de T. Spins tipo Curie são localizados, portanto não contribuem significativamente para a corrente, e, conseqüentemente, para o sinal de RMDE. Por outro lado, a contribuição tipo Pauli vem de spins delocalizados, podendo, portanto, contribuir para a corrente [77]. Isto explica porque não observamos sinal de RMDE abaixo desta temperatura nestas amostras. Vejamos porque ocorre esta transição.

Cálculos numéricos mostram [75,78] que em temperaturas suficientemente baixas, tal que $\mathrm{k}_{\mathrm{B}} \mathrm{T}$, onde $\mathrm{k}_{\mathrm{B}}$ é a constante de Boltzmann, seja menor do que a energia de interação $(\mathrm{U})$ coulombiana média entre elétrons, estados próximos à energia de Fermi $\left(E_{F}\right)$ se tornam ocupados (por spins desemparelhados), e a susceptibilidade de spin exibe uma contribuição tipo Curie:

$$
\chi(T)=\mu_{\mathrm{B}}^{2} \mathrm{~N}_{\mathrm{S}} / \mathrm{kT},
$$

onde $\mathrm{N}_{\mathrm{S}}$ é o número de estados ocupados por spins $1 / 2$ desemparelhados, por unidade de volume. Considerando que há uma densidade de estados finita na energia de Fermi, a contribuição tipo Curie em baixa temperatura vem da ocupação de estados localizados próximos a $\mathrm{E}_{\mathrm{F}}$.

Quando a energia de Fermi é próxima ao limite da mobilidade e muito maior do que a energia de interação $U$, a dependência da susceptibilidade de spin com a temperatura muda gradualmente de um comportamento tipo Curie para um comportamento tipo Pauli, independente de T, com o aumento da temperatura. A região de transição ocorre quando $\mathrm{k}_{\mathrm{B}} \mathrm{T} \approx \mathrm{U}$.

Como o fato de a amostra ser mais ou menos amorfa e de estar mais ou menos dopada pode alterar a energia do nível de Fermi e a energia de interação elétron-elétron, estes cálculos explicam por que diferentes grupos de pesquisa observaram que existe uma dependência entre o aparecimento ou não desta transição e o nível de dopagem e/ou de cristalinidade da amostra estudada $[66,74,76]$. Quanto maior a desordem e/ou menor 
a dopagem, maior a temperatura de transição. Como a maioria dos estudos de RPE em polianilina são feitos com o polímero em pó, altamente desordenado, muitos grupos de pesquisa só observaram a transição Curie-Pauli em amostras altamente dopadas [71]. Nestes casos, foi observado que o sinal de RPE era composto por duas componentes lorentzianas, uma larga e uma fina, como nas medidas apresentadas nesta dissertação. Entretanto, a componente mais larga era dominante, em discrepância com os resultados aqui apresentados. É preciso lembrar, porém, que neste trabalho as medidas foram realizadas em filmes finos de polianilina, portanto menos desordenados do que a forma de pó. Isto permitiu que a transição Curie-Pauli fosse observada em amostras muito pouco dopadas. Segundo Mizoguchi et al. [71], a segunda componente, mais larga, não aparece em amostras não dopadas, mas começa a surgir ao aumentarmos o nível de dopagem, sendo dominante apenas em altas dopagens. $\mathrm{O}$ fato de a componente estreita ser dominante nos espectros aqui apresentados vem, portanto, do baixo nível de dopagem das amostras estudas.

A ligação do aparecimento da linha larga com o aumento da dopagem também foi observado experimentalmente por Lee et al. [72]. Nenhum dos dois trabalhos, porém explicita a razão da linha ser larga. Segundo Kahol et al. [69] quanto maior a localização dos spins na polianilina maior a adsorção de moléculas de $\mathrm{H}_{2} \mathrm{O}$. Como os sítios de adsorção de moléculas de oxigênio são os mesmos do vapor de água, que é onde o pólaron está centrado (por exemplo, $\mathrm{NH}^{+}$-), quanto maior a adsorção de água, menor os sítios livres para a adsorção de oxigênio. Ainda segundo os autores, as cargas positivas localizadas (pólarons) polarizam as moléculas de água mais eficientemente do que as cargas positivas delocalizadas. Houzé e Nechtachein [70] também propõem que moléculas de $\mathrm{H}_{2} \mathrm{O}$ estariam mais fortemente ligadas à cadeia polimérica da Pani do que as moléculas de $\mathrm{O}_{2}$, e que a água faria um papel de escudo entre os pólarons e o oxigênio. Assim, com o aumento da taxa de dopagem, teríamos mais pólarons delocalizados e, portanto, mais sítios para a adsorção de moléculas de oxigênio. A interação das moléculas de oxigênio com centros paramagnéticos aumenta bastante a largura de linha do sinal de RPE, devido a colisões, como descrito no capítulo 3. 
A presença "apenas" de vapor de água também alarga o sinal da Pani, porém em muito menor intensidade, provavelmente devido à presença de algumas poucas moléculas de oxigênio junto com a água. Larguras de linha pico-a-pico $(\Delta \mathrm{Hpp})$, igual à 2,2 G [69] e 2,0 G [70] foram reportadas, respectivamente, para amostras em atmosfera de vapor de água e em atmosfera ambiente. Estes resultados são muito semelhantes à largura de linha dos filmes de Pani estudados neste trabalho $(\Delta \mathrm{Hpp}=2,6 \mathrm{G})$, que foram deixados em atmosfera ambiente. $\mathrm{O}$ fato de observarmos duas componentes, uma larga e uma fina, possivelmente se deve à soma da contribuição de pólarons mais localizados (sítios ocupados por $\mathrm{H}_{2} \mathrm{O}$ ) e pólarons não localizados (alguns sítios ocupados por $\mathrm{O}_{2}$ ). Como a amostra é muito pouco dopada, o sinal da componente fina é dominante.

Nas medidas de RMDE, o sinal largo é dominante, pois ele se deve, principalmente, a pólarons delocalizados (maior efeito de alargamento por $\mathrm{O}_{2}$ ). Entretanto, em baixas tensões, nos dispositivos com contatos em paralelo, observamos uma componente fina, que vai diminuindo de intensidade com o aumento da tensão [31]. Provavelmente, o que ocorre é o seguinte: nas amostras com contatos em paralelo, como a superfície está exposta, existe uma competição entre moléculas de $\mathrm{H}_{2} \mathrm{O}$ e $\mathrm{O}_{2}$ para ocupar os sítios paramagnéticos. Moléculas de água teriam maior probabilidade de ser adsorvidas, diminuindo o efeito do alargamento por oxigênio [69,70]. Assim, o sinal dominante seria estreito e intenso. Já foi reportado [69] que a intensidade do sinal alargado por oxigênio é apenas por volta de $15 \%$ da intensidade do sinal não alargado. Ou seja, a intensidade do sinal devido a pólarons delocalizados (sinal alargado) é menor do que o sinal devido aos pólarons localizados.Com o aumento da tensão, as linhas de campo começam a penetrar no bulk. No volume, não há mais competição entre as moléculas de $\mathrm{H}_{2} \mathrm{O}$ e de $\mathrm{O}_{2}$ presentes no ar e, como a água se liga mais fracamente aos sítios de pólarons delocalizados, com o tempo a maior parte dos sítios paramagnéticos delocalizados captaram $\mathrm{O}_{2}$, contribuindo como um sinal largo. A medida em que aumentamos a tensão, a condução fica dividida entre a superfície, onde a água atua como escudo para o alargamento de linha, e o bulk, onde não há este escudo. Quanto maior a tensão, menor a componente relativa da corrente devido à superfície, e, portanto, menor o sinal da componente fina. Como o sinal alargado por oxigênio é muito menos 
intenso do que o não alargado, em baixas tensões só observamos a componente fina. Segundo este raciocínio, a componente larga deveria aumentar na mesma proporção em que a componente fina diminui, o que não é claramente observado. Entretanto, se lembrarmos que a componente larga é muito menos intensa do que a componente fina (Intensidade $_{\text {larga }}=15 \%$ Intensidade $_{\text {fina, }}$, segundo Kahol et al. [69]), e levando em conta que a queda da intensidade da componente fina foi de, aproximadamente, $3,5 \times 10^{-5}$, na região em que as duas componentes são observadas, a variação da componente larga deveria ser, aproximadamente, da ordem de $5 \times 10^{-6}$, valor que está dentro do erro da medida.

\section{Como ocorre a transição Curie-Pauli?}

Mizoguchi [74] e Wang et al. [77] mostraram que a condutividade macroscópica é dominada pelo hopping intercadeias e/ou inter-regiões metálicas. Segundo Krinichnyi [79], a condutividade macroscópica da Pani, tanto ac quanto dc, é ativada termicamente por volta de $200 \mathrm{~K}$. Portanto, atribuímos o sinal de EPR em altas temperaturas a pólarons móveis, que foram ativados termicamente, a partir de $\sim 220 \mathrm{~K}$ nas amostras estudadas. O sinal de RMDE é atribuído ao hopping intercadeias. Como a formação de estados bipolarônicos é energeticamente favorável em relação à formação de estados polarônicos [72], ao baixarmos a temperatura, aumentamos a formação de bipólarons, resultando em menores valores de susceptibilidade magnética, uma vez que bipólarons são desprovidos de spin. Quando a densidade de pólarons diminui o suficiente, o processo de fusão não mais ocorre e o comportamento tipo Curie em baixas temperaturas é observado devido ao número fixo de pólarons localizados. Isto também explica o porquê do desvio da dependência da susceptibilidade com $1 / \mathrm{T}$, entre de $233 \mathrm{~K}$ e $248 \mathrm{~K}$. 


\section{Dependência do sinal de RMDE com a temperatura}

O sinal de RMDE de filmes de polianilina não-dopada (BE) e dopada se comportam de maneira diferente com a temperatura. Primeiro o sinal da amostra nãodopada só aparece a partir de $273 \mathrm{~K}$, enquanto que o sinal da amostra dopada já pode ser observado desde $210 \mathrm{~K}$. Isto, como já foi discutido, se deve ao deslocamento da temperatura de transição Curie-Pauli em função do nível de dopagem da amostra. Além disso, a intensidade do sinal da Pani não-dopada diminui com o aumento da temperatura entre $273 \mathrm{~K}$ e $350 \mathrm{~K}$, começando a saturar a partir de $\sim 330 \mathrm{~K}$. Por outro lado, a intensidade do sinal de RMDE do filme de Pani levemente dopado é praticamente independente da temperatura entre $210 \mathrm{~K}$ e $300 \mathrm{~K}$. Aumentando bastante acima desta temperatura.

O comportamento da amostra dopada pode ser entendido da seguinte maneira. Como vimos, a medida em que baixamos a temperatura aumentamos a formação de bipólarons [72], ou, equivalentemente, ao aumentarmos a temperatura aumentamos a dissociação térmica de bipólarons em pólarons [80]. Como RMDE observa a corrente dependente de spin, um aumento da condução por processos não-dependentes de spin (bipólarons) diminui a intensidade do sinal. Além disso, o sinal de RMDE foi atribuído ao hopping de pólarons intercadeias, que é ativado termicamente [79]. Isto explicaria o aumento mais pronunciado do sinal a partir de $300 \mathrm{~K}$. Não é claro, entretanto, porque o sinal da amostra não dopada se comporta da maneira observada. Talvez a queda do sinal de RMDE com o aumento da temperatura se deva à eliminação de parte das moléculas de $\mathrm{H}_{2} \mathrm{O}$ ligadas a Pani, o que aumentaria a contribuição do sinal alargado por $\mathrm{O}_{2}$. Como o sinal alargado é menos intenso do que o não alargado, o resultado é uma queda do sinal de RMDE. 


\section{CAPÍTULO 6}

\section{RMDE DE DIODOS DE MEH-PPV}

Neste capítulo, é feita uma análise de possíveis processos de transporte dependentes de spin em diodos de MEH-PPV e sua dependência com a temperatura e com a tensão aplicada, através de medidas de ressonância magnética detectada eletricamente. Os resultados experimentais apresentados são de PLEDs do tipo ITO/MEH-PPV/Al e diodos do tipo ITO/MEH-PPV/Au. Neste último, o transporte é majoritariamente de cargas positivas, exceto quando o campo elétrico aplicado é suficientemente alto $\left(\sim 10^{6} \mathrm{~V} / \mathrm{cm}\right)$.

\subsection{ITO/MEH-PPV/AI}

Os sinais de RMDE nos PLEDs de MEH-PPV estudados apresentam amplitudes da ordem de $10^{-5}$ e somente são observados em modo direto, ou seja, com tensão positiva, em geral V $>10$ volts. O sinal é "quenching”, ou seja, a condutividade da amostra diminui durante a ressonância [36,37] e é semelhante ao observado em PLEDs a base de PPV estudados por Swanson et al. [81]. 
Como foi descrito anteriormente, foi utilizado um amplificador lock-in de modo que o sinal é obtido em duas fases em relação à modulação do campo magnético: uma em $\varphi$ e outra em $\varphi+90^{\circ}$. Utilizando uma matriz de rotação seria possível que todo o sinal fosse observado em apenas um canal (em uma fase $\varphi$, por exemplo). Entretanto, nos PLEDs de MEH-PPV, não foi possível eliminar completamente o sinal de um dos canais. Na figura 6.1, pode-se observar que, fazendo uma análise de forma de linha, o sinal de RMDE (círculos abertos) pode ser simulado (linha sólida) por uma soma de duas componentes: uma derivada de gaussiana (linha tracejada) e uma derivada de lorentziana (linha pontilhada).

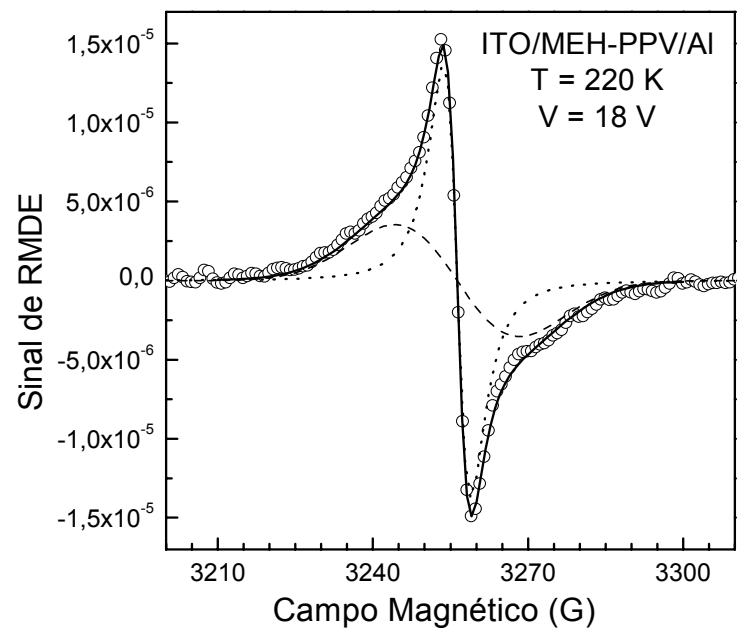

Figura 6. 1: Sinal de RMDE típico de um PLED de MEH-PPV (círculos abertos) decomposto em duas componentes (pontilhada e tracejada). A linha sólida é a soma das duas componentes.

A largura de linha pico-a-pico $(\Delta \mathrm{Hpp})$ da componente lorentziana foi de $5 \mathrm{G}$, enquanto que a da gaussiana, mais larga, apresentou $\Delta \mathrm{Hpp}=24 \mathrm{G}$, ambas com fator $\mathrm{g}=$ 2.0022. Este foi o comportamento típico observado nos PLEDs de MEH-PPV, apesar da intensidade relativa entre as duas componentes variar de amostra para amostra. Foi observado que, nas amostras com maior eficiência de emissão de luz, a relação entre as intensidades das componentes gaussiana/loretziana era quase 1, enquanto que, nas amostras cuja emissão de luz era muito fraca, praticamente imperceptível a olho nu, a 
razão entre as componentes era muito menor que 1 , ou seja, o sinal podia praticamente ser simulado por apenas uma curva lorentziana (vide figura 6.2).

a)

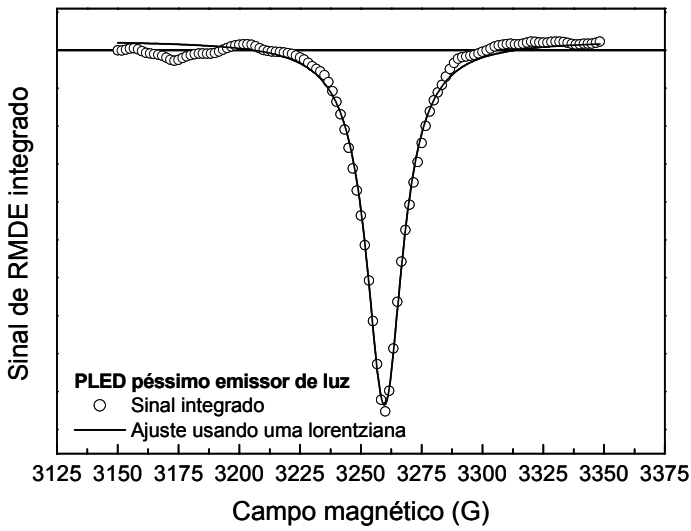

b)

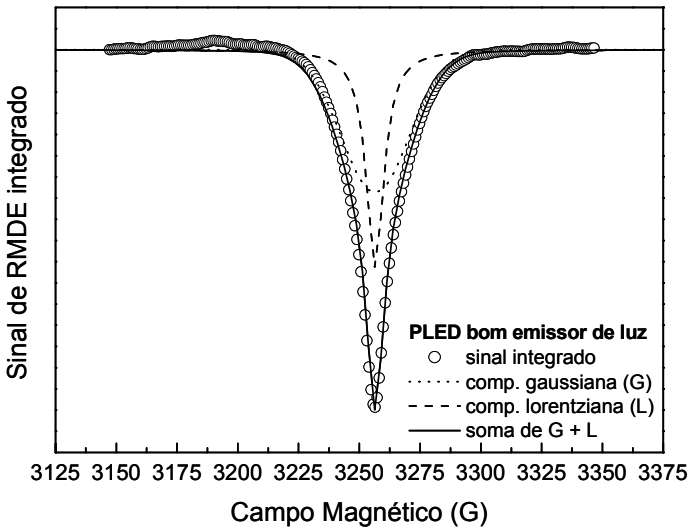

Figura 6. 2: (a) sinal de RMDE integrado de um PLED péssimo emissor de luz simulado por uma lorentziana, (b) sinal de RMDE integrado de um PLED bom emissor de luz composto por duas componentes, uma gaussiana e uma lorentziana.

A figura 6.2a) mostra que o sinal de RMDE de um PLED com muito fraca emissão de luz pode ser simulado por apenas uma curva lorentziana, enquanto a figura 6.2b) mostra que para simularmos o sinal de um PLED com boa emissão de luz é necessário a combinação de duas componentes, uma gaussiana (linha pontilhada) e uma lorentziana (linha tracejada). Nesta figura, os espectros de RMDE foram integrados para permitir uma melhor visualização da diferença entre os sinais das amostras. As duas componentes, lorentziana e gaussiana, apresentam diferentes fases em relação ao sinal de referência usado pelo lock-in. Fenômeno semelhante foi reportado por Dersch et al. [82] em amostras de a-Si:H. Esta diferença de fase ocorre quando as componentes do sinal de RMDE vêm de processos com diferentes tempos de resposta/relaxação. Portanto, o que está sendo observado são, provavelmente, dois processos dependentes de spin distintos. No decorrer deste capítulo serão discutidos quais seriam estes processos. 


\subsection{ITO/MEH-PPV/Au}

O sinal de RMDE dos dispositivos do tipo ITO/MEH-PPV/Au puderam ser simulados por apenas uma componente, a derivada de uma gaussiana, com $\Delta \mathrm{Hpp}=5 \mathrm{G}$ e fator $g=2.0014$. A figura 6.3 mostra o sinal de RMDE (círculos abertos) de um dispositivo hole-only operando com tensão positiva de $26 \mathrm{~V}$ no ITO, ajustado por uma derivada de uma curva tipo gaussiana (linha sólida). Como a energia do nível de Fermi, tanto do ITO quanto do Au, é próxima ao HOMO do MEH-PPV, o sinal pôde ser observado para tensões positivas tanto no ITO quanto no Au. Neste caso, $\Delta \sigma / \sigma$ é da ordem de $10^{-5}$.

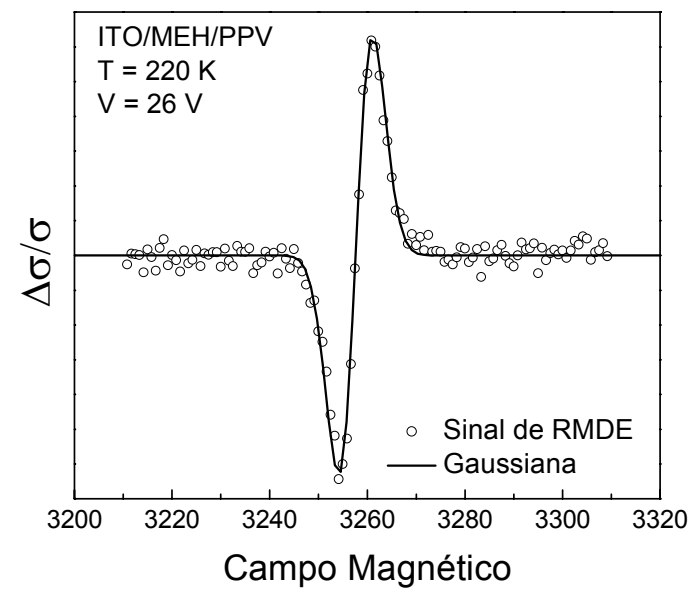

Figura 6.3: Sinal de RMDE de um diodo de ITO/MEH-PPV/Au (círculos abertos) ajustado pela derivada de uma curva tipo gaussiana (linha sólida).

Entretanto, em tensões suficientemente altas $(\mathrm{V}>30$ volts) e em baixas temperaturas ${ }^{9}$, uma segunda componente pode ser observada. Esta também pode ser descrita por uma gaussiana, porém com $\Delta \mathrm{Hpp}=10 \mathrm{G}$ e fator g ligeiramente menor do que a primeira componente, igual a 2.0012. Na figura 6.4, o espectro de RMDE (círculos abertos) está fora de fase para facilitar a visualização da segunda componente, pois esta é muito menos intensa do que a primeira. As linhas pontilhada e tracejada representam

\footnotetext{
${ }^{9}$ Em temperaturas mais baixas a relação sinal/ruído melhora.
} 
as componentes do espectro e são do tipo gaussiana. A linha sólida é a soma das componentes.

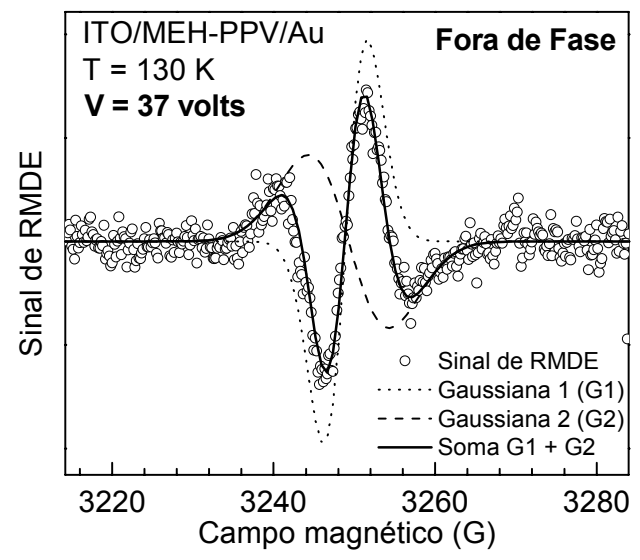

Figura 6. 4: Sinal de RMDE de um diodo de ITO/MEH-PPV/Au (círculos abertos) decomposto em duas componentes (pontilhada e tracejada). A linha sólida é a soma das duas componentes.

\subsection{Dependência com a temperatura}

Medidas de RMDE em função da temperatura mostram que PLEDs com diferentes eficiências de emissão de luz apresentam diferentes dependências com a temperatura (vide figura 6.5a). Na figura 6.5b, é mostrada a dependência da componente dominante no sinal de RMDE de um diodo hole-only. Note que esta é a componente que foi atribuída à fusão de pólarons positivos em bipólarons. Na figura 6.5a, é mostrada a dependência de um PLED com boa eficiência de emissão de luz e de um PLED cuja emissão de luz é quase imperceptível a olho nu. Vale lembrar que o sinal de RMDE do PLED mal-emissor de luz pôde ser simulado por apenas uma curva lorentziana, aquela que atribuímos à fusão de pólarons positivos em bipólarons. Como podemos notar, o sinal deste diodo têm uma dependência com a temperatura semelhante à dependência do sinal do diodo hole-only. 

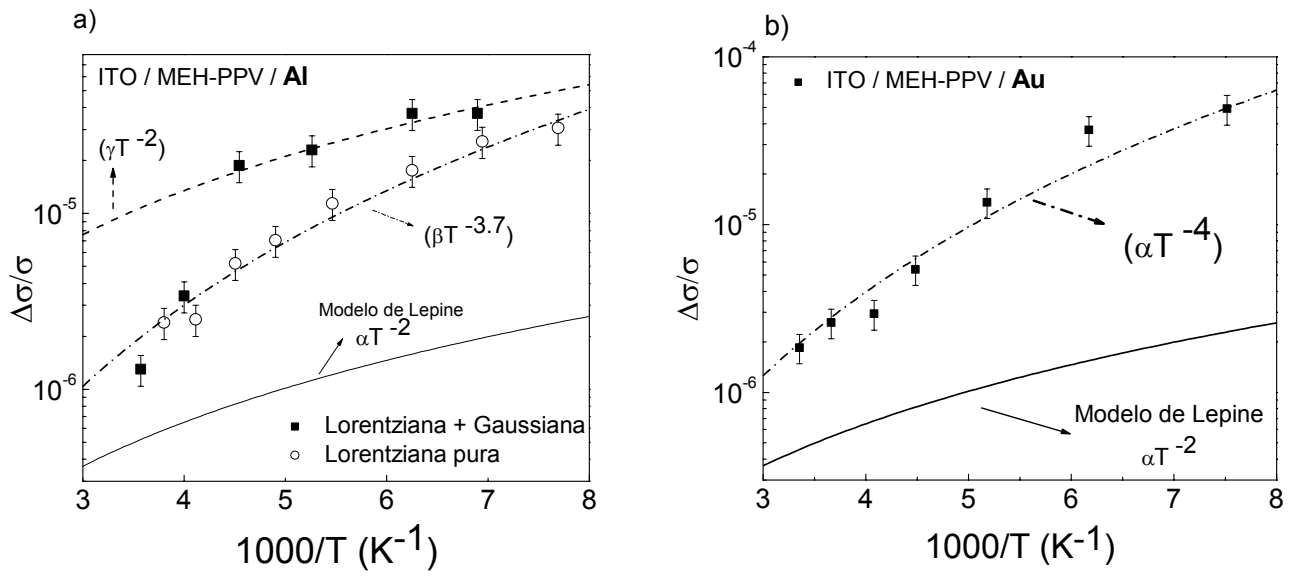

Figura 6.5: Dependência da amplitude do sinal de RMDE com a temperatura para a) LEDs com diferentes eficiências de emissão de luz; b) diodo hole-only (não-emisor luz).A linha em preto representa a máxima amplitude esperada utilizando o modelo de Lepine [56].

A linha em preto mostra o máximo sinal esperado quando utilizamos o modelo de Lepine [56]. Como vemos, a intensidade dos sinais das nossas amostras é bem maior do que o previsto por este modelo. Curiosamente, o LED bom emissor de luz apresenta uma dependência com a temperatura semelhante à prevista por Lepine para temperaturas abaixo de 220 K. O modelo proposto por Kaplan et al. [57] prevê intensidades de sinal bem maiores (até $10^{-1}$ ), porém não prevê esta dependência com a temperatura. Assim, pode-se notar que os modelos atuais não conseguem explicar completamente os fenômenos observados.

\subsection{Dependência com a corrente}

A figura 6.6 mostra a dependência de $\Delta \sigma / \sigma$ com a corrente aplicada em modo direto, tanto para um diodo hole-only (círculos abertos) quanto para um PLED (quadrados cheios). Como já foi mencionado, quando usamos Au como catodo, a injeção de elétrons é minimizada, mas não completamente eliminada. Vale lembrar também que, 
nos PLEDs, apesar de ocorrer injeção tanto de buracos quanto de elétrons, a injeção de buracos, em geral, é muito mais eficiente do que a injeção de elétrons.

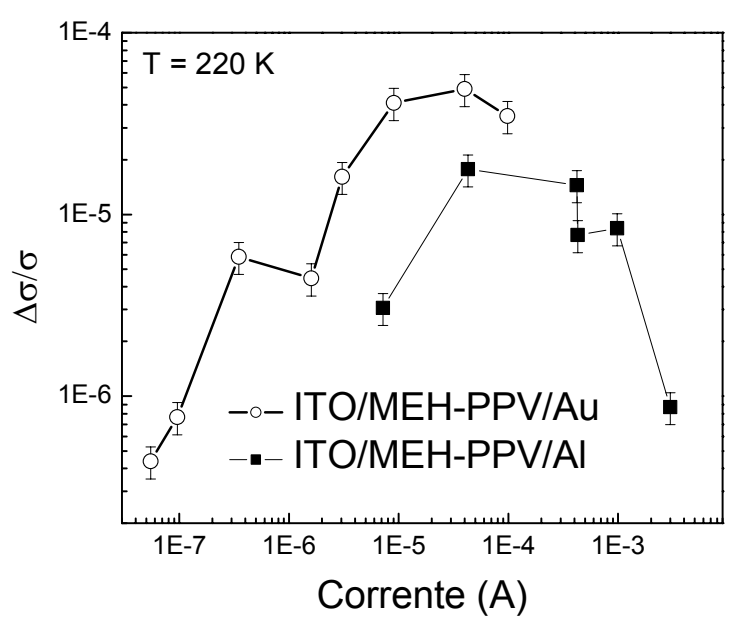

Figura 6.6: Dependência do sinal de RMDE com a corrente para um diodo bipolar (quadrados cheios) e um diodo hole-only (círculos abertos).

Como podemos notar, a intensidade do sinal de RMDE do dispositivo hole-only aumenta bastante com o aumento da corrente (duas ordens de grandeza), começando a saturar a partir de $10 \mu \mathrm{A}$, e mostrando uma leve tendência de queda para correntes mais altas. O PLED apresenta o mesmo comportamento geral, um aumento do sinal, seguido de uma saturação e uma queda com o aumento da corrente. Entretanto a queda observada é muito mais intensa do que o leve declínio do sinal mostrado pelo hole-only.

\subsection{Discussão}

Como vimos pelas medidas de RMDE nos diodos bipolar e hole-only, o sinal de RMDE é composto por duas componentes, uma larga e uma fina. A componente fina é dominante no diodo hole-only, e no PLED com baixa eficiência de emissão de luz. Além disso, a dependência do sinal de RMDE destes dois diodos com a temperatura é muito semelhante, o que indica que a componente fina em ambos os diodos é resultado de um 
mesmo processo. Com o aumento da tensão aplicada no dispositivo hole-only, ocorre o aparecimento de uma segunda componente larga, como nos PLEDs com boa eficiência de emissão de luz. Sabemos que a injeção de elétrons nestes diodos de ITO/MEH$\mathrm{PPV} / \mathrm{Au}$ é praticamente nula, porém ela pode ocorrer em campos elétricos suficientemente altos $\left(\sim 10^{6}-10^{7} \mathrm{~V} / \mathrm{cm}\right)$ [83]. A partir destes resultados e do trabalho de Shinar [84], a linha mais fina, $\Delta \mathrm{Hpp}=5 \mathrm{G}$ foi atribuída à fusão de pólarons positivos formando um bipólaron positivo $\left(\mathrm{p}^{+}+\mathrm{p}^{+} \rightarrow \mathrm{bp} \mathrm{p}^{++}\right)$, enquanto a linha larga foi atribuída à fusão de pólarons negativos para formar um bipólaron negativo $\left(\mathrm{p}^{-}+\mathrm{p}^{-} \rightarrow \mathrm{bp} \mathrm{p}^{--}\right)$. Como bipólarons possuem spin nulo e acredita-se que sua mobilidade nos PPVs seja muito inferior à mobilidade de pólarons [85], o aumento da fusão de pólarons (de spin $\pm 1 / 2$ ) em bipólarons explicaria o quenching do sinal de RMDE. As diferenças de largura de linha entre as componentes podem ser explicadas pela diferença de mobilidade entre pólarons positivos e negativos [86,87]. Devido ao efeito de "motional narrowing", a maior mobilidade dos pólarons positivos leva a um estreitamento da linha de ressonância em relação à dos pólarons negativos. Essa diferença de mobilidade poderia explicar também a diferença de fase observada entre os sinais [21].

O fato de o diodo bipolar com baixa eficiência de emissão de luz apresentar um sinal de RMDE dominado pela formação de bipólarons positivos indica que a deficiência na emissão de luz nestes PLEDs está relacionada a um desbalanceamento de injeção de cargas no polímero. Este resultado é condizente com o fato de que o ITO injeta buracos muito melhor do que o alumínio injeta elétrons no MEH-PPV. Entretanto, como vemos na figura 6.5a, não é apenas a escolha do metal de contato que influência a injeção de cargas. Como os dois PLEDs foram feitos usando os mesmos materiais como eletrodos, provavelmente a diferença na eficiência de emissão do dispositivo deve-se às etapas de limpeza e preparação do substrato, homogeneidade do filme polimérico, entre outros.

Um resultado intrigante, porém, é a diferença de comportamento em função da temperatura entre os diodos bipolar e hole-only. A intensidade do sinal de RMDE dos diodos hole-only de MEH-PPV diminui com, aproximadamente, $\mathrm{T}^{-4}$ a medida em que aumentamos a temperatura. Já nos PLEDs, o sinal também diminui com o aumento da 
temperatura, porém com $\mathrm{T}^{-2}$ até $220 \mathrm{~K}$, caindo abruptamente a partir desta temperatura. $\mathrm{Na}$ temperatura de $220 \mathrm{~K}$ alterações na dependência com a temperatura de diferentes parâmetros [88], como altura da barreira de injeção de buracos e pico do espectro de absorção, já foram reportadas em amostras de ITO/MEH-PPV/A1. Os autores observaram um aumento, em uma taxa de 1,2 meV/K, da barreira de injeção de buracos, na interface ITO/MEH-PPV, a partir de $220 \mathrm{~K}$, sendo esta praticamente independente de $\mathrm{T}$ abaixo de $150 \mathrm{~K}$. Foi observada ainda uma mudança na dependência da mobilidade de buracos com a temperatura a partir de $166 \mathrm{~K}$. Acima desta temperatura a mobilidade é termicamente ativada, com uma energia de ativação de $0,78 \mathrm{eV}$, segundo Lupton e Samuel [88]. Energias de ativação da mobilidade de buracos em diodos hole-only foram reportados por Blom et al. com valores de $0.48 \mathrm{eV}$ [89] e $0.59 \mathrm{eV}$ [6]. As razões para estas mudanças ainda não são completamente compreendidas. Vejamos, porém, algumas possibilidades que devem ser consideradas para explicar o comportamento do sinal de RMDE com a temperatura.

Como já foi discutido no capítulo sobre a polianilina, acima de uma temperatura crítica, começa a ocorrer dissociação térmica de bipólarons [80]. O modelo de Kaplan, discutido no capítulo 3, diz que um par de spins no estado tripleto permanecerá ligado até que uma das três possibilidades ocorra: inversão espontânea de um dos spins, em um tempo característico $\mathrm{T}_{1}$; inversão de um dos sins induzida pelo campo, em um tempo característico $\tau_{\mathrm{SF}}$; ou dissociação do par de spin, em um tempo característico $\tau_{\text {dissociação. }}$ A variação máxima devido à ressonância ocorreria para a condição $\tau_{\text {transição }}<<\tau_{\mathrm{SF}}<<$

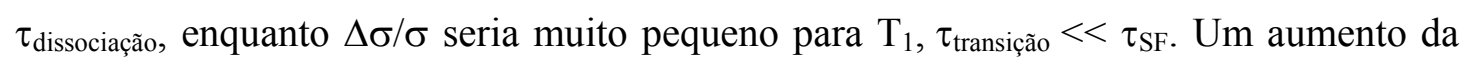
dissociação térmica de bipólarons significa uma diminuição de $\tau_{\text {dissociação, }}$ e, conseqüentemente, uma diminuição do sinal de RMDE. Isto explicaria a queda abrupta de $\Delta \sigma / \sigma$ do PLED de MEH-PPV. Entretanto, nos diodos hole-only, esta queda tão acentuada não é observada. Possivelmente, a diferença seja devido a diferentes dependências dos tempos de relaxação de cada componente com a temperatura, uma vez que o sinal do PLED é composto pela contribuição da formação de bipólarons positivos e negativos, enquanto o sinal do hole-only é devido apenas à formação de bipólarons positivos. 


\section{Dependência com a corrente}

Como vimos na figura 6.6, a dependência de $\Delta \sigma / \sigma$ em função da corrente no dispositivo apresenta comportamento similar tanto para o diodo bipolar quanto para o hole-only. O sinal aumenta no regime de baixa corrente, satura e, então, começa a diminuir. Entretanto a queda no PLED é bem acentuada, diferente da leve diminuição de $\Delta \sigma / \sigma$ mostrada pelo hole-only. No caso deste último, o aumento da corrente significa que mais buracos estão sendo injetados e a probabilidade de ocorrer fusão de pólarons positivos em bipólarons aumenta, aumentando o sinal de RMDE. Em correntes mais altas, ou seja, em campos elétricos mais altos, começa a ocorrer injeção de elétrons, que é evidenciada pelo aparecimento de uma segunda componente no sinal de RMDE, estagnando o aumento de $\Delta \sigma / \sigma$. Uma saturação do sinal de RMDE em altas densidades de corrente similar a esta foi reportada por Swanson et al. [81] em LEDs a base de PPV. Entretanto, eles não observaram a queda do sinal em altas densidades de corrente. Cálculos numéricos realizados por Silva [90] mostraram que tanto pólarons quanto bipólarons são instáveis sob intensos campos elétricos. A estrutura destas excitações é destruída em campos muito intensos, por exemplo, acima de $\sim 10^{6} \mathrm{~V} / \mathrm{m}$, apesar de esta intensidade variar com a concentração de dopagem. Quanto maior a concentração menor o efeito do campo sobre pólarons ou bipólarons. O efeito, entretanto, não é percebido de forma igual pelos dois tipos de excitações, bipólarons são sempre mais estáveis do que pólarons. Em geral, o campo elétrico crítico é uma ordem de magnitude maior para bipólarons. Este resultado pode explicar porque nosso sinal satura e depois começa a diminuir. No regime de altas correntes, o campo é muito alto $\left(\sim 10^{6} \mathrm{~V} / \mathrm{cm}\right)$, reduzindo a população de pólarons e, portanto, diminuindo a probabilidade de formação de bipólarons. Assim, o sinal de RMDE satura e, ao continuarmos aumentando o campo elétrico, começa a diminuir. Entretanto, a queda brusca observada no diodo bipolar não ocorre no hole-only. Isto acontece pois, como o dispositivo com contato de Au possui um excesso de cargas positivas, podemos pensar nele como um material dopado tipo-p. Como, segundo Silva [90], pólarons são mais estáveis em altas taxas de dopagens, é 
necessário um campo muito mais alto para "destruir" os pólarons no hole-only, e, provavelmente nós não atingimos este valor crítico. Outra possibilidade que deve ser considerada é que a taxa de formação de bipólarons poderia saturar no regime de altas correntes se bipólarons fossem formados preferencialmente em sítios de armadilhamento de cargas [91]. Uma terceira possibilidade seria que, no regime de altas correntes, o aumento da temperatura local aumentaria a dissociação térmica de bipólarons, resultando em uma diminuição do sinal de RMDE. 


\section{CAPÍTULO 7}

\section{ESPECTROSCOPIA DE IMPEDÂNCIA ELÉTRICA EM OLEDS DE $\mathrm{ALQ}_{3}$}

\footnotetext{
Algumas técnicas de medida de condutividade elétrica são sensíveis a ponto de auxiliar na obtenção de informações a respeito dos mecanismos de transporte em um material. A espectroscopia de impedância é uma dessas técnicas, sendo bastante versátil no estudo de dielétricos, baterias, condutores iônicos, semicondutores etc. De maneira geral, ela é uma técnica que permite a investigação do movimento de cargas livres ou aprisionadas, seja no volume ("bulk") ou nas interfaces dos diferentes tipos de materiais citados anteriormente [92]. O conceito de impedância elétrica foi introduzido por Oliver Heaviside na década de 1880 e, em seguida, foi desenvolvido em termos de diagramas de vetor e representação complexa por A.E. Kennelly e C.P. Steinmetz. A impedância elétrica, $\mathrm{Z}(\omega)$, é convencionalmente definida como $\mathrm{Z}(\omega) \equiv \mathrm{V}(\mathrm{t}) / \mathrm{I}(\mathrm{t})$, onde $\mathrm{V}(\mathrm{t})$ é uma diferença de potencial elétrico oscilante no tempo $[V(t)=V \operatorname{sen}(\omega t)]$ e $I(t)$ é a resposta em corrente que oscila na mesma freqüência mas com uma certa defasagem $(\phi)$ em relação ao potencial aplicado $[\mathrm{I}(\mathrm{t})=\mathrm{I} \operatorname{sen}(\omega \mathrm{t}+\phi)]$. Tanto a resistência quanto a impedância denotam uma oposição ao fluxo de corrente. Em medidas de corrente
} 
contínua (dc), apenas resistores produzem este efeito, enquanto que, em medidas de corrente alternada (ac), mais dois elementos de circuito fazem este papel: capacitores e indutores. Em geral, a função impedância é expressa em sua forma complexa:

$$
Z(\omega)=Z^{\prime}(\omega)+\mathrm{i} Z^{\prime}(\omega)
$$

onde $Z^{\prime}(\omega)$ é a componente real, que está relacionada à resposta resistiva do sistema, e Z” $(\omega)$ a componente imaginária, que está relacionada às respostas capacitiva (C) e indutiva $(\mathrm{L})$ combinadas.

Além desta, existem outras formas de representar os dados obtidos em medidas de impedância. As mais importantes e as relações entre elas estão apresentadas na tabela abaixo.

\begin{tabular}{|c|c|c|c|c|}
\hline & $\begin{array}{c}\text { Função } \\
\text { módulo }\left(\mathbf{M}^{*}\right)\end{array}$ & $\begin{array}{c}\text { Impedância } \\
\left(\mathbf{Z}^{*}\right)\end{array}$ & $\begin{array}{c}\text { Admitância } \\
(\mathbf{Y})\end{array}$ & $\begin{array}{c}\text { Permissividade } \\
\text { dielétrica }(\varepsilon)\end{array}$ \\
\hline$M^{*}$ & $\mathrm{M}^{*}$ & $\mathrm{i} \omega \mathrm{C}^{*} \mathrm{Z}^{*}$ & $\mathrm{i} \omega \mathrm{C}^{*} / \mathrm{Y}^{*}$ & $1 / \varepsilon^{*}$ \\
\hline $\mathbf{Z}^{*}$ & $\mathrm{M}^{*} / \mathrm{i} \omega \mathrm{C}^{*}$ & $\mathrm{Z}^{*}$ & $1 / \mathrm{Y}^{*}$ & $1 / \mathrm{i} \omega \mathrm{C}^{*} \varepsilon^{*}$ \\
\hline $\mathbf{Y}^{*}$ & $\mathrm{i} \omega \mathrm{C} / \mathrm{M}^{*}$ & $1 / \mathrm{Z}^{*}$ & $\mathrm{Y}^{*}$ & $\mathrm{i} \omega \mathrm{C}^{*} \varepsilon^{*}$ \\
\hline$\varepsilon^{*}$ & $1 / \mathrm{M}^{*}$ & $1 / \mathrm{i} \omega \mathrm{C}^{*} \mathrm{Z}^{*}$ & $\mathrm{Y}^{*} / \mathrm{i} \omega \mathrm{C}^{*}$ & $\varepsilon^{*}$ \\
\hline
\end{tabular}

Tabela 7.1: Relações entre as quatro funções de representação de medidas de impedância mais usuais.

Na tabela acima, $C^{*}$ é a capacitância, $M^{*}$ é a função módulo, $\mathrm{Y}^{*}$ é a função admitância e $\varepsilon^{*}$ é a permissividade dielétrica. O asterisco indica que a função é complexa. Cada uma destas formas de representação é mais útil em determinado caso, dependendo de quais características do sistema se deseja explicitar. Por exemplo, vejamos o caso da admitância.

Y* é dado por:

$$
\mathrm{Y}^{*}=1 / \mathrm{Z}^{*}=\mathrm{Y}^{\prime}+\mathrm{i} \mathrm{Y}^{\prime},
$$


onde Y' é a componente real, dada pela condutância $(G)$, o recíproco da resistência, e Y" é a componente imaginária, dada pela susceptância:

$$
\mathrm{Y}^{*}=\mathrm{G}^{*}+\mathrm{i} \mathrm{B}^{*}
$$

onde $\mathrm{B}^{*}$ pode ser escrita como $\omega \mathrm{C}^{*}$ ou $-1 / \omega \mathrm{L}^{*}$, dependendo se a oposição à corrente vêm mais da parte capacitiva ou indutiva do sistema estudado.

Como a condutividade também depende da freqüência, também se torna necessário o uso da representação complexa.

$$
\sigma^{*}(\omega)=\sigma^{\prime}(\omega)-\mathrm{i} \sigma^{\prime \prime}(\omega)
$$

Entretanto, a condutividade complexa não é definida somente pela resposta condutiva, proveniente do movimento de portadores livres do material. Pelo fato de não se poder separar, experimentalmente, a corrente proveniente da parte condutiva daquela proveniente da parte dielétrica, tanto $\sigma^{\prime}$ quanto $\sigma^{\prime \prime}$ possuem uma componente ligada à resposta dielétrica do material. No entanto, em um regime quase-estático $(\omega \rightarrow 0)$, a componente real da condutividade refletirá somente a parte condutiva do sistema, $\sigma^{\prime}(0) \rightarrow \sigma_{d c}$.

Esta condutividade complexa pode ser relacionada com a constante dielétrica complexa da seguinte forma:

$$
\sigma^{*}=\mathrm{i} \varepsilon^{*} \omega
$$

Como a relação entre a condutividade e a admitância é dada por:

$$
\sigma^{*}=\mathrm{Y}^{*} \mathrm{~L} / \mathrm{A}
$$


onde L é a largura da amostra e A é a área; e a relação entre a capacitância e a constante dielétrica é dada por:

$$
\mathrm{C}^{*}=\varepsilon^{*} \mathrm{~A} / \mathrm{L}
$$

podemos dizer que há uma "capacitância complexa" $\left(\mathrm{C}^{*}\right)$ cuja parte real é a capacitância da amostra, relacionada à acumulação de carga, e cuja parte complexa está relacionada à perda dielétrica. De modo que podemos escrever:

$$
\mathrm{Y}^{*}=\mathrm{i} \mathrm{C}^{*} \omega
$$

e, assim:

$$
C^{\prime}=Y^{\prime \prime} / \omega \text { e } \quad C^{\prime \prime}=-Y^{\prime} / \omega
$$

Como vemos, obter os dados de impedância na forma de admitância é interessante quando se deseja estudar a evolução de sistemas do regime dielétrico para o condutivo, uma vez que podemos diretamente obter a dependência de $\mathrm{C}^{*}$ com a freqüência.

\subsection{Resultados e discussões}

Os resultados apresentados são de medidas de impedância, na faixa de $0,5 \mathrm{~Hz}$ a $10^{6} \mathrm{~Hz}$, de um OLED do tipo ITO/CuPc/ $\alpha-\mathrm{NPD} / \mathrm{Alq}_{3} / \mathrm{LiF} / \mathrm{Al}\left(L_{N P D}=40 \mathrm{~nm}, L_{\mathrm{Alq}}=60\right.$ $\mathrm{nm}$, onde L é a espessura da camada). As medidas foram realizadas a $300 \mathrm{~K}$ para diferentes valores da voltagem dc $\left(V_{d c}\right)$ em modo direto ${ }^{10}$ superposta à voltagem ac $\left(V_{a c}\right.$ $=0,1 \mathrm{~V}$ ). Como o valor de $V_{a c}$ é baixo o suficiente, a injeção de portadores de carga é atribuída apenas a $V_{d c}$.

\footnotetext{
${ }^{10}$ Positivo no ITO e negativo no Al.
} 
Os gráficos da figura 7.1 mostram a dependência com a freqüência das componentes real (a) e imaginária (b) da resposta de impedância. Na figura 7.1a, podemos observar que, em altas freqüências (acima de $10^{5} \mathrm{~Hz}$ ), todas as curvas de Z' convergem para um mesmo patamar em torno de $70 \Omega$. Este patamar é, geralmente, atribuído aos eletrodos, que atuam como uma resistência em série com a amostra. Os valores desta resistência devido aos eletrodos reportados na literatura, em geral, são bem menores (da ordem de $30 \Omega$ ) do que o valor aqui obtido [93,83]. Provavelmente, esta diferença se deve às camadas adicionais de $\mathrm{CuPc}$ e de $\mathrm{LiF}$, que não estão presentes nos dispositivos estudados nas referências citadas. O valor de Z', entretanto, deixa este patamar e começa a aumentar a medida em que diminuímos a freqüência. Em freqüências baixas, Z' atinge um novo patamar, cujo valor diminui com o aumento da voltagem dc aplicada, e está relacionado ao valor da resistência dc da amostra. Este segundo patamar, porém, só pôde ser observado a partir de $\mathrm{V}_{\mathrm{dc}}=3 \mathrm{~V}$, pois para voltagens mais baixas, ele só aparece em freqüências abaixo da faixa estudada.
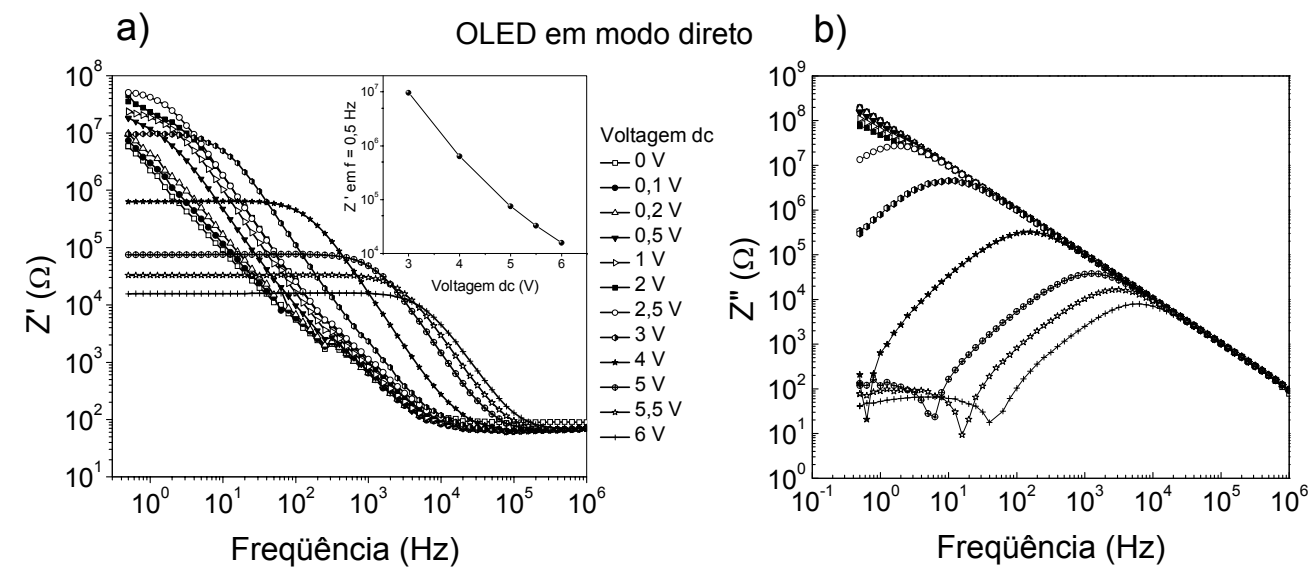

Figura 7.1: Componentes real (a) e imaginária (b) da resposta de impedância de um OLED operando em modo direto em diferentes voltagens dc. No detalhe em (a) é mostrada a dependência de $Z^{\prime}$ com $\mathrm{Vdc}$ em $\mathrm{f} \rightarrow 0$.

No detalhe da figura 7.1a, vemos a diminuição de $Z^{\prime}(\mathrm{em}, \omega \rightarrow 0)$ com o aumento da voltagem dc. Isto se deve ao aumento da injeção de portadores devido à 
diminuição da altura das barreiras de energia nas interfaces com os eletrodos, que leva a um aumento da condutividade do dispositivo devido ao aumento da densidade de portadores de carga no material.

Na figura $7.1 \mathrm{~b}$, é mostrada a resposta da componente imaginária da impedância em função da freqüência para diferentes valores de $\mathrm{V}_{\mathrm{dc}}$. $\mathrm{O}$ ponto de máximo das curvas de Z" nos dá a freqüência a relaxação $\left(f_{r}\right)$ onde ocorre a transição de um patamar de Z' para o outro. Nesta figura fica clara a dependência de $f_{r} \operatorname{com} V_{d c}$, que se desloca para maiores freqüências a medida em que aumentamos a voltagem dc. Isto se deve à dependência do tempo de relaxação dielétrica $\tau=\mathrm{f}_{\mathrm{r}}^{-1}$ com o inverso da condutividade $(\sigma)$, considerando um dielétrico ideal. Como $\mathrm{V}_{\mathrm{dc}}$ aumenta a condutividade, a relaxação dielétrica passa a ser observada em freqüências maiores.
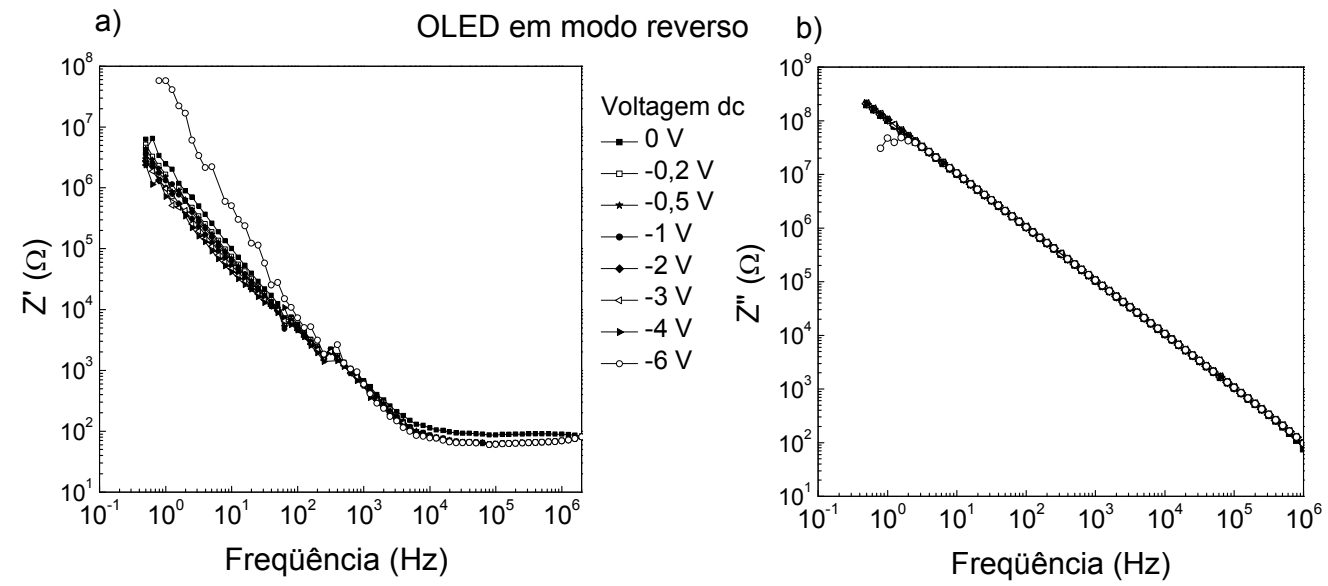

Figura 7.2: Componentes real (a) e imaginária (b) da resposta de impedância de um OLED operando em modo reverso em diferentes voltagens $\mathrm{dc}$.

$\mathrm{Na}$ figura 7.2, vemos a resposta das componentes real e imaginária da impedância do mesmo OLED operando em modo reverso ${ }^{11}$. A componente Z' apresenta o mesmo patamar em altas freqüências, por volta de $70 \Omega$, observado no modo direto. $O$ fato de o valor do patamar não ter mudado é esperado, uma vez que ele está relacionado

\footnotetext{
${ }^{11}$ Tensão positiva no Al e negativa no ITO.
} 
a uma resistência imposta pelos eletrodos, que não foram alterados. Com a diminuição da freqüência, o valor de Z' aumenta, porém o segundo patamar não pode ser observado na região de freqüências estudada. Olhando a componente $Z$ " vemos que apenas em $V_{\mathrm{dc}}$ igual a -6 V observamos o início de um processo de relaxação dielétrico em freqüências bem baixas $(\sim 1 \mathrm{~Hz})$. Antes de prosseguirmos com a análise destes gráficos, é preciso lembram como são os níveis de energia dos materiais que compõem o OLED (vide figura 7.3). Na interface ITO/CuPc, a barreira para a injeção de elétrons é muito alta, da ordem de $1,48 \mathrm{eV}$, da mesma forma que na interface $\mathrm{Al} / \mathrm{LiF} / \mathrm{Alq}_{3}$, a barreira para a injeção de buracos também é muito alta, da ordem de 2,19 eV. Além disso, há mais uma barreira à passagem de elétrons do $\mathrm{CuPc}$ para o $\alpha-\mathrm{NPD}$, da ordem de $1,2 \mathrm{eV}$, e a mobilidade de portadores positivos no $\mathrm{Alq}_{3}$ e negativos no NPD é menor do que a de elétrons e buracos, nas respectivas camadas. Portanto, em modo reverso, a resistência dc da amostra é muito alta.

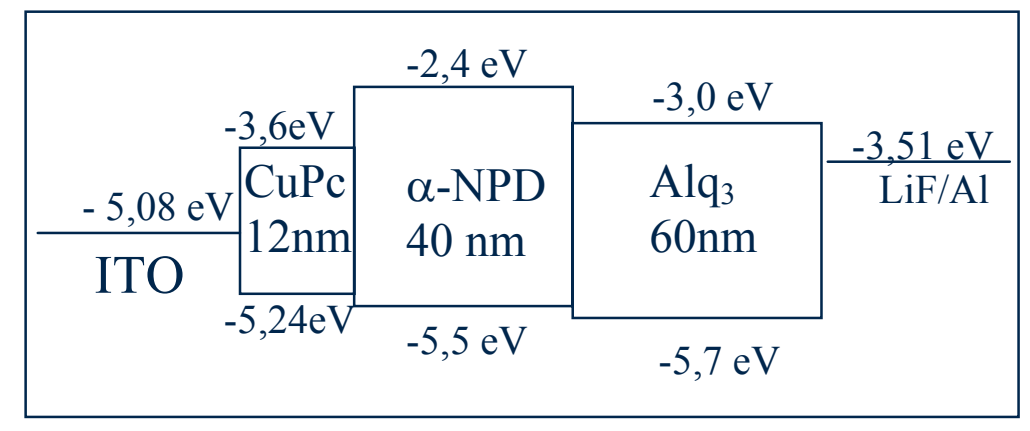

Figura 7.3: Diagrama de energias do HOMO (inferior), LUMO (superior) e nível de Fermi (dos eletrodos) em relação ao nível de vácuo para as camadas que compõem o OLED.

É exatamente isto que é observado na resposta de impedância. Pelo valor de Z' para $\mathrm{V}_{\mathrm{dc}}=-6 \mathrm{~V}$ em $\mathrm{f}=1 \mathrm{~Hz}$, pode-se estimar que para $\omega=2 \pi \mathrm{f} \rightarrow 0$, a resistência da amostra será $>10^{8} \Omega$. Para efeito de comparação, em $V_{d c}=6 \mathrm{~V}$, a resistência dc da amostra era da ordem de $\sim 10^{4} \Omega$, o que mostra o bom fator de retificação ${ }^{12}$ do diodo. $\mathrm{O}$ fato de não observarmos o segundo patamar na faixa de freqüência estudada, se deve também à baixa condutividade da amostra, uma vez que $f_{r}$ depende diretamente de $\sigma$.

\footnotetext{
${ }^{12}$ Razão entre a corrente no modo direto e a corrente no modo reverso para uma mesma tensão. Um diodo é considerado melhor quanto maior for o seu fator de retificação de corrente.
} 
Portanto, quanto menor a condutividade menor a freqüência em que se observa a relaxação dielétrica.

Tanto em modo direto quanto em modo reverso, observamos que Z' diminui em altas freqüências. Isto é simplesmente o resultado das medidas de resposta em freqüência. Em baixas freqüências, somente os portadores (ou processos) mais lentos irão responder à perturbação em freqüência. . Esse é o caso dos portadores injetados (ou intrínsecos - dependendo do valor de $\mathrm{V}_{\mathrm{dc}}$ ) no volume com sua respectiva mobilidade na camada em que se encontram. Por outro lado, em freqüências intermediárias, alguns portadores mais lentos vão deixando de responder até que, em altas freqüências, apenas os portadores com maior mobilidade, relacionados aos eletrodos, irão responder à perturbação em freqüência. Isto permite separar os diferentes fenômenos e estudar a dinâmica dos portadores de cargas nas diferentes regiões do material.

\section{OLED em modo reverso}
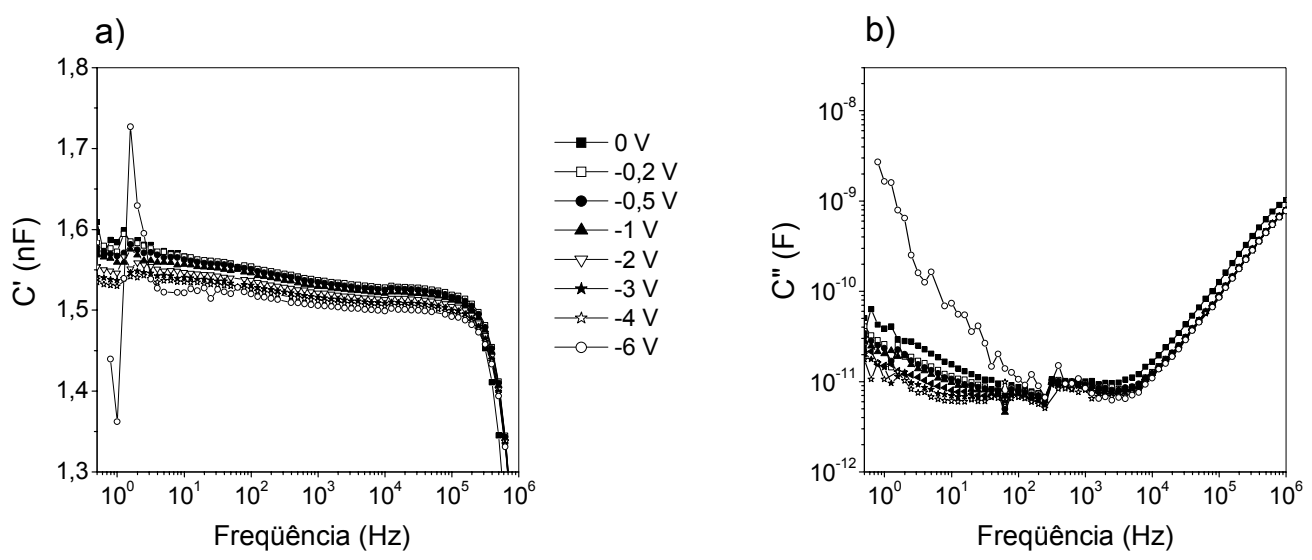

Figura 7.4: Componentes real (a) e imaginária (b) da capacitância complexa para um

OLED operando em modo reverso.

$\mathrm{Na}$ figura 7.4 são mostradas as componentes real (a) e imaginária (b) da capacitância complexa para o OLED em modo reverso. Como foi discutido, a amostra é altamente resistiva quando $\mathrm{V}_{\mathrm{dc}}<0$, portanto o dispositivo deve se comportar como um dielétrico. Isto, de fato, é observado na figura 7.4, que apresenta um valor praticamente constante de $\mathrm{C}^{\prime}=1,55 \pm 0,05 \mathrm{nF}$ entre $0,5 \mathrm{~Hz}$ e $10^{5} \mathrm{~Hz}$, para todas as voltagens dc 
estudadas. A independência do valor de C' com a voltagem se deve ao fato de que em modo reverso não deve haver injeção de cargas no volume do dispositivo, ou seja, praticamente não existe contribuição do movimento de cargas ou ele não responde nesse intervalo de freqüência, em acordo com a figura 7.2. Entretanto, C' não é completamente independente de $\mathrm{V}_{\mathrm{dc}}$. Uma pequena, mas perceptível variação de $\mathrm{C}^{\prime}$ com $\mathrm{V}_{\mathrm{dc}}$ é observada em baixas freqüências. $\mathrm{O}$ valor de C' se aproxima mais de uma constante em relação à freqüência à medida que aumentamos $\mathrm{V}_{\mathrm{dc}}$ em modo reverso. Isso ocorre, pois a contribuição da parte condutiva do sistema é cada vez menor a medida em que aumentamos a voltagem em modo reverso, ou seja, o comportamento do sistema se aproxima mais de um comportamento puramente dielétrico. Como vimos na introdução deste capítulo, $\mathrm{C}^{*}$ está diretamente relacionada à constante dielétrica do sistema, exceto por fatores geométricos. Assim, quanto menor a contribuição condutiva para a capacitância complexa, mais próximo C' fica de representar a constante dielétrica do material. Entretanto, como o OLED é composto por camadas de materiais diferentes, o valor da constante dielétrica de cada material não pode ser obtida diretamente do valor da capacitância total do dispositivo.
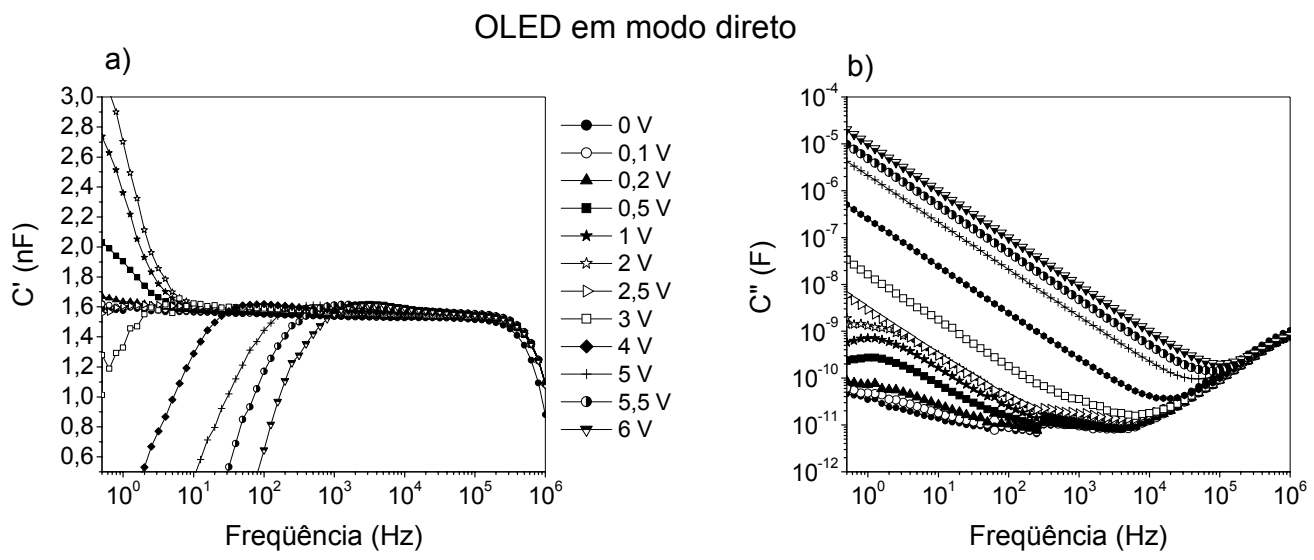

Figura 7.5: Componentes real (a) e imaginária (b) da capacitância complexa do OLED operando em modo direto. 
A Figura 7.5, mostra as componentes real (a) e imaginária (b) da capacitância complexa do OLED operando em modo direto. Na Figura 7.6, o gráfico mostrado na Figura 7.5a foi separado em dois, (a) de $\mathrm{V}_{\mathrm{dc}}=0 \mathrm{~V}$ até $\mathrm{V}_{\mathrm{dc}}=2,5 \mathrm{~V}$, e (b) de $\mathrm{V}_{\mathrm{dc}}=3 \mathrm{~V}$ até $\mathrm{V}_{\mathrm{dc}}=6 \mathrm{~V}$, para facilitar a visualização da dependência de C' em baixas freqüências com a voltagem dc. Em $V_{d c}=0 \mathrm{~V}, C^{\prime}$ apresenta o mesmo valor que em modo reverso, igual a $1,58 \mathrm{nF}$. A medida em que aumentamos $\mathrm{V}_{\mathrm{dc}}$, o valor de C', para $\omega \rightarrow 0$, aumenta até C' $=3,23 \mathrm{nF}$ em $\mathrm{V}_{\mathrm{dc}}=2 \mathrm{~V}$.

a)

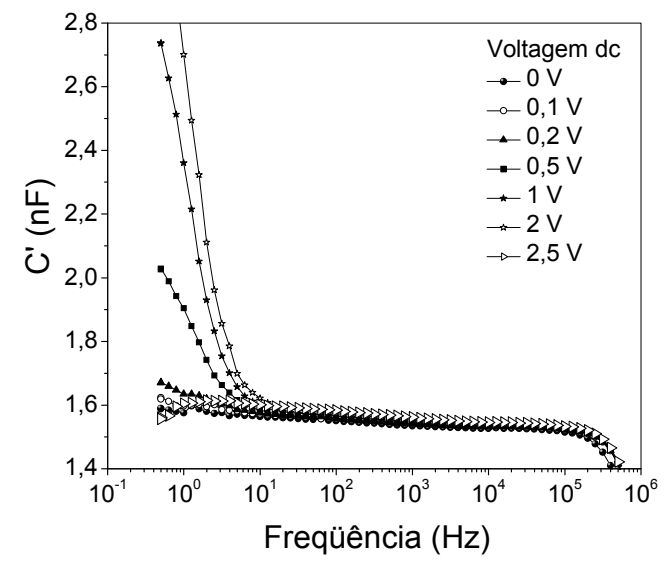

b)

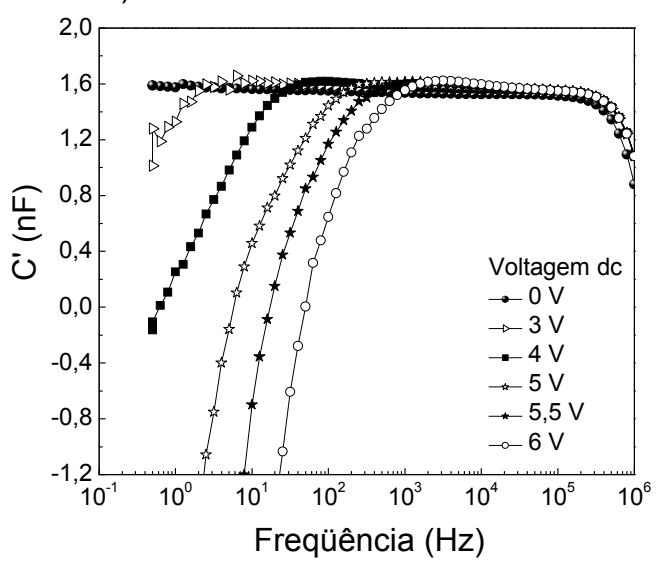

Figura 7.6: Componente real da capacitância complexa para diferentes valores de voltagem dc: (a) de $0 \mathrm{~V}$ a 2,5 V; e (b) de $3 \mathrm{~V}$ a $6 \mathrm{~V}$. Em (b) $\mathrm{V}_{\mathrm{dc}}=0 \mathrm{~V}$ também é mostrado para comparação.

Acima desta voltagem, o valor de C' começa a cair drasticamente, apresentando valores "negativos" $\left(\mathrm{C}^{\prime}[\mathrm{f}=0,5 \mathrm{~Hz}]=-54,49 \mathrm{nF}\right.$ em $\left.\mathrm{V}_{\mathrm{dc}}=6 \mathrm{~V}\right)$. Apesar de estranho, este efeito de "capacitância negativa" já foi observado em outros sistemas, estruturas metal/semicondutor/metal [94], estudos de corrosão [95] e polímeros condutores $[96,83]$. O comportamento observado é similar a um comportamento indutivo em baixa freqüência, mas é expresso como capacitância negativa, pois a natureza do sistema é tal que a geometria sugere uma capacitância e o fenômeno não deve, em termos físicos, estar relacionado a um efeito magnético. Entretanto, os resultados obtidos e as poucas hipóteses formuladas para explicar o fenômeno ainda são muito controversos. 
Na figura $7.5 b$, vemos que C" apresenta um pico de relaxação dielétrica, em baixas freqüências e baixos valores de $\mathrm{V}_{\mathrm{dc}}(<2,5 \mathrm{~V})$. $\mathrm{O}$ máximo do pico indica a freqüência de relaxação média do processo de acúmulo de cargas discutido anteriormente. Este pico se intensifica até voltagens próximas de $2,5 \mathrm{~V}$, quando a recombinação é ativada e o fenômeno não mais é observado.

Brutting et al. [93] observou um aumento de C' em função da voltagem dc até, aproximadamente, $2 \mathrm{~V}$ em OLEDs com estrutura do tipo ITO/NPB/Alq $3 / \mathrm{Ca}$, muito semelhante à aqui estudada. Dependendo da espessura da camada de Alq, foi observada uma pequena queda do valor da capacitância em $\mathrm{V}_{\mathrm{dc}}>2 \mathrm{~V}$. Entretanto, nenhuma capacitância negativa foi observada. Provavelmente, pois as medidas apresentadas só foram realizadas até $\mathrm{V}_{\mathrm{dc}}=3 \mathrm{~V}$ e, o valor de capacitância dc $(\omega \rightarrow 0)$ foi obtido à 100 Hz. Como pode ser observado na figura $7.5 b$, a queda no valor da capacitância só é observado acima de $100 \mathrm{~Hz}$ para $\mathrm{V}_{\mathrm{dc}}>5 \mathrm{~V}$. Grande parte dos estudos de impedância em OLEDs e PLEDs é realizado somente em freqüências a partir de $100 \mathrm{~Hz}$ para cima, o

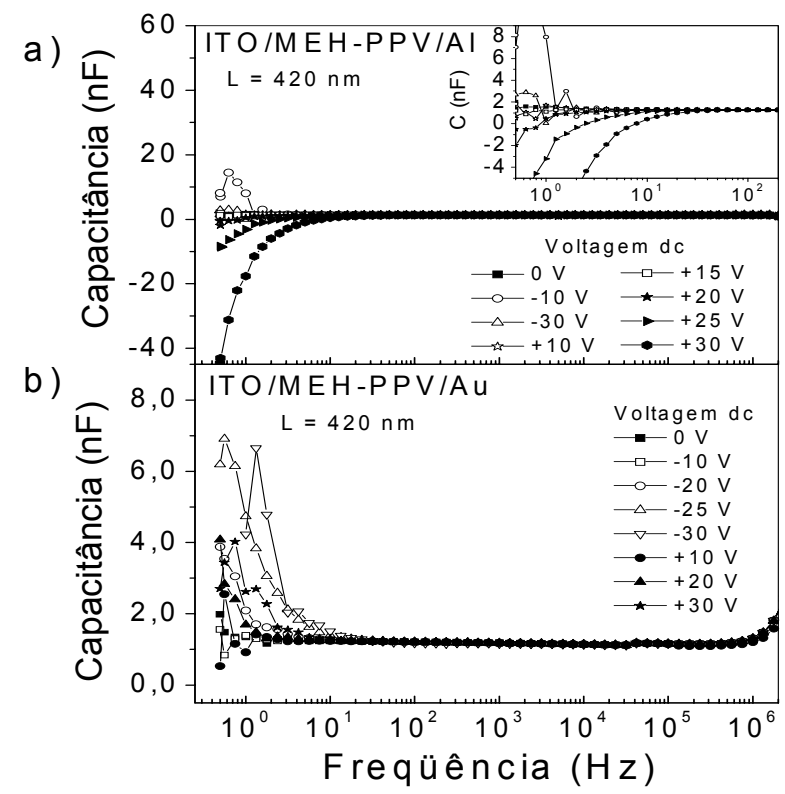

Figura 7.7: Componente real da capacitância complexa para um PLED (a) e um dispositivo hole-only (b), ambos de MEH-PPV e operando em modo direto e em modo reverso. Figura cedida por L.F. Santos [83]. 
que explica porque tão poucos trabalhos reportam este fenômeno.

Como esta capacitância negativa é observada em diferentes sistemas, este efeito não deve ser uma característica do material estudado, mas sim de algum tipo de processo comum a estes diferentes sistemas.

Recentemente, L.F. Santos [83] observou o efeito de capacitância negativa em PLEDs do tipo ITO/MEH-PPV/Al, quando operando em modo direto. Diferente da transição de C' positivo para C' negativo observada no OLED estudado nesta dissertação, apenas C' negativo foi observado no PLED em modo direto. Na figura 7.6, cedida pelo autor, vemos, em (a), C' para o PLED e, em (b), C' de um dispositivo holeonly do tipo ITO/MEH-PPV/Au, ambos operando em modo direto e em modo reverso. No detalhe da figura 7.6a, é mostrado uma ampliação ("zoom") da região de baixas freqüências, para melhor visualização da dependência de $C^{\prime}$ com $\mathrm{V}_{\mathrm{dc}}$. No hole-only não observamos a capacitância negativa, mas apenas o aumento de C' com a tensão, como entre $\mathrm{V}_{\mathrm{dc}}=0$ até $2 \mathrm{~V}$ no OLED.

Vamos tentar entender estas diferenças a partir dos diagramas de energia dos dispositivos analisados. $\mathrm{Na}$ figura 7.7 , vemos o diagrama de energias para o PLED e para o hole-only. No hole-only, ao aplicarmos uma voltagem dc, injetamos cargas positivas que podem percorrer toda a camada polimérica atingindo o seu contra-eletrodo e, assim, contribuir para a corrente. Porém, como a mobilidade dos portadores de carga é baixa no MEH-PPV, um aumento da injeção de cargas leva à formação de carga espacial no volume do polímero. Este aumento da carga acumulada é responsável pelo aumento do valor da capacitância.

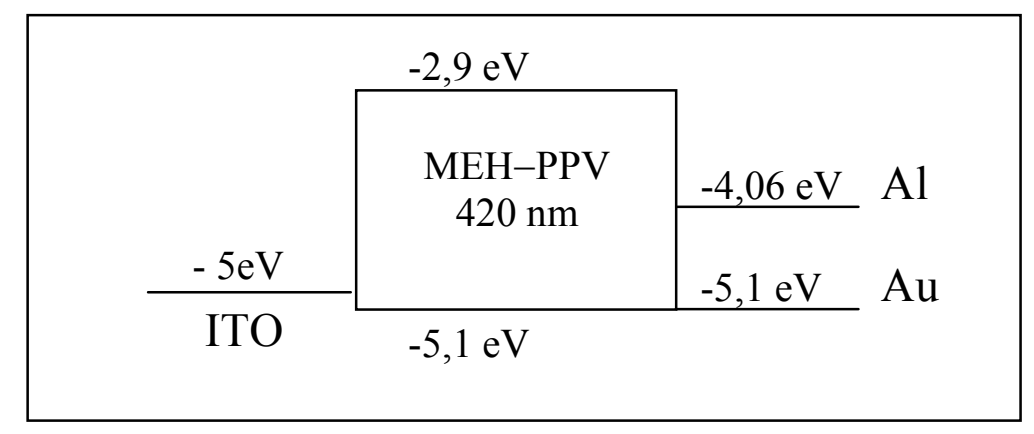

Figura 7.8: Diagrama de energias do HOMO e do LUMO do MEH-PPV e do nível de Fermi dos eletrodos usados no PLED e no hole-only. 
No OLED, em baixas voltagens, o aumento da capacitância deve estar relacionada com o acúmulo de cargas negativas na interface $\alpha-\mathrm{NPD} / \mathrm{Alq}_{3}$, no lado do $\mathrm{Alq}_{3}$, e de cargas positivas na interface $\mathrm{CuPc} / \alpha-\mathrm{NPD}$, devido às diferenças de energia entre os LUMOs e os HOMOs, respectivamente (vide figura 7.3). O acúmulo de cargas nestas interfaces é bastante significativo, como mostram as simulações de modelagens numéricas realizadas por Tutis et al. [97]. O aspecto das curvas de perda dielétrica (C" na figura $7.5 \mathrm{~b}$ ), em que um processo de relaxação é observado nestes potenciais dc, confirmam a interpretação nesta direção. Com o aumento da voltagem dc, mais cargas são injetadas no volume do material, aumentando a quantidade de carga acumulada nestas interfaces. Quando $\mathrm{V}_{\mathrm{dc}}$ é grande o suficiente, as cargas positivas acumuladas passam a ser injetadas na camada de $\alpha$-NPD e rapidamente atingem a interface $\alpha$ $\mathrm{NPD} / \mathrm{Alq}_{3}$, diminuindo o acúmulo de cargas negativas nesta região, por exemplo, devido à recombinação. $\mathrm{O}$ que faz o valor de $\mathrm{C}^{\prime}$ começar a diminuir. A eletroluminescência nestes OLEDs começa a ficar visível (recombinação) justamente a partir de $\mathrm{V}>2 \mathrm{~V}$.

Nos PLEDs, como o dispositivo possui apenas uma camada orgânica e existe a injeção tanto de cargas positivas quanto de cargas negativas, esta primeira etapa de acúmulo de cargas não é observada em modo direto. A queda do valor inicial de C' e o fenômeno de capacitância negativa deve estar muito provavelmente relacionado com a recombinação de portadores de carga. Este fato é reforçado pela presença do fenômeno em diferentes materiais (OLEDs e PLEDs) nas regiões de potencial onde há injeção de portadores e o início da recombinação. Além disso, como mencionado anteriormente, o fenômeno de recombinação depende apenas da interação elétron-buraco e não do material em sí. Os materiais e/ou a configuração dos dispositivos irão apenas contribuir para uma maior ou menor eficiência de recombinação.

Os processos que levam a uma queda tão acentuada de C' ainda permanecem desconhecidos, apesar de haver uma clara relação entre o aparecimento da capacitância negativa e o processo de recombinação. Estudos de espectroscopia de impedância eletroquímica em sistemas de corrosão também apontam para uma resposta de capacitância negativa de natureza semelhante em baixas freqüências. Nestes sistemas, 
tal fenômeno aparece devido a cinética de reação entre uma adsorbato (espécie química em solução - de mobilidade menor) e um elétron (maior mobilidade). A modelagem desta cinética e a concentração dos produtos e reagentes conduzem a um mecanismo de reação cuja equação diferencial resultante da lei diferencial de velocidades, quando solucionada e transporta para o domínio da freqüência, responde como uma capacitância negativa [95]. Uma analogia pode ser realizada para a cinética de reação de recombinação sendo que os elétrons seriam as espécies de menor mobilidade, com a cinética da reação sendo dependente não somente da concentração dos reagentes (elétrons e buracos), mas também da espécie de menor mobilidade (neste caso, elétrons no $\left.\mathrm{Alq}_{3}\right)$. $\mathrm{O}$ estudo do processo cinético de recombinação e a solução deste problema para diferentes condições de potenciais de deverá, em nossos trabalhos futuros, fornecer uma compreensão física melhor deste processo de resposta em freqüência que conduz a um elemento de capacitância negativa nos OLEDs e PLEDs. 


\section{CAPÍTULO 8}

\section{CONCLUSÕES}

Dispositivos eletrônicos e opto-eletrônicos a base de semicondutores orgânicos têm atraído cada vez mais a atenção da comunidade científica e de indústrias, como Philips, Kodak, entre outras. O grande interesse nesses materiais se deve, por um lado, ao seu grande potencial de aplicação tecnológica, e, por outro, à enorme variedade de fenômenos físicos e químicos que podem ser estudados. Apesar dos grandes investimentos em pesquisa e desenvolvimento nesta área, principalmente na última década, os mecanismos de injeção, transporte e recombinação de portadores de carga, responsáveis pela eficiência destes materiais, ainda permanecem pouco compreendidos.

O objetivo deste trabalho foi de estudar processos de transporte eletrônico em dispositivos a base de semicondutores orgânicos através de técnicas avançadas, como ressonância magnética detectada eletricamente (RMDE) e espectroscopia de impedância elétrica em corrente alternada. Além destas, medidas de ressonância paramagnética eletrônica convencional também foram realizadas de forma a complementar as medidas 
de RMDE. Os dispositivos e materiais estudados foram: diodos (hole-only e PLED) de MEH-PPV, polianilina e OLED multicamadas de $\mathrm{Alq}_{3}$ e $\alpha$-NPD.

\section{Sobre a polianilina}

Medidas de RPE em filmes de polianilina mostraram uma transição entre os tipos de spin observados, tipo Curie (localizados) para tipo Pauli (não-localizados), com o aumento da temperatura. Isto explica porque nas medidas de RMDE não foi observado sinal em baixas temperaturas. O sinal de RPE apresentou duas componentes: uma lorentziana fina, largura a meia altura igual à $4 \mathrm{G}$, e uma lorentziana larga, 30-40 G, sendo a linha fina dominante em toda a faixa de temperatura estudada. Nas medidas de RMDE, em dispositivos com contatos coplanares, também foram observadas duas componentes, uma fina e uma larga, em baixos campos elétricos. Com o aumento do campo a intensidade da componente fina diminui consideravelmente, até que a componente larga passa a dominar. Nas amostras com contatos tipo sanduíche somente a componente larga foi observada. O sinal foi atribuído ao hopping intercadeias de pólarons na superfície e de pólarons no volume. O sinal largo é devido a interações entre moléculas de $\mathrm{O}_{2}$ e as espécies paramagnéticas, enquanto o sinal fino vem de sítios paramagnéticos ocupados por moléculas de $\mathrm{H}_{2} \mathrm{O}$ no lugar do $\mathrm{O}_{2}$. $\mathrm{O}$ fato de o sinal fino ser dominante nos espectros de RPE, ao contrário do que ocorre nas medidas de RMDE se deve a contribuição dos spins localizados. A dependência do sinal de RMDE com a temperatura é explicada pelo aumento da dissociação térmica de bipólarons em pólarons e/ou pela eliminação de moléculas de água, permitindo um maior efeito de interação com moléculas de oxigênio.

\section{Sobre o MEH-PPV}

O sinal de RMDE é composto por duas componentes: uma fina e uma larga. A componente larga é atribuída à fusão de pólarons negativos para formar bipólarons negativos, enquanto que a componente fina foi atribuída à fusão de pólarons positivos 
para formar bipólarons positivos. Foi observado que a razão entre as intensidades de cada uma das componentes varia em PLEDs com diferentes eficiências de emissão de luz. Aqueles com fraca emissão de luz apresentaram a linha atribuída à fusão de pólarons positivos muito mais intensa do que àquela atribuída a pólarons negativos. Isto indica que a deficiência na emissão de luz nestes PLEDs se deve a um desbalanceamento entre a injeção de cargas positivas e negativas no polímero. A intensidade do sinal de RMDE dos diodos hole-only de MEH-PPV diminui com, aproximadamente, $\mathrm{T}^{-4}$ na medida em que aumentamos a temperatura. Já nos PLEDs, o sinal também diminui com o aumento da temperatura, porém com $\mathrm{T}^{-2}$ até $220 \mathrm{~K}$, caindo abruptamente a partir desta temperatura. A queda abrupta do sinal do PLED pode ser explicada devido a um aumento da dissociação térmica de bipólarons com o aumento da temperatura, o que leva a uma diminuição do tempo característico de dissociação do par de spins e, conseqüentemente, a uma diminuição do sinal de RMDE. Entretanto, nos diodos hole-only, esta queda tão acentuada não é observada. Possivelmente, a diferença se deve a diferentes dependências dos tempos de relaxação de cada componente com a temperatura, uma vez que o sinal do PLED é composto pela contribuição da formação de bipólarons positivos e negativos, enquanto o sinal do hole-only é devido apenas à formação de bipólarons positivos. Em campos elétricos muito altos, os pólarons se mostraram muito instáveis, comprovando a importância de se diminuir a voltagem de operação dos dispositivos eletrônicos poliméricos. Os resultados mostraram que os modelos atuais de processos eletrônicos dependentes de spin não conseguem explicar completamente os fenômenos observados.

\section{Sobre o Alq3}

As medidas de espectroscopia de impedância em um OLED multicamadas a base de $\mathrm{Alq}_{3}$ permitiram separar, em freqüência, a dinâmica dos portadores de carga em cada região do material. Isto é uma característica importante desta técnica, principalmente para se estudar dispositivos com mais de uma camada orgânica. A dependência da componente real $\left(C^{\prime}\right)$ da capacitância complexa em função da voltagem dc $\left(V_{d c}\right)$ 
superposta à perturbação em corrente alternada apresentou um fenômeno muito pouco estudado na literatura. Aumentando-se o valor de $V_{d c}$, o valor de C' em baixas freqüências $(\omega \rightarrow 0)$ aumenta até $2 \mathrm{~V}$ e em tensões menores diminui drasticamente atingindo altos valores negativos. Foi mostrado que este fenômeno de capacitância negativa também acontece em PLEDs, além de outros sistemas e foi observado que há uma clara relação entre o aparecimento da capacitância negativa e o processo de recombinação. Estudos de espectroscopia de impedância eletroquímica em sistemas de corrosão também apontam para uma resposta de capacitância negativa de natureza semelhante em baixas freqüências. É proposto, portanto, que uma modelagem da cinética de recombinação, em analogia à cinética de corrosão, e a solução das equações diferenciais resultantes para diferentes condições de potenciais dc, possa fornecer uma melhor compreensão da física deste processo de resposta em freqüência que conduz a um elemento de capacitância negativa nos OLEDs e PLEDs.

Como resultado deste trabalho, um artigo foi aceito para publicação e outro está em fase final de redação.

1. Electrically detected magnetic resonance of organic and polymeric light emitting diodes. F.A. Castro, G.B. Silva, L.F. Santos, R.M. Faria, F. Nüesch, L. Zuppiroli and C.F.O. Graeff; Journal of Non-Crystalline Solids, no prelo.

2. Discussion on the crossover from capacitive to inductive chargerelaxation in organic/polymeric light-emitting diodes. F.A. Castro, P.R. Bueno, C.F.O. Graeff, F. Nüesch, L. Zuppiroli, L.F. Santos, R.M. Faria. Em fase final de redação. Será submetido à revista Applied Physics Letters.

Dois trabalhos foram apresentados em congressos, um nacional (pôster) e outro internacional (oral), e um terceiro foi aceito para apresentação no Spring-Meeting MRS 2004.

2003: XXVI ENCONTRO NACIONAL DE FÍSICA DA MATÉRIA CONDENSADA - SBF - de 06 a 10 de maio em Caxambu - MG, com o trabalho: RMDE aplicada a LEDs de MEH-PPV. F.A. Castro, L.F. Santos, R.M. Faria, G.B. Silva e C.F.O. Graeff. 
2003: 20th INTERNATIONAL CONFERENCE ON AMORPHOUS AND MICROCRYSTALLINE SEMICONDUCTORS: SCIENCE AND TECNOLOGY - ICAMS20 - de 25 a 29 de agosto em Campos do Jordão - SP, com o trabalho: Electrically detected magnetic resonance of organic and polymeric light emitting diodes. F.A. Castro, G.B. Silva, L.F. Santos, R.M. Faria, F. Nüesch, L. Zuppiroli and C.F.O. Graeff.

2004: MRS - Spring Meeting - São Francisco - California - USA, Negative capacitance phenomenon in organic/polymeric light emitting diodes: a recombination-dependent event. F.A. Castro, P.R. Bueno, L.F. Santos, R.M. Faria, L. Zuppiroli, F. Nüesch, C.F.O. Graeff. Aceito para apresentação. 


\section{CAPÍTULO 9}

\section{BIBLIOGRAFIA}

1. POPE, M.; KALLMANN, H. P.; MAGNATE, P., Electroluminescence in organic crystals, J. Chem. Phys. 38, 2042 (1963).

2. HELFRICH, W.; SCHNEIDE, Recombination radiation in anthracene crystals, W. G., Phys. Rev. Lett. 14, 229 (1965).

3. CHIANG, C. K.; PARK, Y. W.; HEEGER, A. J.; SHIRAKAWA, H.; LOUIS, E. J.; MACDIARMID, A. G. Conducting Polymers - Halogen Doped Polyacetylene, J. Chem. Phys., 69(11), 5098 (1978).

4. PARKER, I. D., Carrier tunneling and device characteristics in polymer lightemitting-diodes, J. Appl. Phys., 75, p.1656 (1994).

5. DAVIDS, P.S.; KOGAN, S.H.M.; PARKER, I.D.; SMITH, D.L., Charge injection in organic light-emitting diodes: Tunneling into low mobility materials, Appl. Phys. Lett., 69, 2270 (1996).

6. BLOM, P.W.M.; DE JONG, M.J.M.; BREEDJIK, S., Temperature dependent electron-hole recombination in polymer light-emitting diodes, Appl. Phys. Lett.,71, 930 (1997).

7. ANTONIADIS, H.; ABKOWITZ, M.A.; HSIEH, B.R., Carrier deep-trapping mobility-lifetime products in poly(p-phenylene vinylene),Appl. Phys. Lett., 65, 2030 (1994).

8. MALLIARAS, G.G.; SCOTT, J. C., The roles of injection and mobility in organic light emitting diodes, J. Appl. Phys., 83, 5399 (1998). 
9. Site da Uniax, www.uniax.com

10. Site da CDT, www.cdtltd.co.uk

11. Site da Philips, www.philips.com

12. HEEGER, A.J., Light emission from semiconducting polymers: Light-emitting diodes, light-emitting electrochemical cells, lasers and white light for the future, Solid State Commun. 107, 673 (1998).

13. ARKHIPOV, V.I.; EMELIANOVA, E.V.; TAK, Y.H.; BÄSSLER, H., Charge injection into light-emitting diodes: Theory and experiment, J. Appl. Phys. 84(2), 848 (1998).

14. DAVIDS, P.S., CAMPBELL, I.H., SMITH, D.L., Device model for single carrier organic diodes, J. Appl. Phys. 82(12), 6319 (1997).

15. GESCHWIND, S.; COLLINS, R. J.; SCHAWLOW, A. L., Optical detection of paramagnetic resonance in an excited state of cCr-3+ in Al2O3, Phys. Rev. Lett. 3, 545 (1959).

16. BROSSEL, J.; GESCHWIND, S.; SCHAWLOW, A. L., Optical detection of paramagnetic resonance in crystals at low temperatures, Phys. Rev. Lett. 3, 548 (1959).

17. MAXWELL, R.; HONIG, A., Neutral-impurity scattering experiments in silicon with highly spin-polarized electrons, Phys. Rev. Lett. 17, 188 (1966).

18. HONIG, A., Neutral-impurity scattering and impurity zeeman spectroscopy in semiconductors using highly spin-polarized carriers, Phys. Rev. Lett. 17, 186 (1966).

19. GRAEFF, C.F.O.; BRANDT, M.S.; STUTZMANN, M.; HOLZMANN, M.; ABSTREITER, G.; SCHÄFFLER, F., Electrically detected magnetic resonance of two-dimensional electron gases in Si SiGe heterostructures, Phys. Rev. B 59, 13242 (1999).

20. STICH, B.; GREULICH WEBER, S.; SPAETH, J.M., Electrical detection of electron nuclear double resonance in silicon, Appl. Phys. Lett. 68, 1102 (1996).

21. WIMBAUER, T.; BRANDT, M.S.; BAYERL, M.W.; REINACHER, N.M.; STUTZMANN, M.; HOFMANN, D.M.; MOCHIZUKI, Y.; MIZUTA, M., Recombination centers in GaAs/Al0.4Ga0.6As heterostructures investigated by optically and electrically detected magnetic resonance, Phys. Rev. B 58, 4892 (1998).

22. STUTZMANN, M.; BRANDT, M.S.; BAYERL, M.W., Spin-dependent processes in amorphous and microcrystalline silicon: a survey, J. Non-Cryst. Solids 266-269, 1 (2000). 
23. SOLOMON, I.; BIEGELSEN D.K.; KNIGHTS, J.C., Spin-dependent photoconductivity in n-type and p-type amorphous silicon, Solid State Commun. 22, 505 (1977).

24. MOVAGHAR, B.; RIES, B.; SCHWEITER, L., Theory of the resonant and nonresonant luminescence changes in amorphous-silicon, Phil. Mag. B 41, 141 (1980).

25. MOVAGHAR, B.; RIES, B.; SCHWEITER, L., Theory of the resonant and nonresonant luminescence changes in amorphous-silicon, Phil. Mag. B 41, 159 (1980).

26. GRAEFF, C.F.O.; STUTZMANN, M.; BRANDT, M.S., Spin-dependent photoconductivity in hydrogenated amorphous-germanium and silicongermanium alloys, Phys. Rev. B 49, 11028 (1994).

27. GRAEFF, C.F.O. BRANDT, M.S.; STUTZMANN, M.; POWELL, M.J., Defect creation in amorphous-silicon thin-film transistors, Phys. Rev. B 52, 4608 (1995).

28. KAWACHI, G.; GRAEFF, C.F.O.; BRANDT, M.S.; STUTZMANN, M., em Amorphous and Microcrystalline Silicon Technology 1997, vol. 467, Editores Schiff, E. A.; Hack, M.; Wagner, S.; Schropp, R. e Schimizu, I., (MRS, Pittsburgh, 1997), p. 851.

29. GRAEFF, C.F.O.; ROHRER, E.; NEBEL, C.E.; STUTZMANN, M.; GÜTTLER, H.; ZACHAI, R. em III-Nitride, SiC and Diamond Materials for Electronic Devices, Editores Gaskill, D. K.; Brandt, C.D.; e Nemanich, R.J., (MRS, Pittsburgh, 1996) p. 495.

30. BRANDT, M.S.; BAYERL, M.W.; STUTZMANN, M.; GRAEFF, C.F.O., Electrically detected magnetic resonance of a-Si : H at low magnetic fields: the influence of hydrogen on the dangling bond resonance, J. Non-Cryst. Solids 343, 227-230 (1998).

31. GRAEFF, C.F.O.; BRANDT, M.S.; FARIA, R.M.; LEISING, G., Electrically detected magnetic resonance in undoped polyacetylene and polyaniline, Phys. Status Solidi A 162, 713 (1997).

32. GRAEFF, C.F.O.; BRUNELLO, C.A., Thermal annealing effects on polyaniline studied by electrically detected magnetic resonance, J. Non-Cryst. Solids 273, 289 (2000).

33. HIROMITSU, I.; KAIMORI, Y.; ITO, T., Photovoltaic effect and electrically detected electron spin resonance of a H-2-phthalocyanine/C-60 heterojunction, Solid State Commun. 104, 511 (1997). 
34. EICKELKAMP, T.; ROTH, S.; MEHRING, M., Electrically detected magnetic resonance in photoexcited fullerenes, Mol. Phys. 95, 967 (1998).

35. HIROMITSU, I.; KAIMORI, Y.; KITANO, M.; ITO, T., Spin-dependent recombination of photoinduced carriers in phthalocyanine/C-60 heterojunctions, Phys. Rev. B 59, 2151 (1999).

36. SILVA, G.B.; SANTOS, L.F.; FARIA, R.M.; GRAEFF, C.F.O., in Organic and Polymeric Materials and Devices edited by Jabbour, G.E.; Sariciftci, N.S.; Lee, S.T.; Carter, S. e Kido, J.; MRS, Pittsburgh (2003), in print.

37. CASTRO, F.A.; SILVA, G.B.; SANTOS, L.F.; FARIA, R.M.; NÜESCH, F.; ZUPPIROLI, L.; GRAEFF, C.F.O., Electrically detected magnetic resonance of organic and polymeric light emitting diodes, J. Non-Cryst. Solids, no prelo.

38. HAMMONS, T.J., Power cables in the twenty-first century, Electric Power Components and Systems 31(10), 967 (2003).

39. SHUVALOV, M; MAVRIN, M; OVSIENKO, V; ROMASHKIN, A., Analysis of water trees in power cable polymeric insulation, Journal of Applied Polymer Science 88 (6), 1543 (2003).

40. GREENHAM, N.C.; FRIEND, R.H., Semiconductor device physics of conjugated polymers, Sol. Stat. Phys. 49, 1 (1995).

41. ALONSO, M.; FINN, E. Fundamental University Physics: Volume III Quantum and Statistical Physics. Addison-Weley Publishing Company.1968.

42. PEIERLS, R. E. Quantum theory of solids. Oxfords, Clarendon Press, 1955.

43. FRIEND R.H., Electronic properties of conjugated polymers, Phys. Chem. Elec. Ions in Cond. Mat., 625 (1984).

44. POPE M., SWENBERG C.E., Electronic process in organic crystals and polymers, Clarenfon press, 2nd Ed., Oxford Press (1999).

45. KNUPFER, M.; FINK, J.; FICHOU, D., Strongly confined polaron excitation in charged organic semiconductors, Phys. Rev. B 63, 165203 (2001).

46. BURROUGHES, J.H.; BRADLEY D.D.C.; BROWN A.R.; MARKS R.N.; MACKAY K.; FRIEND R.H.; BURNS P.L.; HOLMES A.B., Light-emitting diodes based on conjugated polymers, Nature 347, 539 (1990).

47. FRIEND, R.H.; GYMER R.W.; HOLMES A.B.; BURROUGHES J.H.; MARKS R.N.; TALIANI C.; BRADLEY D.D.C.; DOS SANTOS D.A.; BREDAS J.L.; LOGDLUND M.; SALANECK W.R., Electroluminescence in conjugated polymers, Nature 397, 121 (1999). 
48. BURROUGHES J.H., JONES C.A., FRIEND R.H., New semiconductor device physics in polymer diodes and transistors, Nature 335, 8, 137 (1988).

49. BRÜTTING W., BERLEB S., MÜCKL A.G., Device physics of organic lightemitting diodes based on molecular materials, Organic Elec. 2, 1 (2001).

50. FRIEND R., BURROUGHES J., SHIMODA T., Polymer diodes, Phys. World 12 (6) 35 (1999).

51. HÜMMELGEN I. A., ROMAN L.S., NART F.C., PÉRES L.O., SÁ E.L., Polymer and polymer/metalinterface characterization via Fowler-Nordheim tunneling measurements, Appl. Phys. Lett. 68, 3194 (1996).

52. SLICHTER, C.P., Principles of magnetic resonance, em Springer Series in Solid-State Sciences 1, 3rd Edition, Springer (1996).

53. MORIGAKI, K.; ONDA, M., Resistivity decrease due to donor spin-resonance in n-type germanium, J. Phys. Soc. Jpn 33(4), 1031 (1972).

54. GRAEFF, C.F.O., Electrically Detected Magnetic Resonance, In: Encyclopedia of Nanoscience and Nanotechnology.1ed. Stevenson Ranch: ASP, 2003.

55. KÖHLER, J.; DISSELHORST, J.A.J.M.; DONCKERS, M.C.J.M.; GROENEN, E.J.J.; SCHMIDT, J.; MOERNER, W.E., Magnetic-resonance of a single molecular spin, Nature 363, 242 (1993).

56. LEPINE, D.J., Spin-dependent recombination on silicon surface, Phys. Rev. B 6(2), 436 (1972).

57. KAPLAN, D.; SOLOMON, I.; MOTT, N.F., Explanation of large spindependent recombination effect in semiconductors, J. Phys. Lett. 39(4), L51 (1978).

58. WHITE, R.M.; GOUYET, J.F., Theory of spin-dependent effects in silicon, Phys. Rev. B 16 (8), 3596 (1977).

59. LIPS, K.; LERNER, C.; FUHS, W., Semiclassical model of electrically detected magnetic resonance in undoped a-Si:H, J. Non-Cryst. Sol. 200, 267 (1996).

60. GENIES E.M., BOYLE A., LAPKOWSKI M., TSINITAVIS C., Polyaniline: $a$ historical survey, Synt. Met. 36, 139 (1990).

61. BIANCHI, R. F., Estudo das propriedades eletrônicas e ópticas de filmes e dispositivos poliméricos, Tese de doutorado, IFSC - USP, (2002).

62. CHAUDHURI, D.; KUMAR, A.; SARMA, D.D.; GARCIA-HERNANDES, M.; JOSHI, J.P.; BHAT, S.V., Magnetic study of an amorphous conducting polyaniline, Appl. Phys. Lett. 82, 1733 (2003). 
63. ZHOU, Q.; ZHUANG, L.; LU, J., In situ ESR studies over wide temperature range for conducting polymers, Electrochem. Comm. 4, 733 (2002).

64. NECHTSCHEIN, M.; GENOUD, F.; MENARDO, C.; MIZOGUCHI, K. TRAVERS, J.P.; VILLERET, B., On the nature of the conducting state of polyaniline, Synth. Met. 29, E211 (1989).

65. ANAND, J.; PALANIAPPAN, S; SATHYANARAYANA, D.N., Variabletemperature EPR and transport studies on poly(4,4'-methylenedianiline): evidence for bipolarons, J. Phys. Chem. 99, 10324 (1995).

66. SARICIFCTI, N.S.; HEEGER, A.J.; CAO, Y., Paramagnetic susceptibility of highly conducting polyaniline: Disordered metal with weak electron-electron interactions (Fermi glass), Phys. Rev. B 49, 5988 (1994).

67. JOZEFOWICZ, M.E.; LAVERSANNE, R.; JAVADI, H.H.S.; EPSTEIN, A.J.; POUGET, J.P.; TANG, X.; MACDIARMID, A.G., Multiple Lattice Phases and polaron-lattice-spinless-defects competition in polyaniline, Phys. Rev. B 39, 12958 (1989).

68. HARIMA, Y.; EGUCHI, T.; YAMASHITA, K.; KOJIMA, K.; SHIOTANI, M., An in situ ESR study on poly 3-methylthiophene: charge transport due to polarons and bipolarons before the evolution of metallic conduction, Synth. Met. 105, 121 (1999).

69. KAHOL, P.K.; DYAKONOV, A.J.; MCCORMICK, B.J., An electron-spinresonance study of polyaniline and its derivatives: polymer interactions with moisture, Synth. Met. 84, 691 (1997).

70. HOUZE, E., NECHTACHEIN, M., ESR in conducting polymers: Oxygeninduced contribution to the linewidth, Phys. Rev. B 53 (21), 14309 (1996).

71. MIZOGUCHI, K.; OBANA,T; UENO,S.; KUME,K., In situ ESR of polyaniline by electrochemical doping: polarons to Pauli-like instead of polaron to bipolaron, Synth. Met. 55-57, 601 (1993).

72. LEE, C.E.; OH, D.K.; JIN, J.L.; NAM, B.K., EPR study of the PPV conducting polymers, Synth. Met. 69, 425 (1995).

73. NALWA, H.S., Phase transitions in polypyrrole and polythiophene conducting polymers demonstrated by magnetic susceptibility measurements, Phys. Rev. B 39, 5964 (1989).

74. MIZOGUCHI, K., Spin dynamics study in conducting polymers by magnetic resonance, Jpn. J. Appl. Phys. 34, 1 (1995).

75. BUSSAC, M.N., ZUPPIROLI, L., Bipolaron singlet and triplet states in disordered conducting polymers, Phys. Rev. B 47, 5493 (1993). 
76. MAGON, C.J.; DE SOUZA, R.R.; COSTA-FILHO, A.J.; VIDOTO, E.A.; FARIA, R.M.; NASCIMENTO, O.R., Spin dynamics study in doped polyaniline by continuous wave and pulsed electron paramagnetic resonance, J. Chem. Phys. 112, 8 (2000).

77. WANG, Z.H.; SCHERR, E.M.; MACDIARMID, A.G.; EPSTEIN, A.J., Transport and EPR studies of polyaniline: A quasi-one-dimensional conductor with three-dimensional "metallic" states, Phys. Rev. B 45, 4190 (1992)

78. KAMIMURA, H., Philos. Mag. B 42, 763 (1980); em Electron-Electron Interactions in Disordered Systems, editado por Efros, A.L. e Polak, M. (Amsterdam, Holanda, 1985).

79. KRINICHNYI, V.I., 2-mm Waveband electron paramagnetic resonance spectroscopy of conducting polymers, Synth. Met. 108, 173 (2000).

80. CHAUVET, O.; EMIN, D.; FORRO, L.; ASELAGE, T.L.; ZUPPIROLI, L., Spin susceptibility of boron carbides: Dissociation of singlet small bipólarons, Phys. Rev. B 53, 14450 (1996).

81. SWANSON, L.S.; SHINAR, J.; BROWN, A.R.; BRADLEY, D.D.C.; FRIEND, R.H.; BURN, P.L.; KRAFT, A.; HOLMES, A.B., Electroluminescence-detected magnetic-resonance study of polyparaphenylenevinylene (PPV)-based lightemitting diodes, Phys. Rev. B 46, 15072 (1992).

82. DERSCH, H.; SCHWEITZER, L.; STUKE, J., Recombination processes in a-Si$H$ - spin-dependent photoconductivity, Phys. Rev. B 28, 4678 (1983).

83. SANTOS, L.F., Estudo de Processos de Transporte em Dispositivos Poliméricos Emissores de Luz, Tese de Doutorado, IFSC-USP, São Carlos - SP (2003).

84. SHINAR, J., in: H.S. Nalwa (Ed.), Handbook of Organic Conductive Molecules and Polymers, Vol. 3, Wiley, New York, 1997, pp. 319-366.

85. BLOM, P.W.M.; DE JONG, M.J.M; VLEGGAAR, J.J.M., Electron and hole transport in poly(p-phenylene vinylene) devices, Appl. Phys. Lett. 683308 (1996).

86. FRIEND, R.H.; BRADLEY, D.D.C.; TOWNSEND, P. D., Photoexcitation in conjugated polymers, J. Phys. D Appl, Phys. 20, 1367 (1987).

87. COLANERI, N.F.; BRADLEY, D.D.C.; FRIEND, R.H.; BURN, P.L.; HOLMES, A.B.; SPANGLER, C.W., Photoexcited states in poly(paraphenylene vinylene) - comparison with trans,trans-distyrylbenzene, a model oligomer, Phys. Rev. B 42, 11671 (1990). 
88. LUPTON, L.M.; SAMUEL, I.D.W., Temperature-dependent device model for polymer light-emitting diodes: significance of barrier height, Synth. Met. 111112, 381 (2000).

89. BLOM, P.W.M., DEJONG, M.J.M., VAN MUNSTER, M.G., Electric-field and temperature dependence of the hole mobility in poly(p-phenylene vinylene), Phys. Rev. B 55, R656 (1997).

90. SILVA, G.M., Electric-field effects on the competition between polarons and bipólarons in conjugated polymers, Phys. Rev. B 61, 10777 (2000).

91. PICHLER, K.; HALLIDAY, D. A.; BRADLEY, D.D. C.; BURN, P.L.; FRIEND, R. H.; HOLMES, A.B., Optical spectroscopy of highly ordered poly(pphenylene vinylene), J. Phys-Condens. Mat. 5, 7155 (1993).

92. MACDONALD, J.R.; JOHNSON, W.B., Fundamentals of impedance spectroscopy, em Impedance Spectroscopy, editado por Macdonald, J. R., New York: John Wiley \& Sons, (1987).

93. BRUTTING, W.; BERLEB, S.; MÜCKL, A.G., Device physics of organic lightemitting diodes based on molecular materials, Organic Electronics 2, 1 (2001).

94. JONES, B.K.; SANTANA, J.; MCPERSON, M., Negative capacitance effects in semiconductor diodes, Sol. State Comm. 107 (2), 47 (1998)

95. MELO, H.G., Estudo por impedância eletroquímica do mecanismo de crescimento/dissolução da película de óxido de alumínio em solução de ácido cítrico, Tese de Doutorado, Escola Politécnica-USP, São Paulo - SP (1999).

96. CAMPBELL I.H.; HAGLER, T.W.; SMITH, D.L.; FERRARIS, J.P., Direct measurement of conjugated polymer electronic excitation energies using metal/polymer/metal structures, Phys. Rev. Lett. 76, 1900-1903 (1996)

97. TUTIS, E.; BERNER, D.; ZUPPIROLI, L., Internal electric field and charge distribution in multilayer organic light-emitting diodes, J. Appl. Phys. 93, 4594 (2003). 